Métodos de fronteira imersa em mecânica dos fluidos 

SERVIÇO DE PÓS-GRADUAÇÃO DO ICMC-USP

Data de Depósito:

Assinatura:

\title{
Métodos de fronteira imersa em mecânica dos fluidos
}

\author{
Larissa Alves Petri
}

Orientador: Prof. Dr. Gustavo Carlos Buscaglia

Dissertação apresentada ao Instituto de Ciências Matemáticas e de Computação - ICMC-USP, como parte dos requisitos para obtenção do título de Mestre em Ciências - Ciências de Computação e Matemática Computacional.

USP - São Carlos

Fevereiro/2010 

Dedico às pessoas que mais amo na vida:

minha família. 



\section{Agradecimentos}

A Deus por esta oportunidade.

A minha família que está sempre presente em minha vida.

Ao professor Gustavo Carlos Buscaglia pela orientação, apoio e paciência.

Aos professores Leandro Franco de Souza, Fabrício Simeoni de Sousa, Cássio Machiaveli Oishi e Antônio Castelo Filho pelas colaborações.

Aos meus amigos, em especial, os companheiros do LCAD, que compartilharam os momentos de alegrias e dificuldades durante este período.

A FAPESP pelo apoio financeiro fornecido através da bolsa de estudos.

Ao ICMC - USP pela oportunidade de qualificação e crescimento científico.

E finalmente a todos que contribuíram para a realização deste trabalho. 


\section{Resumo}

No desenvolvimento de códigos paralelos, a biblioteca PETSc se destaca como uma ferramenta prática e útil. Com o uso desta ferramenta, este trabalho apresenta um estudo sobre resolvedores de sistemas lineares aplicados a escoamentos incompressíveis de fluidos em microescala, além de uma análise de seu comportamento em paralelo.

Após um estudo dos diversos aspectos dos métodos de fronteira imersa, é apresentado um método de fronteira imersa paralelo de primeira ordem. Na sequência, é apresentada uma proposta de melhoria na precisão do método, baseada na minimização da distância entre a condição de contorno exata e aproximada, no sentido de mínimos quadrados.

O desenvolvimento de uma ferramenta paralela eficiente é demonstrado na solução numérica de problemas envolvendo escoamentos incompressíveis de fluidos viscosos com fronteiras imersas.

Palavras-chave: método de fronteira imersa, método acoplado, método de projeção, pré-condicionadores, computação paralela. 


\section{Abstract}

In the development of parallel codes, PETSc library has an important position as a practical and useful tool. With this tool, this work presents a study about linear system solvers applied to incompressible flow in microscale problems, furthermore an analysis of the parallel behavior of these methods is presented.

After a study of several aspects of immersed boundary methods, and taking advantage of the flexibility of PETSc, a parallel first order immersed boundary method is presented. Thereafter, an improvement in the accuracy of the method is presented, based on the minimization of the distance between exact and approximated boundary conditions, in the least square sense.

The development of a parallel and efficient tool is demonstrated in the numerical solution of incompressible viscous flow problems with immersed boundary.

Keywords: immersed boundary methods, monolithic solver, projection method, preconditioners, parallel computing. 


\section{Sumário}

1 Introdução 1

2 Formulação Matemática $\quad 3$

2.1 Equações de Navier-Stokes . . . . . . . . . . . . . . . . . . . 3

2.2 Condições Iniciais e de Contorno . . . . . . . . . . . . . . . . . . . 4

2.3 Discretização Espacial e Temporal . . . . . . . . . . . . . . . . . . 5

2.3.1 Discretização por Diferenças Finitas . . . . . . . . . . . . . . 6

2.4 Discretização Espacial das Condições de Contorno . . . . . . . . . . . . . . . . 10

2.4.1 Condição de Contorno de Entrada . . . . . . . . . . . . . . . . . . 10

2.4.2 Condição de Contorno de Saída . . . . . . . . . . . . . . . . . 11

2.4.3 Condição de Contorno sobre Superfície Rígida . . . . . . . . . . . . . . . . 13

3 Métodos para Escoamentos Incompressíveis em Microescala 15

3.1 Introdução . . . . . . . . . . . . . . . . . . . 15

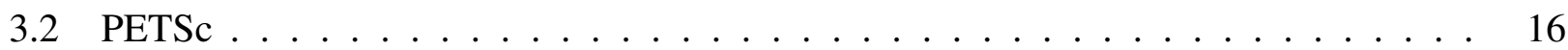

3.3 Métodos para Solução de Escoamentos Incompressíveis . . . . . . . . . . . . . . . 17

3.3.1 Discretização por Elementos Finitos . . . . . . . . . . . . . . . . . 17

3.3 .2 Método Acoplado . . . . . . . . . . . . . . . . . . . . . . 18

3.3.3 Métodos Segregados: Método de Projeção . . . . . . . . . . . . . . . . . 18

3.4 Testes Numéricos . . . . . . . . . . . . . . . . . . . . . . . . . 21

$3.4 .1 \quad$ Acoplado $\times$ Projeção . . . . . . . . . . . . . . . . . . . . . 21

3.4 .2 Discussão do Transiente Espúrio . . . . . . . . . . . . . . . . . . . . . 24

3.4.3 Estudo de Resolvedores Lineares para o Método Acoplado . . . . . . . . . . 25

3.4.4 Comportamento do Método Acoplado em Processamento Paralelo . . . . . . 27

3.5 Conclusões . . . . . . . . . . . . . . . . . . . . . . . . . 29

4 Métodos de Fronteira Imersa

4.1 Introdução . . . . . . . . . . . . . . . . . . . . . . 31 
4.2 Aproximação de Primeira Ordem . . . . . . . . . . . . . . . . . . . 32

$4.2 .1 \quad \operatorname{Resultados} \ldots \ldots \ldots \ldots \ldots \ldots$

4.3 Aproximação de Maior Ordem . . . . . . . . . . . . . . . . . . . . 37

4.3 .1 Testes Numéricos . . . . . . . . . . . . . . . . . . . . 41

4.3 .2 Resultados . . . . . . . . . . . . . . . . . . . 44

4.3 .3 Conclusões . . . . . . . . . . . . . . . . . . . . . 49

5 Aplicações $\quad 51$

5.1 Aplicações 2D . . . . . . . . . . . . . . . . . . . . 51

5.1.1 Escoamento ao Redor de Cilindro Circular . . . . . . . . . . . . . . . . 51

5.1.2 Escoamento em um Canal com Obstáculo em Forma de “c” . . . . . . . . . 53

5.2 Aplicações 3D . . . . . . . . . . . . . . . . . . . 55

5.2 .1 Simulação em Microcanais . . . . . . . . . . . . . . . . . . 55

5.2 .2 Canal com Esferas . . . . . . . . . . . . . . . . . 57

5.2 .3 Conclusões . . . . . . . . . . . . . . . . . . . . 59

6 Conclusões e Trabalhos Futuros $\quad 61$

6.1 Síntese do Trabalho . . . . . . . . . . . . . . . . . . . . . . 61

6.2 Considerações Finais sobre os Resultados . . . . . . . . . . . . . . . . . 62

6.3 Trabalhos Futuros . . . . . . . . . . . . . . . . . . . . 62

$\begin{array}{lc}\text { Referências Bibliográficas } & 68\end{array}$ 


\section{Lista de Figuras}

1.1 a) Malha que respeita o contorno (RC). b) Malha contendo o domínio, adequada para métodos FI. . . . . . . . . . . . . . . . . . . . . . . . . 1

2.1 Representação dos domínios e das fronteiras . . . . . . . . . . . . . . . . . . 4

2.2 Exemplos de armazenamento em uma malha deslocada para os casos: a) bidimensional e b)

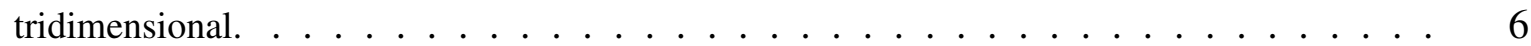

2.3 Volume de controle para a velocidade $u_{i+\frac{1}{2}, j} \ldots \ldots \ldots \ldots \ldots \ldots$

2.4 Volume de controle para a velocidade $v_{i, j+\frac{1}{2}} \ldots \ldots \ldots \ldots$

2.5 Volume de controle para a pressão $p_{i, j} \ldots \ldots \ldots \ldots \ldots$

2.6 Posição do contorno de entrada de fluido $\Gamma_{i n}$ em relação à malha deslocada. . . . . . . . . 11

2.7 Posição do contorno de saída de fluido $\Gamma_{\text {out }}$ em relação à malha deslocada. . . . . . . . . . 11

2.8 Posição do contorno sobre superfície rígida que respeita a malha $\Gamma_{f i t}$ em relação à malha deslocada. . . . . . . . . . . . . . . . . . . . . 13

3.1 Representação do canal, com dimensões $L=3$ e $H=1$ e com condições de contorno de entrada $\left(\operatorname{azul}\left(\Gamma_{i n}\right)\right.$ ), saída (vermelho $\left(\Gamma_{\text {out }}\right)$ ) e sobre superfície rígida que respeita a malha $\left(\right.$ amarelo $\left.\left(\Gamma_{f i t}\right)\right) \ldots \ldots \ldots \ldots \ldots \ldots \ldots$

3.2 Evolução da velocidade horizontal $u$ com o tempo no ponto $(0.21644,0.223198)$ para os métodos: a) acoplado e b) de projeção, ambos na formulação de elementos finitos. . . . . . 22

3.3 Evolução da velocidade horizontal $u$ com o tempo no ponto $(0.2,0.2)$ para os métodos: a) acoplado e b) de projeção, ambos na formulação de diferenças finitas. . . . . . . . . . . .

3.4 Comportamento do resíduo das equações estacionárias em função do tempo para o método de projeção nas formulações a) de elementos finitos e b) de diferenças finitas. . . . . . . . . . 24

3.5 Comportamento do resíduo das equações estacionárias em função do número de iterações para o método de projeção nas formulações a) de elementos finitos e b) de diferenças finitas.

3.6 a) Speed-up e b) eficiência do método acoplado (GMRES + MGS, $n=1500$, ASM com 16 blocos) na simulação do escoamento tridimensional. . . . . . . . . . . . . . . . 
4.1 Representação do domínio $\mathcal{B}$, com uma malha cartesiana $\mathcal{T}_{h}$. Em amarelo temos as células de $\mathcal{R}_{h}$ e em verde as células de $\mathcal{Q}_{h}$. O contorno $\Gamma_{h}$ é representado em vermelho. . . . . . . .

4.2 Representação esquemática para a cavidade com tampa deslizante, com dimensão $L=1 \mathrm{e}$ condições de contorno de desizamento da tampa $\left(\Gamma_{i n}\right)$ e sobre superfície rígida que respeita a

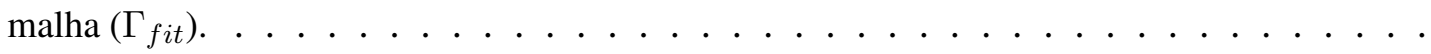

4.3 Linhas de corrente coloridas segundo a magnitude da velocidade a) condição inicial e b) solução no estado estacionário.

4.4 a) Perfil da velocidade $u$ ao longo da linha vertical que passa pelo centro do domínio e b) perfil da velocidade $v$ ao longo da linha horizontal que passa pelo centro do domínio, comparadas com os resultados obtidos por Ghia et al. (1982) . . . . . . . . . . . . . . . . . . . . . .

4.5 Representação esquemática para o escoamento em um degrau, com dimensões $h_{i}=1, h_{s}=$ 1, $L_{1}=5, L_{2}=80$ e $H=2$ e com condições de contorno de entrada de fluido $\left(\Gamma_{i n}\right)$, saida de fluido $\left(\Gamma_{\text {out }}\right)$ e sobre superfície rígida que respeita a malha $\left(\Gamma_{f i t}\right) \ldots \ldots \ldots$

4.6 Linhas de corrente coloridas segundo a magnitude da velocidade para a) a condição inicial e b) a solução com $R e=100$ do escoamento em um degrau. . . . . . . . . . . . . . . . .

4.7 Representação da malha próxima ao contorno. Os elementos em azul são os elementos cortados pelo contorno $\Gamma \ldots \ldots \ldots \ldots \ldots \ldots \ldots$

4.8 Elementos da malha cortados pelo contorno $\Gamma$. Os círculos verdes representam os pontos onde os elementos são interceptados por $\Gamma$, os triângulos azuis são os nós internos, pertencentes a $\Omega$ e quadrados amarelos são os nós externos ao domínio, não pertencentes a $\Omega$. . . . . . . .

4.9 Representação do domínio por uma função implícita. A linha vermelha mostra onde $\phi=0$, a área amarela mostra onde $\phi>0$ e a área azul mostra onde $\phi<0 \ldots$. . . . . . . . . . . .

4.10 Elemento do domínio cortado pelo contorno, em que $A, B$ e $C$ são os vértices do elemento e $x$ e $y$ são os pontos onde o contorno $\Gamma$ corta as arestas do elemento. . . . . . . . . . . . .

4.11 Representação do domínio $\mathcal{B}=(0,4)$, onde $x_{\Gamma}=\pi$ e $\Omega=(0, \pi) \ldots \ldots \ldots \ldots$

4.12 Decaimento do erro com o refinamento da malha para a solução da equação do calor, em escala logarítmica. . . . . . . . . . . . . . . . . . .

4.13 Soluções exata $U$ e aproximada $u$ para a) $h=0.4444$ e b) $h=0.00625$. Podemos notar, na ampliação, que a condição de contorno está sendo imposta no ponto correto, com valor exato.

4.14 Decaimento do erro com a redução do tamanho $h$, em escala $\log \times \log$, para a) o círculo e b) o quadrado. . . . . . . . . . . . . . . . . . . . . 44

4.15 Valores das pressões a) exata e b) aproximada para o problema com solução analítica. . . . .

4.16 Linhas de corrente coloridas segundo a magnitude da velocidade a) exata e b) aproximada para o problema com solução analítica. . . . . . . . . . . . . . . . . . 46

4.17 Magnitude da velocidade a) exata e b) aproximada para o problema com solução analítica. .

4.18 Ampliação do canto superior direito da figura 4.15, representando a pressão obtida na solução aproximada para o problema com solução analítica. 
4.19 Célula do "canto" do domínio, onde $u_{\text {in }}$ e $v_{\text {in }}$ são velocidades dentro do domínio $\Omega, u_{o u t}$ e $v_{\text {out }}$ são velocidades fora do domínio $\Omega, p$ é a pressão e $\Gamma$ é o contorno. . . . . . . . . . . .

4.20 Representação esquemática para a cavidade com tampa deslizante, com dimensão $L=1 \mathrm{e}$ condições de contorno de deslizamento da tampa $\left(\Gamma_{i n}\right)$ e sobre superfície rígida imersa na malha $(\gamma) \ldots \ldots \ldots \ldots \ldots \ldots$

4.21 Linhas de corrente coloridas segundo a magnitude da velocidade para a cavidade com tampa deslizante para $R e=100$ a) condição inicial e b) solução no estado estacionário. . . . . . . .

4.22 a) Perfil da velocidade $u$ ao longo da linha vertical que passa pelo centro do domínio e b) perfil da velocidade $v$ ao longo da linha horizontal que passa pelo centro do domínio, comparadas com os resultados obtidos por Ghia et al. (1982) . . . . . . . . . . . . . . . . . . .

5.1 Representação esquemática para o escoamento ao redor de um cilindro circular, com dimensões $L=8, H=1$ e raio do cilindro $r=0.1$ e com condições de contorno de entrada de fluido $\left(\Gamma_{i n}\right)$, saída de fluido $\left(\Gamma_{\text {out }}\right)$ e sobre superfície rígida que respeita a malha $\left(\Gamma_{f i t}\right) \ldots \ldots$

5.2 Resultados para o estado estacionário do escoamento ao redor de um cilindro circular, com $R e=10^{-2}$. a) Pressão; b) Magnitude da velocidade; c) Linhas de corrente coloridas segundo a magnitude da velocidade. . . . . . . . . . . . . . . . . . . .

5.3 Resultados para o escoamento ao redor de um cilindro circular, com $R e=100$. a) Pressão; b) Magnitude da velocidade; c) Linhas de corrente coloridas segundo a magnitude da velocidade.

5.4 Representação esquemática para o escoamento em um canal com obstáculo em forma de "c", com dimensões $L=6, H=1$ e tamanho característico do obstáculo $l=0.2$ e com condições de contorno de entrada de fluido $\left(\Gamma_{i n}\right)$, saída de fluido $\left(\Gamma_{o u t}\right)$ e sobre superfície rígida que respeita a malha $\left(\Gamma_{f i t}\right) \ldots \ldots \ldots \ldots \ldots$

5.5 Resultados para o canal com obstáculo em forma de "c", com $R e=10^{-2}$ e $t=10$. a) Pressão; b) Magnitude da velocidade; c) Linhas de corrente coloridas segundo a magnitude da velocidade. . . . . . . . . . . . . . . . . . .

5.6 Resultados para o canal com obstáculo em forma de "c", com $R e=20$ e $t=1000$. a) Pressão; b) Magnitude da velocidade; c) Linhas de corrente coloridas segundo a magnitude da velocidade. . . . . . . . . . . . . . . . . . .

5.7 Representação do microcanal utilizado para a simulação 3D, com comprimento $L=14$, largura $H=6$ e altura $Z=1.5$ e com condições de contorno de entrada de fluido (azul $\left(\Gamma_{i n}\right)$ ), saída de fluido (vermelho $\left(\Gamma_{\text {out }}\right)$ ) e sobre superfície rígida.que respeita a malha (amarelo $\left(\Gamma_{f i t}\right)$ ). 56

5.8 Fitas de corrente coloridas segundo a magnitude da velocidade para o microcanal 3D. . . . 56

5.9 Representação do canal com esferas na seção central, com comprimento do canal $L=3$, largura $H=1$ e altura $Z=1$ e com condições de contorno de entrada de fluido (azul $\left(\Gamma_{i n}\right)$ ), de saída de fluido (verde $\left(\Gamma_{\text {out }}\right)$ ) e sobre superfície rígida que respeita a malha (canal em amarelo e esferas em vermelho $\left.\left(\Gamma_{f i t}\right)\right) \ldots \ldots \ldots \ldots \ldots$

5.10 Linhas de corrente para $R e=10^{-2}$, coloridas segundo a magnitude da velocidade para o canal com esferas. 
5.11 Linhas de corrente para $R e=100$, coloridas segundo a magnitude da velocidade para o canal com esferas. 


\section{Lista de Tabelas}

3.1 Tempo de processamento (em segundos) para o método acoplado na simulação do canal (figura 3.1) $\operatorname{com} h=0.1$ e $\delta t=10^{-1} \ldots \ldots \ldots \ldots \ldots \ldots \ldots$

3.2 Tempo de processamento (em segundos) para o método acoplado na simulação do canal (figura 3.1) com $\delta t=10^{-1}$ e vários valores para $h \ldots \ldots \ldots$. . . . . . . . 27

3.3 Tempo de processamento do método acoplado com GMRES ( $n=1500$, com MGS) e os PCs ASM e BJacobi na simulação numérica em um canal 3D, com 8 processos em 8 computadores. 28

3.4 Tempo de processamento do método acoplado (GMRES + MGS, $n=1500$, ASM com 16 blocos) na simulação do escoamento tridimensional. . . . . . . . . . . . . . . . . . . 29 


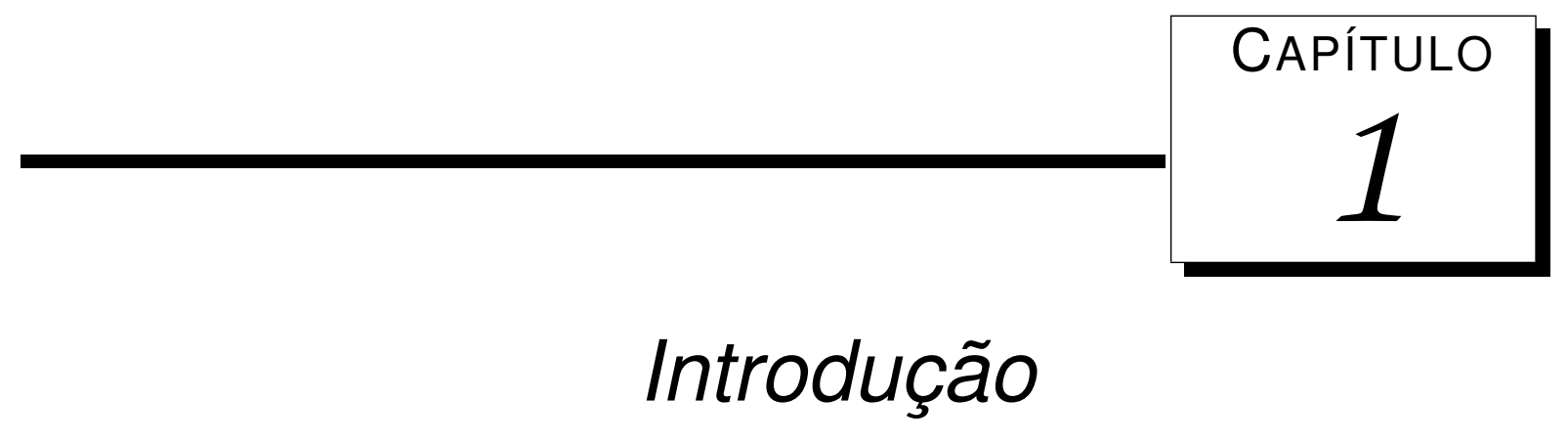

Os métodos numéricos "com malhas" existentes para a aproximação de equações diferenciais podem classificar-se em dois grandes grupos: métodos que respeitam o contorno (boundary-fitted, RC) e métodos de fronteiras imersas (immersed boundary methods, FI) (Peskin, 1972, 1977, 2002).

Nos métodos RC, a malha de cálculo coincide com o domínio do problema, portanto é fácil impor as condições de contorno. A maioria dos métodos de elementos finitos são métodos RC, como também muitos dos métodos de diferenças finitas ou volumes finitos formulados em malhas curvilíneas ou não-estruturadas. Uma malha RC típica é mostrada na figura 1.1.a.

a)

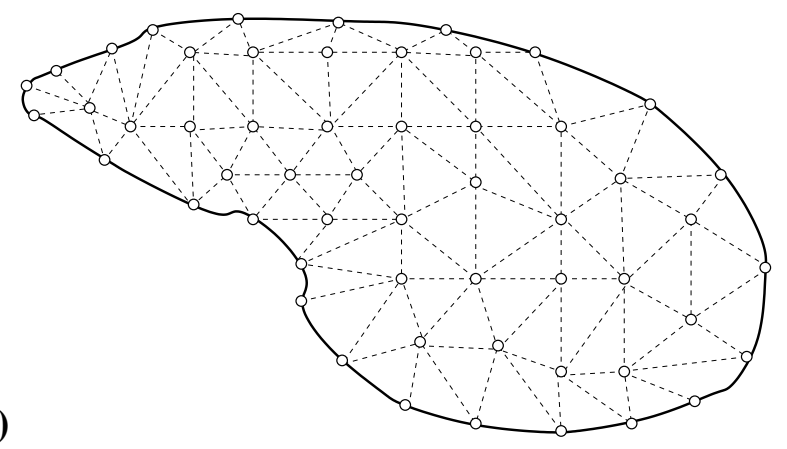

b)

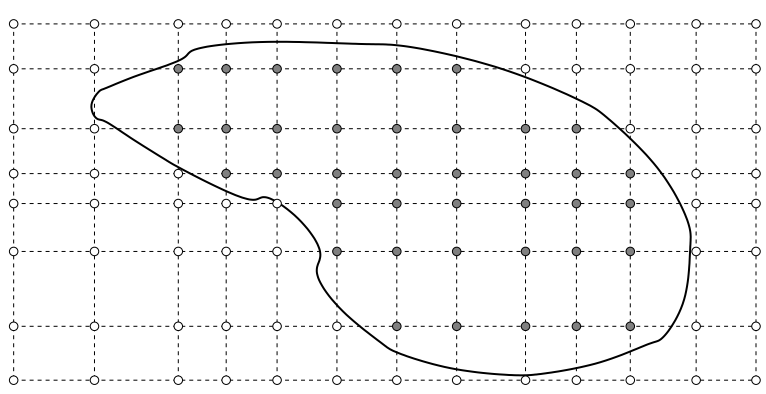

Figura 1.1: a) Malha que respeita o contorno (RC). b) Malha contendo o domínio, adequada para métodos FI.

Por outro lado, os métodos FI caracterizam-se por trabalhar com malhas de cálculo que contém o domínio do problema, sem respeitar a fronteira, fazendo com que a imposição das condições de contorno sejam incluídas na formulação numérica, que é a principal dificuldade destes métodos. Neste trabalho são considerados, na classe de métodos FI, os métodos conhecidos como "fronteiras virtuais" (Goldstein et al., 1993), "domínios fictícios" (Girault and Glowinski, 1995; Glowinski et al., 1994, 1999), "malhas imersas" (Tilch et al., 2008), "interfaces imersas" (Lee and Leveque, 2003; Leveque 
and Li, 1994; Mittal and Iaccarino, 2005; Ye et al., 1999) e "elementos finitos imersos" (Liu et al., 2005; Zhang et al., 2004), entre outros. Um exemplo de malha FI pode ser visto na figura 1.1.b.

Primeiramente, neste trabalho, considera-se uma malha que respeita o contorno, a partir da qual é feito um estudo do comportamento dos métodos acoplado e de projeção na solução numérica de escoamentos incompressíveis em problemas com grande diferenças de escalas e com baixo número de Reynolds. Este estudo permitiu a verificação do aparecimento de um transiente espúrio para o campo de velocidades, quando utiliza-se o método de projeção para a solução das equações. Porém, a utilização do método acoplado gera matrizes são muito mal condicionadas. Por isso, é efetuado um segundo estudo, no sentido de determinar a melhor combinação entre métodos para solução de sistemas lineares e pré-condicionadores para a solução desse tipo de problema. Para este estudo foi de fundamental importância a utilização da biblioteca PETSc (Balay et al., 2008, 2009), que fornece estruturas de dados e implementação dos resolvedores de sistemas lineares e pré-condicionadores.

Entretanto, em problemas com geometrias mais complexas, a maioria do tempo dedicado à preparação de um cálculo provém da geração da malha, o que é praticamente imediato nos métodos FI. A utilidade dos métodos FI, em problemas de geometria complexa, torna-se, assim, evidente. Esses métodos adaptam-se especialmente bem a geometrias definidas digitalmente, a partir de imagens fotográficas ou tomográficas, o que os torna ainda mais atrativos. Devido a isso, existe um grande interesse no desenvolvimento de métodos FI eficientes e precisos, visando aplicações em tecnologias que envolvem escoamentos em geometrias complexas e dinâmicas, tais como microfluídica (Atzberger et al., 2007), fluídica celular (Eggleton and Popel, 1998; Rejniak, 2007), hemodinâmica (Beratlis et al., 2005; Cebral and Löhner, 2005; Steinman et al., 2003), fluidos magnéticos (Ito and Li, 2003) e muitos problemas de interação fluido-estrutura (Ge and Sotiropoulos, 2007; Kim and Peskin, 2007; Yang and Balaras, 2006).

A principal dificuldade dos métodos FI é a imposição das condições de contorno. Neste trabalho leva-se em consideração, em particular, as condições de contorno de Dirichlet, por serem as que apresentam maior dificuldade numérica e também por serem as que necessitam de maior precisão. Em um contorno rígido, se a condição de Dirichlet para a velocidade não for satisfeita com precisão, o efeito será uma penetração do fluido através do contorno, um efeito claramente contrário à física.

Recentemente, Codina and Baiges (2009) propuseram um novo método de imposição aproximada, no qual os graus de liberdade de determinados nós da malha de elementos finitos são utilizados para minimizar a diferença entre as condições de contorno exata e aproximada. Husain and Floryan (2008b) também propuseram o método das condições de fronteira imersa, no qual as condições de contorno são representadas como restrições no espaço de Fourier. Ambos os métodos minimizam a distância entre as condições de contorno exata e aproximada no sentido de mínimos quadrados.

$\mathrm{Na}$ dissertação proposta pretende-se estudar o comportamento das diversas técnicas disponíveis para a imposição das condições de contorno em métodos FI, em particular os métodos propostos por Codina and Baiges (2009) e Husain and Floryan (2008b). Este método será implementado para o caso das equações de Navier-Stokes, tratado por diferenças finitas. 


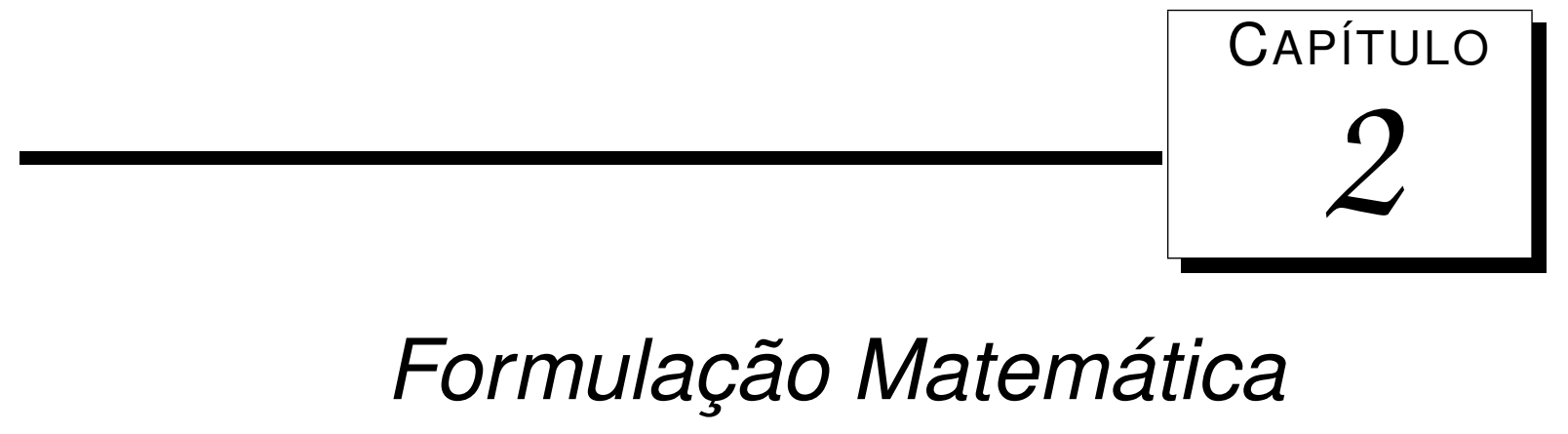

Neste capítulo serão apresentadas as equações que descrevem o problema a ser resolvido, assim como as condições iniciais e de contorno envolvidas. Na sequência, são introduzidas as discretizações espacial e temporal que serão utilizadas.

\subsection{Equações de Navier-Stokes}

A expressão matemática de princípios físicos, tais como a conservação da massa e a conservação da quantidade de movimento (segunda lei de Newton) são representados pelas equações de Navier-Stokes.

As equações que modelam escoamentos incompressíveis de fluidos newtonianos viscosos são as equações de conservação da massa (continuidade)

$$
\nabla \cdot \boldsymbol{u}=0
$$

e de conservação de quantidade de movimento

$$
\frac{\partial \boldsymbol{u}}{\partial t}+(\boldsymbol{u} \cdot \nabla) \boldsymbol{u}=-\frac{1}{\rho} \nabla p+\nu \nabla^{2} \boldsymbol{u}+f
$$

onde $\boldsymbol{u}$ denota o campo de velocidades e $p$ o campo de pressões. Ainda, $t$ é o tempo, $\rho$ é a massa específica, $\nu$ a viscosidade cinemática do fluido e $f$ são forças externas (por exemplo, gravidade).

As equações acima estão definidas em um domínio $\Omega$ e suas condições de contorno estão definidas em $\partial \Omega=\Gamma_{\text {in }} \cup \Gamma_{\text {out }} \cup \Gamma_{\text {fit }} \cup \gamma$, com $\partial \Omega$ fronteira de $\Omega, \Gamma_{\text {in }}$ contorno de entrada de fluido, $\Gamma_{\text {out }}$ contorno de saída de fluido, $\Gamma_{\text {fit }}$ contorno de superfície rígida que coincide com a malha e $\gamma$ contorno de superfície rígida imersa na malha, como mostrado na figura 2.1. O domínio externo $\mathcal{B}$, que contém 
o domínio $\Omega$ e suas fronteiras, é a região onde será gerada a malha.

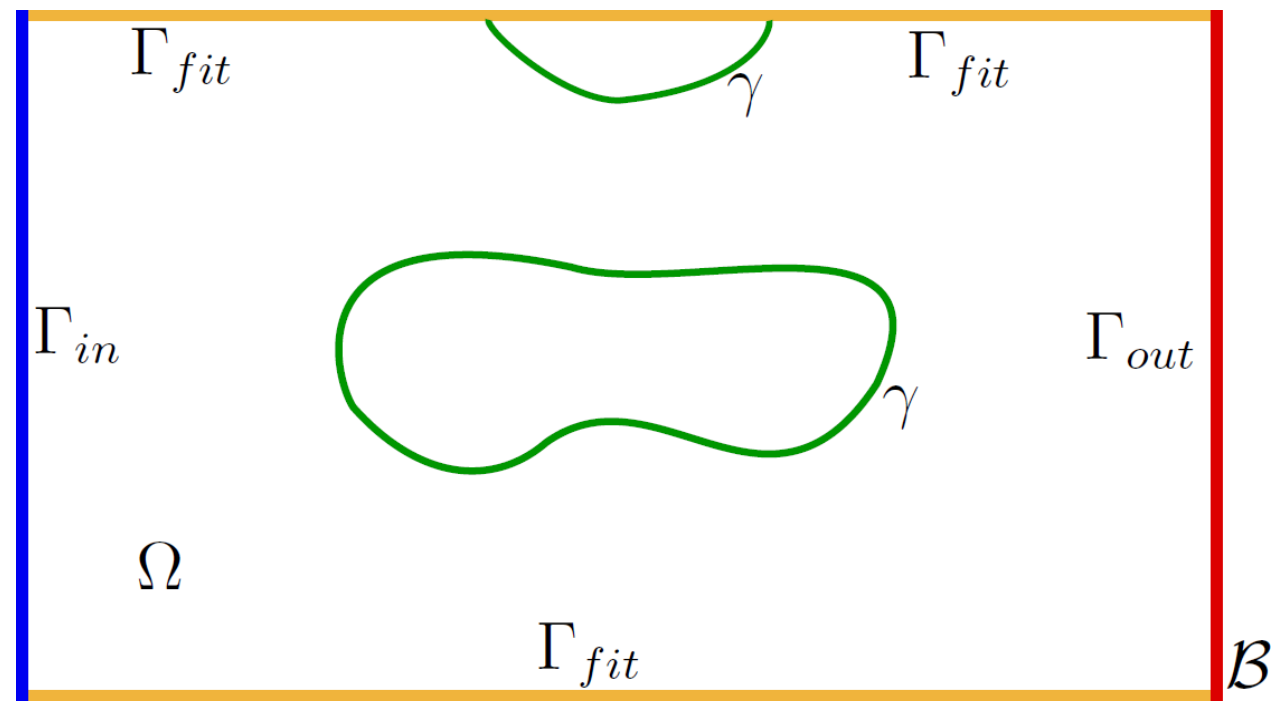

Figura 2.1: Representação dos domínios e das fronteiras

A seguir são especificadas as condições iniciais e de contorno que serão utilizadas.

\subsection{Condições Iniciais e de Contorno}

A escolha das condições iniciais e de contorno é fundamental para a solução dos problemas modelados por equações diferenciais parciais, pois o comportamento físico da solução depende da escolha dessas condições. Para as condições iniciais do escoamento, deve-se conhecer, em $t=0$, a distribuição espacial das variáveis dependentes. Para as condições de contorno é preciso ter alguma informação física, para todo tempo $t$, das variáveis dependentes na fronteira da região limitando o escoamento.

Nos problemas de interesse nesse trabalho, existem basicamente 4 tipos de condições de contorno que serão empregadas:

- Condições na entrada de fluido no domínio de solução (inflow):

$$
\left.\boldsymbol{u}\right|_{\Gamma_{i n}}=\boldsymbol{u}_{i n}
$$

onde $\boldsymbol{u}_{i n}$ é o vetor de velocidade conhecido na entrada de fluido e $\Gamma_{i n}$ é a fronteira de entrada;

- Condições na saída de fluido do domínio de solução (outflow):

$$
\left.\sigma \cdot \boldsymbol{n}\right|_{\Gamma_{\text {out }}}=0
$$

onde $\sigma$ é o tensor de Cauchy, que pode ser escrito como

$$
\sigma=-p \mathbb{I}_{d}+\mu\left(\nabla \boldsymbol{u}+\nabla^{T} \boldsymbol{u}\right)
$$


sendo $\mathbb{I}_{d}$ a matriz identidade, em que $d$ é a dimensão $(d=2,3)$, e $\mu=\rho \nu$ o coeficiente de viscosidade dinâmica. Ainda, $\boldsymbol{n}$ é o vetor unitário normal externo à fronteira e $\Gamma_{\text {out }}$ é a fronteira de saída;

- Condição sobre uma superfície rígida que respeita a malha (fitted):

$$
\left.\boldsymbol{u}\right|_{\Gamma_{f i t}}=0
$$

onde $\Gamma_{\text {fit }}$ é a fronteira rígida (fitted);

- Condição sobre uma superfície rígida imersa na malha (immersed):

$$
\left.\boldsymbol{u}\right|_{\gamma}=0
$$

em que $\gamma$ é a fronteira imersa.

A condição inicial deve ser fornecida somente para a velocidade

$$
\left.u\right|_{t=0}=u_{0}
$$

devendo satisfazer a equação da continuidade

$$
\nabla \cdot \boldsymbol{u}_{0}=0
$$

Com as condições iniciais e de contorno definidas, pode-se definir as discretizações espacial e temporal, apresentadas abaixo.

\subsection{Discretização Espacial e Temporal}

Para considerar as equações governantes na sua forma discreta, inicialmente, reescreve-se as equações (2.1)-(2.2) na forma adimensional, ou seja,

$$
\begin{aligned}
& \frac{\partial \boldsymbol{u}}{\partial t}+\nabla \cdot(\boldsymbol{u u})=-\nabla p+\frac{1}{R e} \nabla^{2} \boldsymbol{u}, \\
& \nabla \cdot \boldsymbol{u}=0
\end{aligned}
$$

onde $R e=\frac{L V}{\nu}$ é o número de Reynolds, em que $L$ e $V$ são os parâmetros de escala de comprimento e velocidade, respectivamente.

As equações (2.7)-(2.8) serão discretizadas por diferenças finitas, tanto no tempo quanto no espaço, como mostrado na próxima seção. 


\subsubsection{Discretização por Diferenças Finitas}

As equações (2.7)-(2.8) podem ser discretizadas no tempo como

$$
\begin{aligned}
& \frac{\boldsymbol{u}^{n+1}-\boldsymbol{u}^{n}}{\delta t}+\nabla \cdot(\boldsymbol{u} \boldsymbol{u})^{n+\theta}=-\nabla p^{n+1}+\frac{1}{R e} \nabla^{2} \boldsymbol{u}^{n+\theta}, \\
& \nabla \cdot \boldsymbol{u}^{n+1}=0
\end{aligned}
$$

onde o parâmetro $\theta \in[0,1]$ permite avaliar os termos convectivo e difusivo de maneira explícita $(\theta=0)$, implícita $(\theta=1)$, ou intermediária $(0<\theta<1)$.

A discretização espacial das equações (2.7)-(2.8) é realizada em uma malha deslocada (staggered grid) introduzida inicialmente por Harlow and Welch (1965). Este tipo de malha é muito utilizado em esquemas de projeção combinados com o método MAC (Marker-And-Cell) (Harlow and Welch, 1965), pois além de ser facilmente implementada, possui várias propriedades atrativas, como por exemplo, satisfazer a conservação da massa exatamente em cada célula de pressão. Como pode-se ver na figura 2.2, a célula de uma malha deslocada possui as componentes da velocidade armazenadas nas faces da célula, enquanto que as quantidades escalares, como a pressão, são armazenadas no centro da célula.

a)
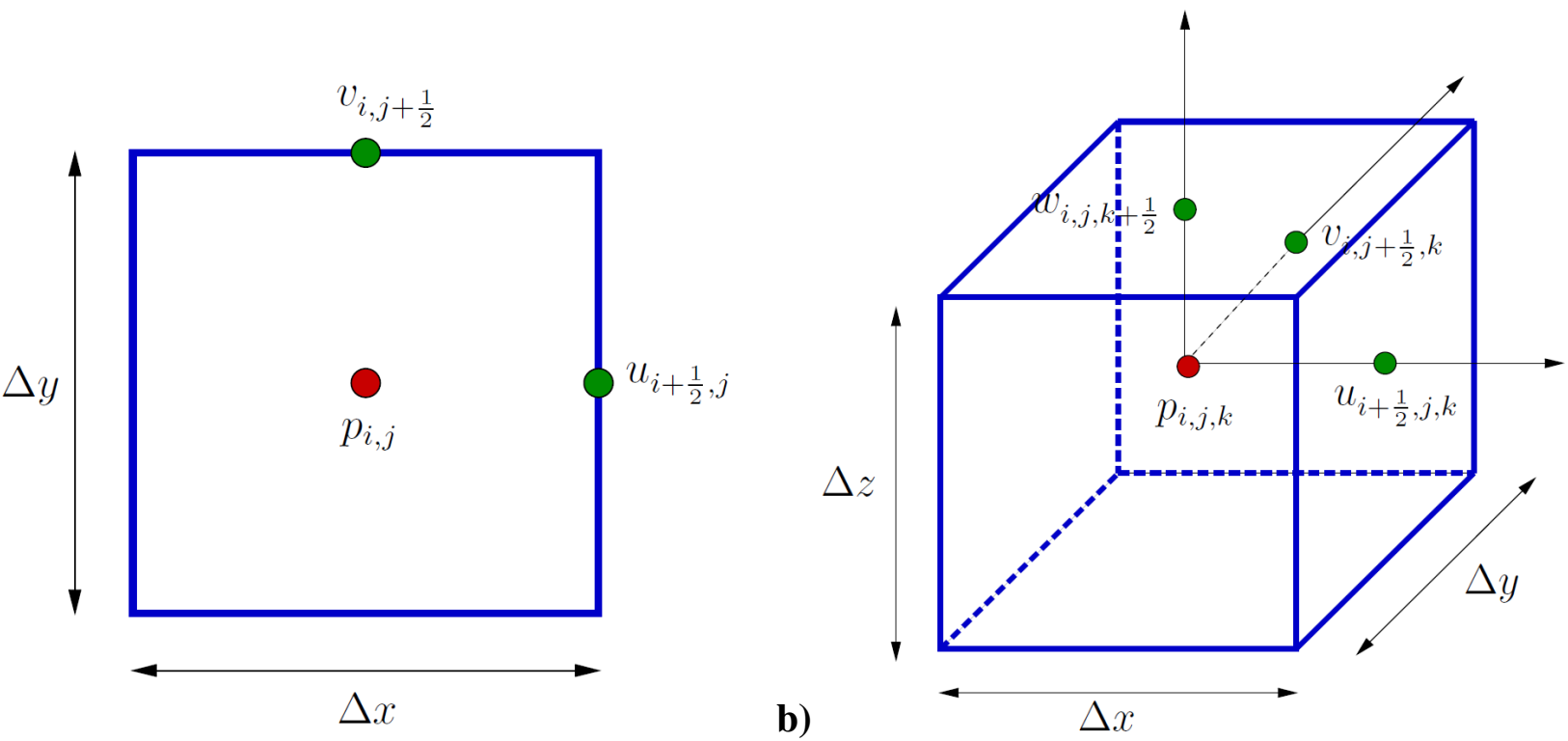

Figura 2.2: Exemplos de armazenamento em uma malha deslocada para os casos: a) bidimensional e b) tridimensional.

Para definir a discretização espacial, considera-se, por simplicidade, o caso bidimensional. Em coordenadas cartesianas, as equações (2.7)-(2.8) tornam-se

$$
\frac{\partial u}{\partial t}+\frac{\partial(u u)}{\partial x}+\frac{\partial(u v)}{\partial y}=-\frac{\partial p}{\partial x}+\frac{1}{R e}\left(\frac{\partial^{2} u}{\partial x^{2}}+\frac{\partial^{2} u}{\partial y^{2}}\right)
$$




$$
\begin{aligned}
& \frac{\partial u}{\partial t}+\frac{\partial(u v)}{\partial x}+\frac{\partial(v v)}{\partial y}=-\frac{\partial p}{\partial y}+\frac{1}{R e}\left(\frac{\partial^{2} v}{\partial x^{2}}+\frac{\partial^{2} v}{\partial y^{2}}\right) \\
& \frac{\partial u}{\partial x}+\frac{\partial v}{\partial y}=0
\end{aligned}
$$

onde $u$ e $v$ serão as componentes da velocidade nas direções $x$ e $y$, respectivamente.

A equação de quantidade de movimento na direção $x$ (2.11) é discretizada no ponto onde localizase a velocidade $u$ na célula da malha deslocada, ou seja, no ponto $\left(i+\frac{1}{2}, j\right)$. O volume de controle de $u_{i+\frac{1}{2}, j}$ é apresentado na figura 2.3.

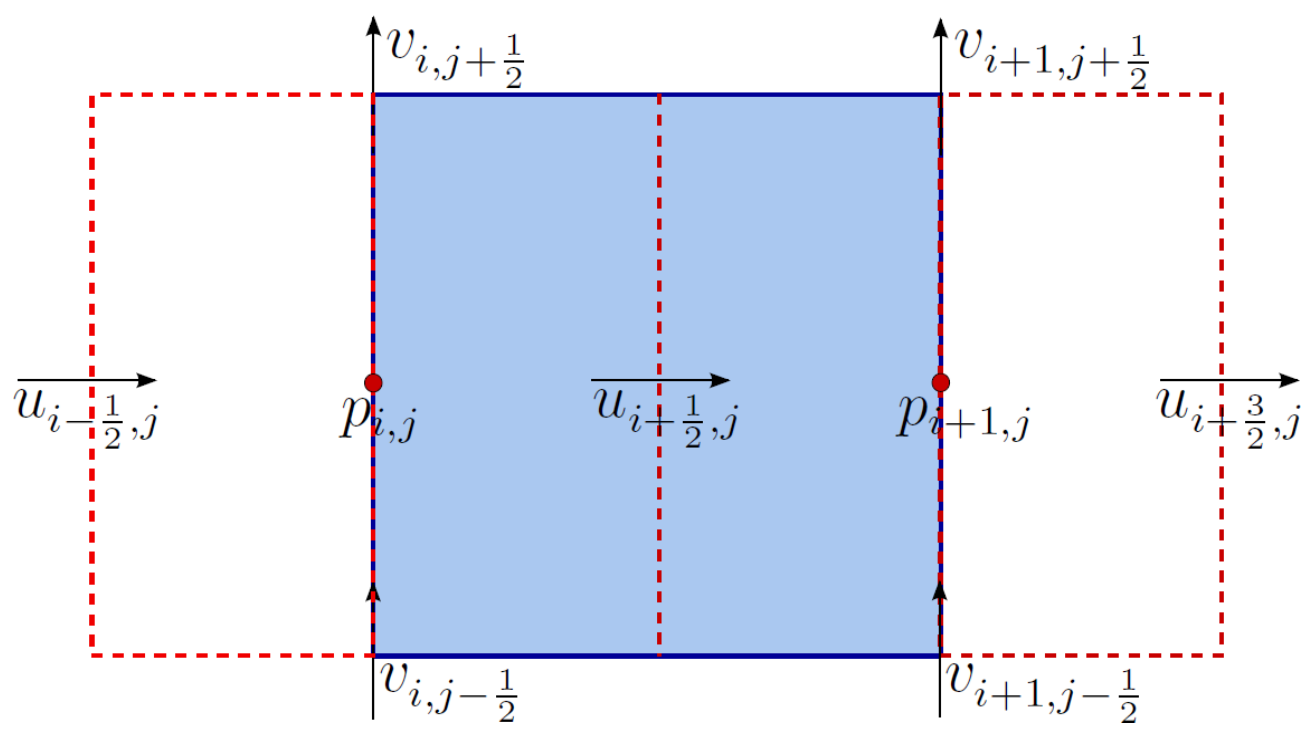

Figura 2.3: Volume de controle para a velocidade $u_{i+\frac{1}{2}, j}$.

Assim, pode-se definir a discretização desta equação calculando-se os fluxos nas faces do volume de controle. Tem-se então

$$
\begin{aligned}
& \left.\frac{\partial u}{\partial t}\right|_{i+\frac{1}{2}, j}=\frac{u_{i+\frac{1}{2}, j}^{n+1}-u_{i+\frac{1}{2}, j}^{n}}{\delta t}+O(\delta t), \\
& \left.\frac{\partial(u u)^{(n+\theta)}}{\partial x}\right|_{i+\frac{1}{2}, j}=\frac{1}{\Delta x}\left(\frac{u_{i+\frac{3}{2}, j}^{n+\theta}+u_{i+\frac{1}{2}, j}^{n+\theta}}{2}\right)^{2}-\frac{1}{\Delta x}\left(\frac{u_{i+\frac{1}{2}, j}^{n+\theta}+u_{i-\frac{1}{2}, j}^{n+\theta}}{2}\right)^{2}+O\left(\Delta x^{2}\right), \\
& \left.\frac{\partial(u v)^{(n+\theta)}}{\partial y}\right|_{i+\frac{1}{2}, j}=\frac{1}{\Delta y}\left(\frac{v_{i+1, j+\frac{1}{2}}^{n+\theta}+v_{i, j+\frac{1}{2}}^{n+\theta}}{2}\right)\left(\frac{u_{i+\frac{1}{2}, j+1}^{n+\theta}+u_{i+\frac{1}{2}, j}^{n+\theta}}{2}\right) \\
& -\frac{1}{\Delta y}\left(\frac{v_{i+1, j-\frac{1}{2}}^{n+\theta}+v_{i, j-\frac{1}{2}}^{n+\theta}}{2}\right)\left(\frac{u_{i+\frac{1}{2}, j}^{n+\theta}+u_{i+\frac{1}{2}, j-1}^{n+\theta}}{2}\right)+O\left(\Delta y^{2}\right),
\end{aligned}
$$




$$
\begin{aligned}
& \left.\frac{\partial p^{(n+1)}}{\partial x}\right|_{i+\frac{1}{2}, j}=\frac{p_{i+1, j}^{n+1}-p_{i, j}^{n+1}}{\Delta x}+O\left(\Delta x^{2}\right), \\
& \left.\frac{\partial^{2} u^{(n+\theta)}}{\partial x^{2}}\right|_{i+\frac{1}{2}, j}=\frac{u_{i+\frac{3}{2}, j}^{n+\theta}-2 u_{i+\frac{1}{2}, j}^{n+\theta}+u_{i-\frac{1}{2}, j}^{n+\theta}+O\left(\Delta x^{2}\right),}{\Delta x^{2}} \\
& \left.\frac{\partial^{2} u^{(n+\theta)}}{\partial y^{2}}\right|_{i+\frac{1}{2}, j}=\frac{u_{i+\frac{1}{2}, j+1}^{n+\theta}-2 u_{i+\frac{1}{2}, j}^{n+\theta}+u_{i+\frac{1}{2}, j-1}^{n+\theta}}{\Delta y^{2}}+O\left(\Delta y^{2}\right),
\end{aligned}
$$

em que $\delta t$ é o passo temporal e $\Delta x$ e $\Delta y$ são os espaçamentos da malha nas direções $x$ e $y$, respectivamente.

Juntando as equações (2.14)-(2.19), tem-se

$$
\frac{u_{i+\frac{1}{2}, j}^{n+1}-u_{i+\frac{1}{2}, j}^{n}}{\delta t}+\mathrm{C}_{i+\frac{1}{2}, j}^{n+\theta}=-\frac{p_{i+1, j}^{n+1}-p_{i, j}^{n+1}}{\Delta x}+\frac{1}{R e} \mathbf{V}_{i+\frac{1}{2}, j}^{n+\theta},
$$

onde

$$
\begin{aligned}
\mathrm{C}_{i+\frac{1}{2}, j}^{n+\theta}= & \frac{1}{\Delta x}\left[\left(\frac{u_{i+\frac{3}{2}, j}^{n+\theta}+u_{i+\frac{1}{2}, j}^{n+\theta}}{2}\right)^{2}-\left(\frac{u_{i+\frac{1}{2}, j}^{n+\theta}+u_{i-\frac{1}{2}, j}^{n+\theta}}{2}\right)^{2}\right] \\
+ & \frac{1}{\Delta y}\left[\left(\frac{v_{i+1, j+\frac{1}{2}}^{n+\theta}+v_{i, j+\frac{1}{2}}^{n+\theta}}{2}\right)\left(\frac{u_{i+\frac{1}{2}, j+1}^{n+\theta}+u_{i+\frac{1}{2}, j}^{n+\theta}}{2}\right)\right. \\
& \left.-\left(\frac{v_{i+1, j-\frac{1}{2}}^{n+\theta}+v_{i, j-\frac{1}{2}}^{n+\theta}}{2}\right)\left(\frac{u_{i+\frac{1}{2}, j}^{n+\theta}+u_{i+\frac{1}{2}, j-1}^{n+\theta}}{2}\right)\right]
\end{aligned}
$$

é o termo convectivo e

$$
\mathbf{V}_{i+\frac{1}{2}, j}^{n+\theta}=\frac{u_{i+\frac{3}{2}, j}^{n+\theta}-2 u_{i+\frac{1}{2}, j}^{n+\theta}+u_{i-\frac{1}{2}, j}^{n+\theta}}{\Delta x^{2}}+\frac{u_{i+\frac{1}{2}, j+1}^{n+\theta}-2 u_{i+\frac{1}{2}, j}^{n+\theta}+u_{i+\frac{1}{2}, j-1}^{n+\theta}}{\Delta y^{2}}
$$

é o termo viscoso.

Para a equação de quantidade de movimento na direção $y$ (2.12) a discretização é feita no ponto onde localiza-se a velocidade $v$, isto é, no ponto $\left(i, j+\frac{1}{2}\right)$. O volume de controle para $v_{i, j+\frac{1}{2}}$ é mostrado na figura 2.4 .

A equação é definida calculando-se o fluxo nas faces do volume de controle. Analogamente à direção $x$, tem-se

$$
\frac{v_{i, j+\frac{1}{2}}^{n+1}-v_{i, j+\frac{1}{2}}^{n}}{\delta t}+\mathbf{C}_{i, j+\frac{1}{2}}^{n+\theta}=-\frac{p_{i, j+\frac{1}{2}}^{n+1}-p_{i, j-\frac{1}{2}}^{n+1}}{\Delta y}+\frac{1}{R e} \mathbf{V}_{i, j+\frac{1}{2}}^{n+\theta},
$$




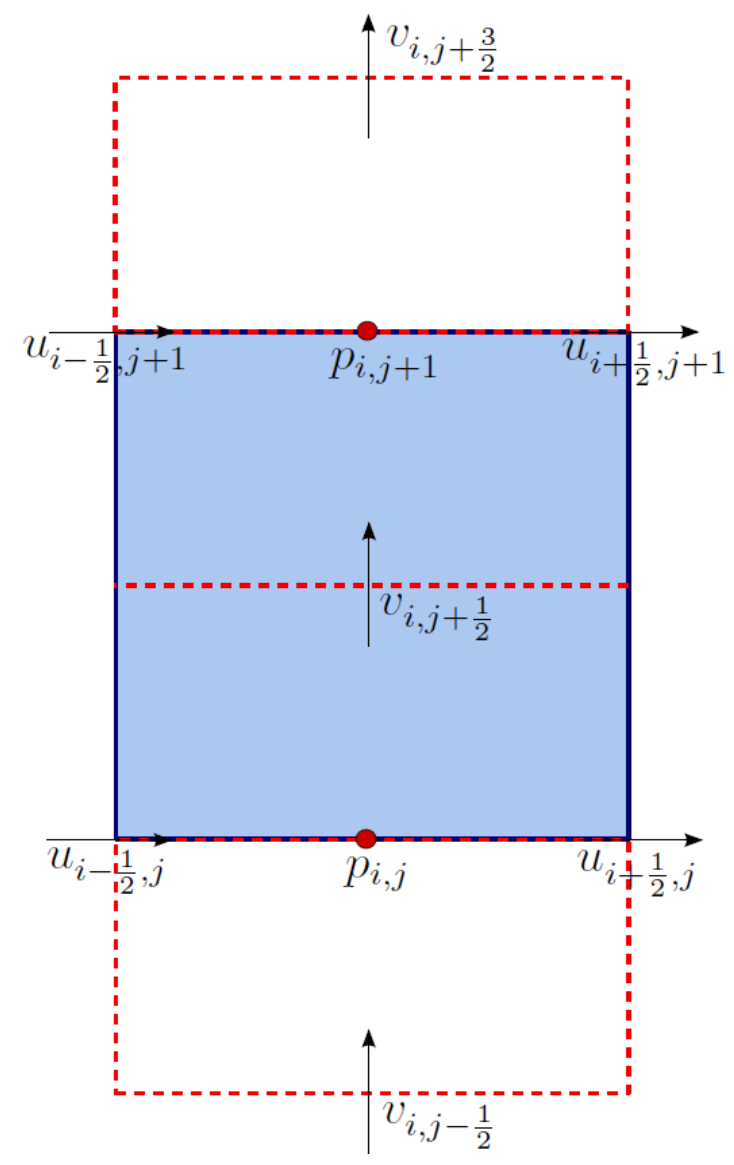

Figura 2.4: Volume de controle para a velocidade $v_{i, j+\frac{1}{2}}$.

onde

$$
\mathbf{V}_{i, j+\frac{1}{2}}^{n+\theta}=\frac{v_{i+1, j+\frac{1}{2}}^{n+\theta}-2 v_{i, j+\frac{1}{2}}^{n+\theta}+v_{i-1, j+\frac{1}{2}}^{n+\theta}}{\Delta x^{2}}+\frac{v_{i, j+\frac{3}{2}}^{n+\theta}-2 v_{i, j+\frac{1}{2}}^{n+\theta}+v_{i, j-\frac{1}{2}}^{n+\theta}}{\Delta y^{2}}
$$

é o termo viscoso e

$$
\begin{aligned}
\mathrm{C}_{i, j+\frac{1}{2}}^{n+\theta}= & \frac{1}{\Delta x}\left[\left(\frac{u_{i+\frac{1}{2}, j+1}^{n+\theta}+u_{i+\frac{1}{2}, j}^{n+\theta}}{2}\right)\left(\frac{v_{i+1, j+\frac{1}{2}}^{n+\theta}+v_{i, j+\frac{1}{2}}^{n+\theta}}{2}\right)\right. \\
& \left.-\left(\frac{u_{i-\frac{1}{2}, j+1}^{n+\theta}+u_{i-\frac{1}{2}, j}^{n+\theta}}{2}\right)\left(\frac{v_{i, j+\frac{1}{2}}^{n+\theta}+v_{i-1, j+\frac{1}{2}}^{n+\theta}}{2}\right)\right] \\
& +\frac{1}{\Delta y}\left[\left(\frac{v_{i, j+\frac{3}{2}}^{n+\theta}+v_{i, j+\frac{1}{2}}^{n+\theta}}{2}\right)^{2}-\left(\frac{v_{i, j+\frac{1}{2}}^{n+\theta}+v_{i, j-\frac{1}{2}}^{n+\theta}}{\Delta y}\right)^{2}\right]
\end{aligned}
$$

é o termo convectivo.

Finalmente, a equação da conservação da massa (2.13) é discretizada no ponto onde localiza-se a 
incógnita de pressão, ou seja, no ponto $(i, j)$. O volume de controle de $p_{i, j}$ é mostrado na figura 2.5.

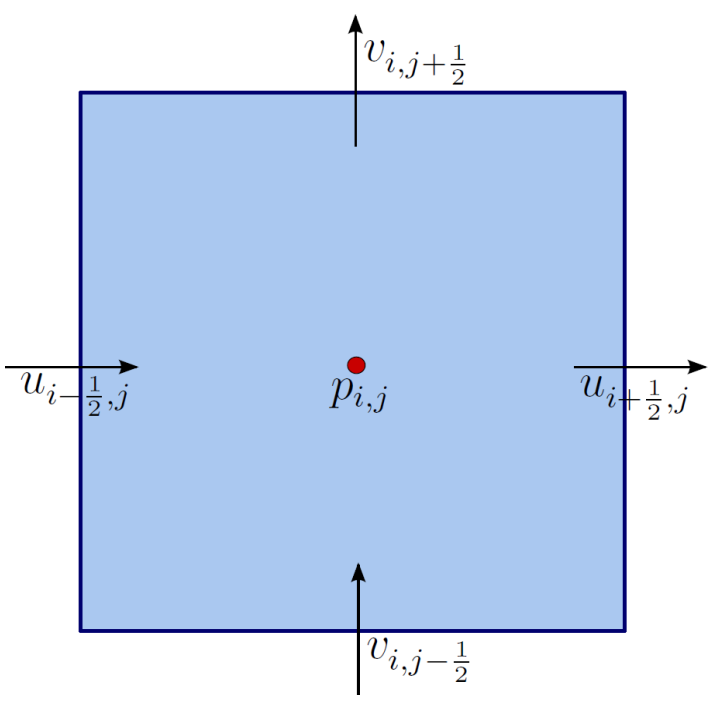

Figura 2.5: Volume de controle para a pressão $p_{i, j}$.

Como nas equações de quantidade de movimento, pode-se definir a discretização da equação (2.13) calculando-se os fluxos das componentes nas faces do volume de controle. Assim, tem-se

$$
\frac{u_{i+\frac{1}{2}, j}^{n+1}-u_{i-\frac{1}{2}, j}^{n+1}}{\Delta x}+\frac{v_{i, j+\frac{1}{2}}^{n+1}-v_{i, j-\frac{1}{2}}^{n+1}}{\Delta y}=0 .
$$

As equações (2.20), (2.23) e (2.26), discretizadas acima, serão utilizadas nos capítulos seguintes para resolver numericamente escoamentos de fluidos incompressíveis.

\subsection{Discretização Espacial das Condições de Contorno}

Nesta seção, são apresentadas as discretizações das condições de contorno de entrada de fluido, saída de fluido e sobre superfícies rígidas.

\subsubsection{Condição de Contorno de Entrada}

A condição de entrada de fluido é dada pela equação (2.3). Para a imposição desta condição, vamos considerar que o contorno de entrada é paralelo ao eixo $y$ e coincide com a face da célula deslocada onde está localizada a velocidade $u$, como pode-se ver na figura 2.6.

Considerando-se a posição do contorno desta forma, as velocidades e a pressão no contorno de entrada são definidas como

$$
\begin{aligned}
& u_{i+\frac{1}{2}, j}=u_{i n}, \\
& v_{i, j+\frac{1}{2}}=-v_{i+1, j+\frac{1}{2}}, \\
& p_{i, j}=p_{i+1, j},
\end{aligned}
$$




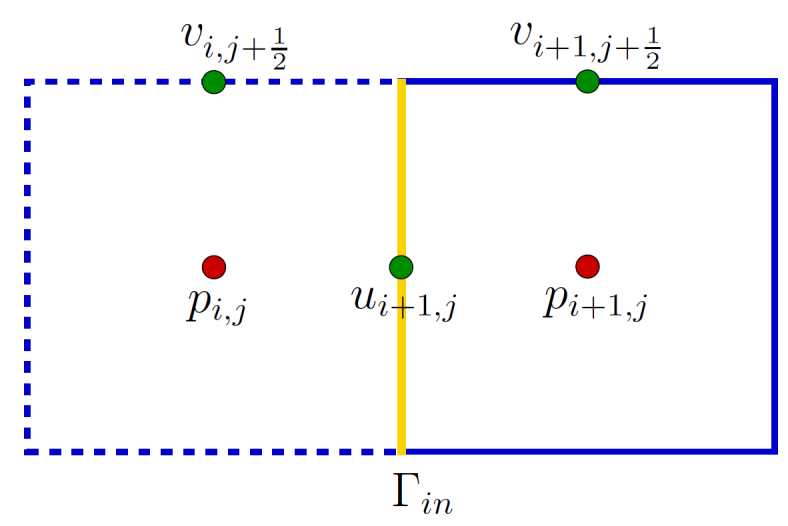

Figura 2.6: Posição do contorno de entrada de fluido $\Gamma_{i n}$ em relação à malha deslocada.

onde $u_{i n}$ é a velocidade de entrada na direção $x$ e $v_{i, j+\frac{1}{2}}$ e $p_{i, j}$ são a velocidade e a pressão "fantasmas" fora do domínio, respectivamente.

A condição de contorno de entrada é análoga quando o contorno de entrada é paralelo ao eixo $x$, coincidindo com a face onde está localizada a velocidade $v$.

\subsubsection{Condição de Contorno de Saída}

A condição de contorno de saída de fluido é dada pela equação (2.4). Analogamente à condição de contorno de entrada, considera-se o contorno passando sobre a face onde se encontra a velocidade $u$, como mostrado na figura 2.7. Assim, as velocidades e a pressão no contorno de saída são definidas como mostrado abaixo.

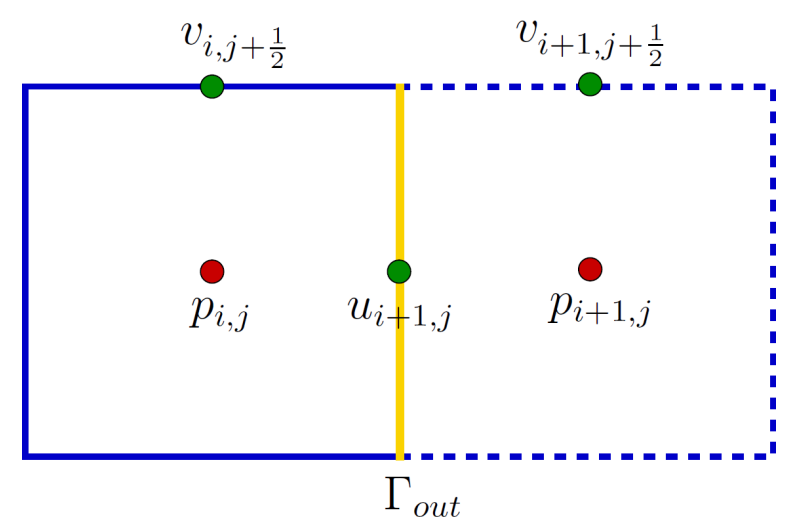

Figura 2.7: Posição do contorno de saída de fluido $\Gamma_{\text {out }}$ em relação à malha deslocada.

Iniciando-se pela equação de quantidade de movimento na direção $x$, o termo viscoso, definido na equação (2.22), será reescrito da seguinte forma

$$
\mathrm{V}_{i+\frac{1}{2}, j}^{n+\theta}=\frac{-u_{i+\frac{1}{2}, j}^{n+\theta}+u_{i-\frac{1}{2}, j}^{n+\theta}}{\Delta x^{2}}+\frac{u_{i+\frac{1}{2}, j+1}^{n+\theta}-2 u_{i+\frac{1}{2}, j}^{n+\theta}+u_{i+\frac{1}{2}, j-1}^{n+\theta}}{\Delta y^{2}}
$$

pois o gradiente de $u$ na direção normal ao escoamento é zero. 
Já o termo convectivo, definido na equação (2.21), será considerado como sendo o fluxo convectivo de $u_{i-\frac{1}{2}, j}$ no tempo anterior, ou seja,

$$
\begin{aligned}
\mathrm{C}_{i+\frac{1}{2}, j}^{n+\theta}= & \frac{1}{\Delta x}\left[\left(\frac{u_{i+\frac{1}{2}, j}^{n-1}+u_{i-\frac{1}{2}, j}^{n-1}}{2}\right)^{2}-\left(\frac{u_{i-\frac{1}{2}, j}^{n-1}+u_{i-\frac{3}{2}, j}^{n-1}}{2}\right)^{2}\right] \\
& +\frac{1}{\Delta y}\left[\left(\frac{v_{i, j+\frac{1}{2}}^{n-1}+v_{i-1, j+\frac{1}{2}}^{n-1}}{2}\right)\left(\frac{u_{i-\frac{1}{2}, j+1}^{n-1}+u_{i-\frac{1}{2}, j}^{n-1}}{2}\right)\right. \\
& \left.-\left(\frac{v_{i, j-\frac{1}{2}}^{n-1}+v_{i-1, j-\frac{1}{2}}^{n-1}}{2}\right)\left(\frac{u_{i-\frac{1}{2}, j}^{n-1}+u_{i-\frac{1}{2}, j-1}^{n-1}}{2}\right)\right] .
\end{aligned}
$$

Para o gradiente de pressão da equação (2.20), considera-se $p_{i+1, j}=0$, onde $p_{i+1, j}$ é a pressão "fantasma" fora do domínio. Então,

$$
\left.\frac{\partial p^{n+1}}{\partial x}\right|_{i+\frac{1}{2}, j}=-\frac{p_{i, j}^{n+1}}{\Delta x}
$$

Dessa forma, tem-se que a equação de quantidade de movimento na direção $x$ para o contorno de saída será

$$
\frac{u_{i+\frac{1}{2}, j}^{n+1}-u_{i+\frac{1}{2}, j}^{n}}{\delta t}+\mathrm{C}_{i+\frac{1}{2}, j}^{n+\theta}=+\frac{p_{i, j}^{n+1}}{\Delta x}+\frac{1}{R e} \mathbf{V}_{i+\frac{1}{2}, j}^{n+\theta},
$$

onde $\mathrm{C}_{i+\frac{1}{2}, j}^{n+\theta}$ e $\mathrm{V}_{i+\frac{1}{2}, j}^{n+\theta}$ são dados pelas equações (2.28) e (2.27), respectivamente.

Agora, considerando-se a equação de quantidade de movimento na direção $y$, tem-se que o gradiente de $v$ na direção normal ao escoamento é zero. Logo,

$$
v_{i+1, j+\frac{1}{2}}=-v_{i, j+\frac{1}{2}}
$$

onde $v_{i+1, j+\frac{1}{2}}$ é a velocidade "fantasma" fora do domínio. Assim, o termo viscoso, definido pela equação (2.24), será reescrito da seguinte forma

$$
\mathbf{V}_{i, j+\frac{1}{2}}^{n+\theta}=\frac{-3 v_{i, j+\frac{1}{2}}^{n+\theta}+v_{i-1, j+\frac{1}{2}}^{n+\theta}}{\Delta x^{2}}+\frac{v_{i, j+\frac{3}{2}}^{n+\theta}-2 v_{i, j+\frac{1}{2}}^{n+\theta}+v_{i, j-\frac{1}{2}}^{n+\theta}}{\Delta y^{2}} .
$$


Da mesma forma, o fluxo convectivo, definido pela equação (2.25), será reescrito como

$$
\begin{aligned}
\mathrm{C}_{i, j+\frac{1}{2}}^{n+\theta}= & \frac{1}{\Delta x}\left[-\left(\frac{u_{i-\frac{1}{2}, j+1}^{n+\theta}+u_{i-\frac{1}{2}, j}^{n+\theta}}{2}\right)\left(\frac{v_{i, j+\frac{1}{2}}^{n+\theta}+v_{i-1, j+\frac{1}{2}}^{n+\theta}}{2}\right)\right] \\
& +\frac{1}{\Delta y}\left[\left(\frac{v_{i, j+\frac{3}{2}}^{n+\theta}+v_{i, j+\frac{1}{2}}^{n+\theta}}{2}\right)^{2}-\left(\frac{v_{i, j+\frac{1}{2}}^{n+\theta}+v_{i, j-\frac{1}{2}}^{n+\theta}}{\Delta y}\right)^{2}\right] .
\end{aligned}
$$

Tem-se então que a equação da quantidade de movimento na direção $y$ será dada por

$$
\frac{v_{i, j+\frac{1}{2}}^{n+1}-v_{i, j+\frac{1}{2}}^{n}}{\delta t}+\mathbf{C}_{i, j+\frac{1}{2}}^{n+\theta}=-\frac{p_{i, j+1}^{n+1}-p_{i, j}^{n+1}}{\Delta y}+\frac{1}{R e} \mathbf{V}_{i, j+\frac{1}{2}}^{n+\theta},
$$

onde $\mathrm{C}_{i, j+\frac{1}{2}}^{n+\theta}$ e $\mathrm{V}_{i, j+\frac{1}{2}}^{n+\theta}$ são dados pelas equações (2.30) e (2.29), respectivamente.

Para os casos em que o contorno está em outras posições a discretização das condições de contorno será análoga.

\subsubsection{Condição de Contorno sobre Superfície Rígida}

As condições de contorno sobre superfícies rígidas são classificadas em dois grupos: as que respeitam a malha e as que estão imersas na malha. A seguir, são apresentadas as discretizações destas condições para cada um dos casos.

\subsubsection{Superfície Rígida que Respeita a Malha}

A condição de contorno sobre uma superfície rígida que respeita a malha é dada pela equação (2.5). Para a imposição desta condição, considera-se o contorno passando pela face da célula onde se encontra a velocidade $v$, como mostrado na figura (2.8).

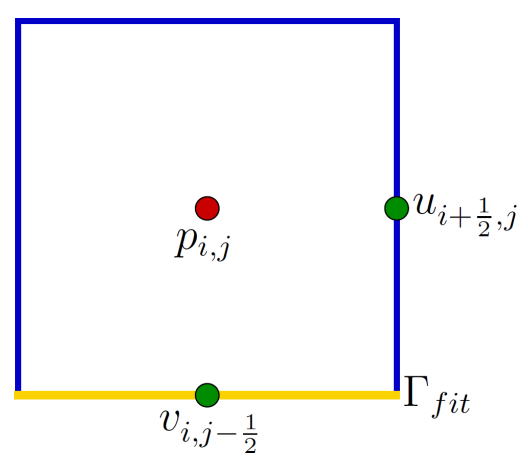

Figura 2.8: Posição do contorno sobre superfície rígida que respeita a malha $\Gamma_{f i t}$ em relação à malha deslocada.

Para a equação de quantidade de movimento na direção $x$, tem-se que

$$
u_{i+\frac{1}{2}, j-1}=-u_{i+\frac{1}{2}, j}
$$


onde $u_{i+\frac{1}{2}, j-1}$ é a velocidade "fantasma" fora do domínio. Então, o termo viscoso torna-se

$$
\mathbf{V}_{i+\frac{1}{2}, j}^{n+\theta}=\frac{u_{i+\frac{3}{2}, j}^{n+\theta}-2 u_{i+\frac{1}{2}, j}^{n+\theta}+u_{i-\frac{1}{2}, j}^{n+\theta}}{\Delta x^{2}}+\frac{u_{i+\frac{1}{2}, j+1}^{n+\theta}-3 u_{i+\frac{1}{2}, j}^{n+\theta}}{\Delta y^{2}} .
$$

E o termo convectivo é então escrito da seguinte forma

$$
\begin{aligned}
\mathrm{C}_{i+\frac{1}{2}, j}^{n+\theta}= & \frac{1}{\Delta x}\left[\left(\frac{u_{i+\frac{3}{2}, j}^{n+\theta}+u_{i+\frac{1}{2}, j}^{n+\theta}}{2}\right)^{2}-\left(\frac{u_{i+\frac{1}{2}, j}^{n+\theta}+u_{i-\frac{1}{2}, j}^{n+\theta}}{2}\right)^{2}\right] \\
& +\frac{1}{\Delta y}\left[\left(\frac{v_{i+1, j+\frac{1}{2}}^{n+\theta}+v_{i, j+\frac{1}{2}}^{n+\theta}}{2}\right)\left(\frac{u_{i+\frac{1}{2}, j+1}^{n+\theta}+u_{i+\frac{1}{2}, j}^{n+\theta}}{2}\right)\right] .
\end{aligned}
$$

Logo, a equação de quantidade de movimento na direção $x$ será dada por

$$
\frac{u_{i+\frac{1}{2}, j}^{n+1}-u_{i+\frac{1}{2}, j}^{n}}{\delta t}+\mathrm{C}_{i+\frac{1}{2}, j}^{n+\theta}=-\frac{p_{i+1, j}^{n+1}-p_{i, j}^{n+1}}{\Delta x}+\frac{1}{R e} \mathbf{V}_{i+\frac{1}{2}, j}^{n+\theta},
$$

onde os termos convectivo e viscoso são dados pelas equações (2.32) e (2.31), definidas acima.

Para a equação de quantidade de movimento na direção $y$, impõe-se o valor da velocidade no contorno, ou seja,

$$
v_{i, j-\frac{1}{2}}=0
$$

De maneira análoga, a condição sobre superfície rígida que respeita a malha pode ser imposta da mesma forma para outras direções.

\subsubsection{Superfície Rígida Imersa na Malha}

A condição de superfície rígida imersa na malha é dada pela equação (2.6). A discretização desta condição de contorno será descrita no capítulo 4 , de acordo com os métodos que serão apresentados neste capítulo. 


\section{CAPÍTULO}

\section{Métodos para Escoamentos Incompressíveis em Microescala}

Inicialmente, neste capítulo, será apresentada a biblioteca PETSc. Em seguida, será feita uma comparação entre métodos monolíticos e segmentados e um estudo sobre resolvedores de sistemas na solução numérica de escoamentos incompressíveis em microescala.

\subsection{Introdução}

Nos últimos anos, grandes avanços foram alcançados em escoamentos em microescala, que aparecem em um grande número de aplicações, como por exemplo em microrreatores químicos, injetores em impressoras jato de tinta, redes de microcanais, diversos sensores e atuadores, como acelerômetros utilizados em airbags, jogos interativos, etc. O escoamento de microbolhas em microcanais (de aproximadamente $800 \mu \mathrm{m}$ ), por exemplo, pode ser utilizado para induzir processos de mistura mais eficientes em microrreatores químicos, onde a razão entre área superficial e volume das bolhas propiciam boas taxas de transferência de massa e calor (Akbar and Ghiaasiaan, 2006; Wörner et al., 2007; Kreutzer, 2003). Outras aplicações na área de engenharia podem ser encontradas em Whitesides (2006), Squires and Quake (2005) e Stone et al. (2004).

Aplicações em biofluidodinâmica também se beneficiam de avanços nesta área, como por exemplo a simulação do sistema hemodinâmico, com vasos capilares da espessura de um fio de cabelo e simulação de aneurismas cerebrais (Mut, 2008). Outras aplicações em medicina e biologia podem ser vistas em Beebe et al. (2002).

Apesar de várias aplicações importantes, o desenvolvimento de métodos numéricos para escoamentos de fluidos nestas escalas de comprimento (da ordem de centenas de mícrons a poucos milímetros), ainda não está completamente aperfeiçoado, sendo vários os desafios encontrados na mode- 
lagem de tais escoamentos.

Neste capítulo, são apresentados dois desafios impostos aos métodos numéricos utilizados para resolver problemas em microescala: o primeiro concerne à escolha adequada do resolvedor de Navier-Stokes, levando-se em conta os baixos números de Reynolds ( $R e$ ) envolvidos. É mostrado neste trabalho o aparecimento de um transiente espúrio quando se utiliza uma formulação baseada em método de projeção, degradando a solução numérica.

Por outro lado, a utilização de métodos totalmente acoplados introduz o segundo desafio: trata-se da dificuldade de se obter soluções quando as diferenças de escalas são muito discrepantes, gerando matrizes muito mal condicionadas. Este estudo mostra que, apesar de pré-condicionadores e métodos para sistemas lineares serem bem conhecidos e estudados, a aplicação dos métodos mais conhecidos falha quando se tem escalas muito diferentes no domínio.

Para fazer este estudo de métodos para sistemas lineares e pré-condicionadores foi utilizada a biblioteca PETSc, que será apresentada a seguir.

\subsection{PETSc}

O Portable, Extensible Toolkit for Scientific Computation (PETSc) (Balay et al., 2008, 2009) foi desenvolvido no Mathematics and Computer Science Division, no Argonne National Laboratory.

PETSc é um conjunto de bibliotecas que possui uma gama de ferramentas para a implementação de códigos de aplicações de grande escala que envolvem a solução de equações diferenciais parciais (EDPs) e problemas similares. Dentre essas ferramentas estão rotinas para a criação de vetores, matrizes e arrays distribuídos, sequenciais e paralelos, assim como bibliotecas para a solução numérica de problemas lineares e não lineares. Há ainda métodos de avanço temporal e janelas gráficas. Para a comunicação (troca de mensagens) entre os processos, quando em paralelo, utiliza-se a biblioteca MPI (Message-Passing Interface).

É uma ferramenta de fácil utilização, por ser bem documentada e por fornecer vários códigos de exemplo, que vão de simples resoluções de sistemas lineares à problemas mais complicados como a simulação de escoamentos.

O uso do PETSc permite maior flexibilidade da aplicação, pois permite que o usuário altere os parâmetros do programa, como o tipo de resolvedor a ser utilizado, o tamanho do problema, o valor de tolerância do erro, etc, em tempo de execução. Isto torna fácil a comparação entre diferentes métodos para a solução de um mesmo problema, sem a necessidade de alterar o código. Existem também as opções de executar o programa com debugger e mostrar informações sobre o desempenho do programa, como número de operações ponto flutuante, quantidade de memória utilizada em cada rotina e número de mensagens trocadas entre processos.

Além destas diversas características, PETSc possui a flexibilidade de ser utilizado em códigos escritos em Fortran, C, C++ e Python.

A seguir, será apresentado um código para solução de escoamentos incompressíveis que foi implementado utilizando PETSc. Neste código foram usadas várias rotinas para: 
- a manipulação de vetores, matrizes e arrays distribuídos;

- a solução de problemas não lineares (SNES - Nonlinear Equations Solver);

- a solução de sistemas lineares (KSP - Krylov Subspace Methods);

- o pré-condicionamento de matrizes, na resolução de sistemas lineares.

Existem ainda rotinas para a integração temporal de EDOs (TS - Timestepping) e resolução de problemas utilizando multigrid (DMMG), que não foram utilizadas. Neste trabalho, foi utilizada a versão 3.0.0 do PETSc.

\subsection{Métodos para Solução de Escoamentos Incompressí- veis}

Nesta seção, será feito um estudo sobre métodos numéricos para a solução de escoamentos incompressíveis em microescala. Para tal, serão apresentados os métodos acoplado e segregado (método de projeção). Em seguida, serão mostrados os resultados e conclusões sobre o comportamento destes métodos para esta classe de problemas.

Para os experimentos numéricos foram utilizadas as formulações de diferenças finitas, apresentada no capítulo 2, e de elementos finitos, apresentada abaixo, para comparação.

\subsubsection{Discretização por Elementos Finitos}

A formulação de Lagrange-Galerkin das equações (2.7)-(2.8), considerando espaços discretos $V_{h}$ e $Q_{h}$ para velocidade e pressão, respectivamente, é

$$
\begin{aligned}
\int_{\Omega}\left[\frac{\boldsymbol{u}_{h}^{n+1}(x)-\boldsymbol{u}_{h}^{n}\left(X\left(x, t_{n+1}, t_{n}\right)\right)}{\Delta t} \cdot \boldsymbol{v}_{h}(x)\right. & + \\
\left.\frac{1}{R e}\left(\nabla \boldsymbol{u}_{h}^{n+1}(x)+\nabla^{T} \boldsymbol{u}_{h}^{n+1}(x)\right): \nabla \boldsymbol{v}_{h}(x)-p_{h}^{n+1}(x) \nabla \cdot \boldsymbol{v}_{h}(x)\right] d x & =0, \\
\int_{\Omega} q_{h}(x) \nabla \cdot \boldsymbol{u}_{h}^{n+1}(x) d x & =0,
\end{aligned}
$$

a serem satisfeitas para todo $\boldsymbol{v}_{h} \in V_{h}$ e $q_{h} \in Q_{h}$. Em (3.1), o ponto $X\left(x, t_{n+1}, t_{n}\right)$ é a posição ocupada, ao tempo $t_{n}$, pela partícula de fluido que, ao tempo $t_{n+1}$, ocupa a posição $x$.

O elemento finito utilizado é o mini-elemento de Arnold et al. (1984), no qual o espaço de pressões consiste do espaço $P_{1}$ conforme, e o espaço de velocidades consiste também do espaço $P_{1}$ conforme para cada componente, enriquecido com funções bolha cúbicas. Como é bem conhecido, esse elemento satisfaz a condição de Babuska-Brezzi e, portanto, não precisa de estabilização. 


\subsubsection{Método Acoplado}

As equações (2.9)-(2.10), uma vez discretizadas através da formulação de diferenças finitas ou de elementos finitos, levam a um sistema algébrico da seguinte forma

$$
\left[\begin{array}{ll}
\mathrm{A} & \mathrm{G} \\
\mathrm{D} & 0
\end{array}\right]\left[\begin{array}{l}
\boldsymbol{U}^{n+1} \\
\boldsymbol{P}^{n+1}
\end{array}\right]=\left[\begin{array}{c}
\mathbf{r}^{n} \\
0
\end{array}\right]+\left[\begin{array}{l}
\mathbf{b c} \\
\mathbf{b c}
\end{array}\right],
$$

onde

$$
\mathrm{A}=\frac{1}{\delta t} \mathrm{M}+\mathrm{N}\left(\boldsymbol{U}^{n+1}\right)-\frac{1}{R e} \mathrm{~L}
$$

M é a matriz identidade no caso da formulação de diferenças finitas e a matriz de massa no método de elementos finitos; $\mathrm{N}\left(\boldsymbol{U}^{n+1}\right)$ representa o operador discreto implícito dos termos não-lineares (ele não aparece na formulação de elementos finitos, nem se $\theta=0$ ); $L$ é o operador laplaciano; $G$ é o operador gradiente e $\mathrm{D}$ é o operador divergente. $\mathrm{O}$ vetor $\mathbf{r}^{n}$ depende só de valores conhecidos, assim como o vetor bc, que contém as contribuições das condições de contorno (daqui em diante, qualquer vetor que só contenha informação das condições de contorno será chamado de bc, de maneira genérica).

No presente trabalho, considera-se o método acoplado, ou monolítico, como a resolução do sistema algébrico (3.3) por métodos diretos ou iterativos, sem decompor o vetor de incógnitas em incógnitas de pressão e de velocidade.

\subsubsection{Métodos Segregados: Método de Projeção}

Um fato significante na solução numérica das equações de Navier-Stokes é que o sistema de equações (2.7)-(2.8) acopla os campos de velocidade e pressão devido à restrição de incompressibilidade.

Os métodos conhecidos como "métodos de projeção" ou "métodos de passo fracionário" foram originalmente propostos por Chorin (1968) e Temam (1969), com o intuito de reduzir o tamanho dos sistemas lineares a serem resolvidos. A seguir são descritas suas variantes diferencial e algébrica.

\subsubsection{Método de Projeção Diferencial}

Neste caso, a formulação matemática dos métodos de projeção está relacionada com o teorema de Helmholtz-Hodge (ver em Hodge (1952)). A ideia básica é usar a equação de quantidade de movimento (2.7) para calcular um campo de velocidade intermediária $\widetilde{\boldsymbol{u}}$, que geralmente não satisfaz a equação da continuidade (2.8), ou seja, define-se a equação

$$
\frac{\partial \widetilde{\boldsymbol{u}}}{\partial t}+\nabla \cdot(\boldsymbol{u u})=-\nabla \widetilde{p}+\frac{1}{R e} \nabla^{2} \boldsymbol{u}
$$

onde $\widetilde{p}$ é uma aproximação para a pressão (ou uma pressão provisória). Neste momento aplica-se a decomposição de Helmholtz-Hodge, interpretando que a velocidade $\widetilde{\boldsymbol{u}}$ é o campo vetorial decomposto 
como

$$
\widetilde{\boldsymbol{u}}=\boldsymbol{u}+\Delta t \nabla \phi
$$

$\operatorname{com} \nabla \cdot \boldsymbol{u}=0$ e $\phi$ uma função escalar, onde foi introduzido o fator $\Delta t$ (passo de tempo) por conveniência de notação. Em geral a velocidade $\widetilde{\boldsymbol{u}}$ não é solenoidal, pois em geral $p \neq \widetilde{p}$. A função da pressão em escoamentos incompressíveis é fazer com que o campo de velocidade satisfaça a equação da continuidade (2.8). Portanto, é necessário calcular a pressão no próximo passo.

Para isto, uma equação elíptica é resolvida para que a equação (2.8) seja satisfeita e a pressão determinada. A importância dessa equação elíptica para a pressão é que ela faz a ligação entre as equações de quantidade de movimento e da continuidade. Para obter esta equação, aplica-se o divergente na equação (3.6), e em seguida utiliza-se a equação da continuidade (2.8) para definir

$$
\Delta t \nabla^{2} \phi=\nabla \cdot \widetilde{\boldsymbol{u}}
$$

Após esse passo, utiliza-se a equação (3.6) para atualizar os campos de velocidade e de pressão. Portanto, a principal vantagem da classe de métodos tipo projeção é que os cálculos dos campos de velocidade e pressão estão desacoplados. Mais precisamente, a cada passo no tempo resolve-se um conjunto de equações do tipo convecção-difusão transiente para a velocidade, e uma equação escalar do tipo Poisson para a pressão.

Estudos rigorosos sobre a consistência e estabilidade dos métodos de projeção para escoamentos incompressíveis foram apresentados por Shen (1996), Guermond and Shen (2003), Denaro (2003), Guermond et al. (2006), entre outros.

\subsubsection{Método de Projeção Algébrico}

Neste método, o desacoplamento das equações de Navier-Stokes (2.7)-(2.8) pode ser visto como uma fatoração aproximada das equações na forma discreta, ou seja, considerando um sistema algébrico. Um exemplo da prática desta variação do método de projeção para as equações de Navier-Stokes pode ser encontrado em Dukowicz and Dvinsky (1992) e Perot (1993). De acordo com estes trabalhos, a construção de um método de projeção pode ser interpretada via fatoração do tipo LU para superar algumas dificuldades encontradas em uma análise padrão. Essa afirmação baseia-se no fato de que o erro introduzido no momento do desacoplamento das equações (2.7) e (2.8) está diretamente conectado à fatoração aproximada utilizada, e não com a correção da pressão ou com as condições de contorno. Os trabalhos de Dukowicz and Dvinsky (1992) e Perot (1993) despertaram a atenção de outros pesquisadores que começaram a analisar o método de fatoração aproximada (veja por exemplo em Quarteroni et al. (2000), Lee et al. (2001), Zhang (2005), entre outros). A seguir será feita uma breve descrição desta técnica.

Somando e subtraindo o termo $G \widetilde{\boldsymbol{P}}^{n}$ na primeira equação do sistema (3.3), onde $\widetilde{\boldsymbol{P}}^{n}$ é, por en- 
quanto, arbitrário, obtém-se

$$
\left[\begin{array}{ll}
\mathrm{A} & \mathrm{G} \\
\mathrm{D} & 0
\end{array}\right]\left[\begin{array}{c}
\boldsymbol{U}^{n+1} \\
\boldsymbol{P}^{n+1}-\widetilde{\boldsymbol{P}}^{n}
\end{array}\right]=\left[\begin{array}{c}
\mathbf{r}^{n}-\mathrm{G} \widetilde{\boldsymbol{P}}^{n} \\
0
\end{array}\right]+\left[\begin{array}{l}
\mathbf{b c} \\
\mathbf{b c}
\end{array}\right] .
$$

Utilizando a fatoração LU, pode-se reescrever a equação (3.8) da seguinte forma

$$
\left[\begin{array}{cc}
\mathrm{A} & 0 \\
\mathrm{D} & -\mathrm{DA}^{-1} \mathrm{G}
\end{array}\right]\left[\begin{array}{cc}
\mathrm{II} & \mathrm{A}^{-1} \mathrm{G} \\
0 & \mathrm{II}
\end{array}\right]\left[\begin{array}{c}
\boldsymbol{U}^{n+1} \\
\boldsymbol{P}^{n+1}-\widetilde{\boldsymbol{P}}^{n}
\end{array}\right]=\left[\begin{array}{c}
\mathbf{r}^{n}-\mathrm{G} \widetilde{\boldsymbol{P}}^{n} \\
0
\end{array}\right]+\left[\begin{array}{l}
\mathbf{b c} \\
\mathbf{b c}
\end{array}\right],
$$

o que leva finalmente a

$$
\begin{aligned}
\mathrm{A} \widetilde{\boldsymbol{U}}^{n+1} & =\mathbf{r}^{n}-\mathrm{G} \widetilde{\boldsymbol{P}}^{n}+\mathbf{b c} \\
\mathrm{DA}^{-1} \mathrm{G} \boldsymbol{\Phi}^{n+1} & =\mathrm{D} \widetilde{\boldsymbol{U}}^{n+1}+\mathbf{b c} \\
\boldsymbol{U}^{n+1} & =\widetilde{\boldsymbol{U}}^{n+1}-\mathrm{A}^{-1} \mathrm{G} \boldsymbol{\Phi}^{n+1}, \\
\boldsymbol{P}^{n+1} & =\widetilde{\boldsymbol{P}}^{n}+\boldsymbol{\Phi}^{n+1}
\end{aligned}
$$

onde $\widetilde{\boldsymbol{U}}^{n+1}$ e $\boldsymbol{\Phi}^{n+1}$ são valores intermediários definidos consequentemente pela fatoração. Até agora a fatoração é, obviamente, exata e o resultado coincide com o do método acoplado.

Na prática, desde que o cálculo da matriz $A^{-1}$ é muito custoso, ela é substituída por outra matriz, muitas vezes diagonal, que, neste trabalho, será chamada de B. Ainda, para que o algoritmo esteja totalmente definido, falta especificar a escolha do vetor $\widetilde{\boldsymbol{P}}^{n}$. Considera-se então, a escolha mais frequente, isto é,

$$
\widetilde{\boldsymbol{P}}^{n}=\boldsymbol{P}^{n}
$$

Resumindo, o método de projeção algébrico consiste do sistema (3.10)-(3.13), onde são feitas as substituições $A^{-1} \leftarrow B$ e $\widetilde{\boldsymbol{P}}^{n} \leftarrow \boldsymbol{P}^{n}$. Neste trabalho, assumiremos $\mathrm{B}=\delta t$ II no caso da formulação de diferenças finitas, e $B=\delta t \mathrm{M}^{-1}$, com $\mathrm{M}$ a matriz de massa, no caso da formulação de elementos finitos (corresponde a aproximar $A^{-1}$ pela inversa de apenas o primeiro termo da equação (3.4)).

Observação: A formulação de diferenças finitas, com B $=\delta t \mathbb{I}$, resulta (da equação (3.11)) como equação para $\Phi^{n+1}$ :

$$
\delta t \mathrm{DG} \boldsymbol{\Phi}^{n+1}=\mathrm{D} \widetilde{\boldsymbol{U}}^{n+1}+\mathbf{b c} .
$$

Por outro lado, a discretização da equação correspondente no método de projeção diferencial, equação (3.7), é

$$
\delta t \mathbf{L} \Phi^{n+1}=\mathrm{D} \widetilde{\boldsymbol{U}}^{n+1}+\mathbf{b c} .
$$


Para a discretização por diferenças finitas, desde que o operador discreto do laplaciano (L) é igual à composição dos operadores discretos do divergente (D) e do gradiente $(G)$, isto é, $L=D G$, resulta que ambas as equações acima são iguais. Isto mostra que as variantes algébrica e diferencial do método de projeção levam à mesma equação discreta de pressão no caso da discretização por diferenças finitas, e portanto as formulações são equivalentes.

Já no caso da discretização de elementos finitos, a variante algébrica leva a matrizes menos esparsas que a variante diferencial, existindo vantagens e desvantagens para cada uma das variantes. Nesse trabalho utiliza-se a variante algébrica do método de projeção para ambas discretizações.

\subsection{Testes Numéricos}

\subsubsection{Acoplado $\times$ Projeção}

Um dos objetivos deste trabalho é comparar, mediante testes numéricos, o comportamento dos métodos acoplado e de projeção para baixo número de Reynolds $(R e<<1)$.

Para isso, considerou-se o domínio como sendo o canal mostrado na figura 3.1, com $L=3$ e $H=1$ sendo as dimensões do canal e $\Gamma_{i n}, \Gamma_{\text {out }}$ e $\Gamma_{f i t}$ sendo as condições de contorno definidas na seção 2.2, ou seja,

$$
\begin{array}{rlrl}
\boldsymbol{u} & =\boldsymbol{u}_{\text {in }}, & & \mathrm{em} \Gamma_{\text {in }} \\
\sigma \cdot \boldsymbol{n} & =\mathbf{0}, & \mathrm{em} \Gamma_{\text {out }} \\
\boldsymbol{u} & =\mathbf{0}, & \mathrm{em} \Gamma_{f i t} .
\end{array}
$$

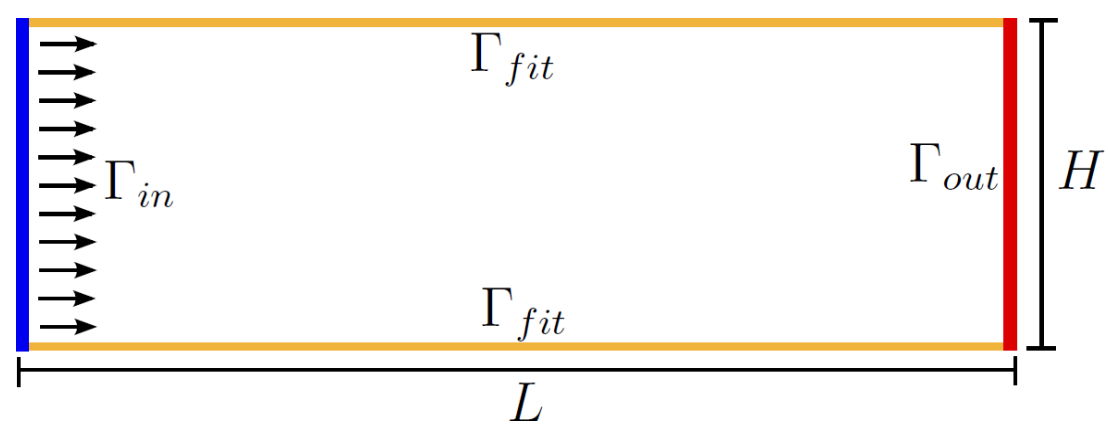

Figura 3.1: Representação do canal, com dimensões $L=3$ e $H=1$ e com condições de contorno de entrada (azul $\left(\Gamma_{i n}\right)$ ), saída (vermelho $\left.\left(\Gamma_{\text {out }}\right)\right)$ e sobre superfície rígida que respeita a malha (amarelo $\left.\left(\Gamma_{f i t}\right)\right)$.

Neste teste considerou-se $R e=10^{-2}$, partindo da condição inicial $\boldsymbol{u}=0$ em todo o domínio. Logo depois do instante inicial, a condição de entrada estabelece uma velocidade praticamente uniforme no canal, que demora um tempo $t \simeq R e=10^{-2}$ para ser levada ao escoamento estacionário pelos efeitos viscosos. Em termos dimensionais, esse tempo corresponde a $10^{-2} \frac{\mathrm{H}}{\mathrm{V}}$, o que com $H=10^{-5} \mathrm{~m}$ e $V=10^{-2} \mathrm{~m} / \mathrm{s}$ leva a um valor de $10 \mu$ segundos. Normalmente esse transiente, que é físico, não tem interesse na modelação, o que levou ao tratamento implícito do termo viscoso. 
Escolhendo malhas com $h=0.1$, em que $h$ é o espaçamento da malha, foram executados os diversos programas com os seguintes passos de tempo: $\delta t=10^{-2}, 10^{-3}, 10^{-4}, 10^{-5}, 10^{-6}, 10^{-7}$. Para a solução do sistema linear dos métodos acoplado, em ambas as discretizações, e de projeção, discretizado por elementos finitos, foi utilizado o método LU. Já para o método de projeção, discretizado por diferenças finitas, foi utilizado o programa FREEFLOW (Castelo et al., 2000), que utiliza o método dos gradientes conjugados, pré-condicionado por Jacobi para a solução da equação de Poisson.

Pode-se ver, para vários passos de tempo, a evolução da velocidade horizontal $u$ com o tempo no ponto $(0.21644,0.223198)$, na figura 3.2.a, e no ponto $(0.2,0.2)$, na figura 3.3.a. Para $\delta t \leq 10^{-5}$ as soluções numéricas convergem para uma mesma função do tempo, a solução exata do problema, que tende assintoticamente para seu valor estacionário com um transiente físico de tempo característico $\simeq 10^{-2}$. Os resultados das figuras 3.2. a e 3.3. a foram calculados com o método acoplado, nas formulações de elementos finitos e de diferenças finitas, respectivamente. Vê-se que o método acoplado, por ter tratamento implícito do termo viscoso, não tem restrição no passo de tempo e pode calcular o estado estacionário em apenas um passo (simplesmente tomando $\delta t=10^{-2}$ ).
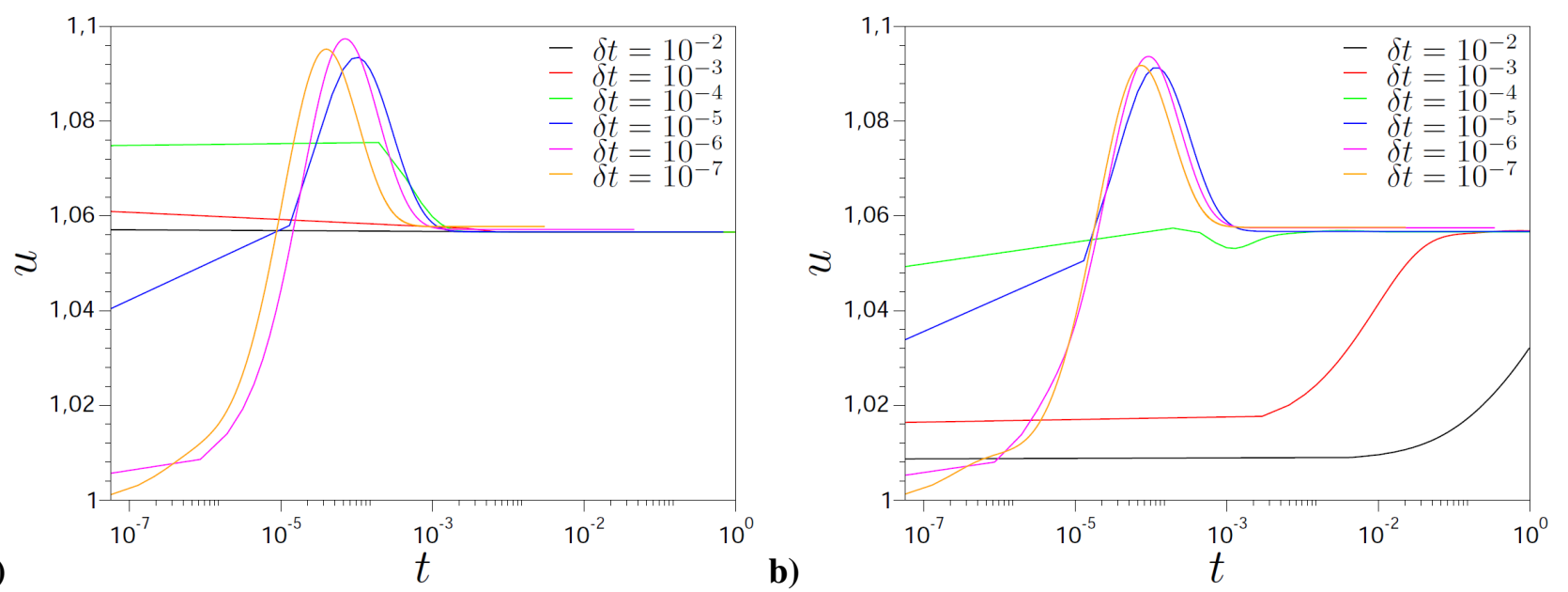

Figura 3.2: Evolução da velocidade horizontal $u$ com o tempo no ponto $(0.21644,0.223198)$ para os métodos: a) acoplado e b) de projeção, ambos na formulação de elementos finitos.

Considerando agora o método de projeção, a mesma evolução é mostrada nas figuras 3.2.b e 3.3.b, nas formulações de elementos finitos e de diferenças finitas, respectivamente, para vários passos de tempo. Aqui pode-se observar que o método é, de fato, convergente, já que novamente para $\delta t$ suficientemente pequeno converge-se para o transiente físico. A novidade aparece para $\delta t \geq 10^{-4}$. As soluções numéricas se afastam do transiente físico de maneira evidente, surgindo um transiente espúrio cuja duração é maior quanto maior o $\delta t$.

Esse transiente espúrio traz duas desvantagens sérias nas aplicações:

- Por um lado, ele pode ser interpretado como um transiente físico, em particular se o campo de velocidades é utilizado para transportar campos escalares tais como a temperatura ou a concen- 

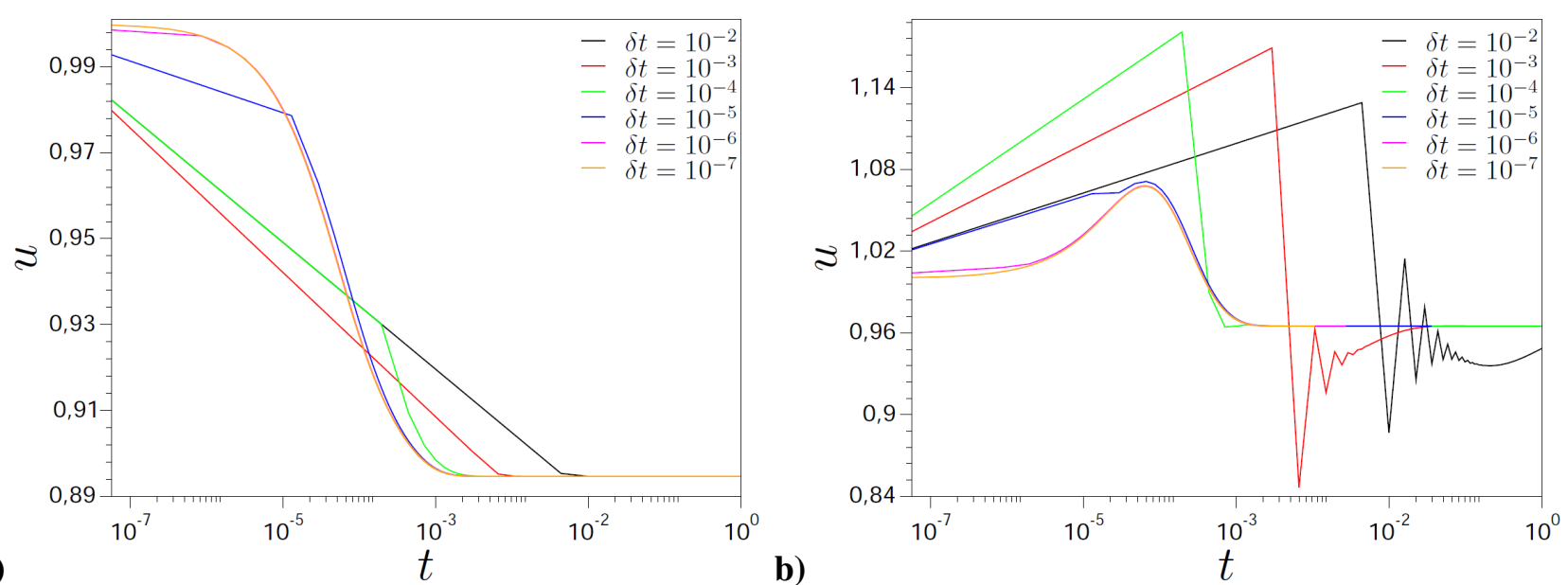

Figura 3.3: Evolução da velocidade horizontal $u$ com o tempo no ponto $(0.2,0.2)$ para os métodos: a) acoplado e b) de projeção, ambos na formulação de diferenças finitas.

tração de algum soluto. Durante o transiente espúrio, o transporte será feito com um campo de velocidades errado, o que afetará a precisão do cálculo das outras quantidades.

- Por outro lado, se o único interesse é determinar o estado estacionário, deve-se aguardar até o transiente espúrio decair, e, como mostrado nas figuras 3.2.b e 3.3.b, isto pode requerer muitos passos de tempo. Nessa situação, os passos de tempo podem ser vistos simplesmente como iterações para calcular o estado estacionário, e obviamente existe interesse em que o número dessas iterações seja o menor possível.

As figuras 3.4 e 3.5 mostram, para o método de projeção, o resíduo das equações estacionárias em função do tempo e do número de iterações, respectivamente, considerando cada passo de tempo como uma iteração na procura do estado estacionário. Nestas simulações foram utilizados distintos valores de $\delta t$. Nas figuras 3.4.a e 3.5. a foi utilizada a formulação de elementos finitos, enquanto nas figuras 3.4.b e 3.5.b foi utilizada a formulação de diferenças finitas.

É fácil ver, das figuras 3.4 e 3.5, que existe um $\delta t$ ótimo, da ordem de $10^{-4}$, para o qual se alcança uma tolerância de, por exemplo, $10^{-6}$, no mínimo número de iterações (aproximadamente 100). Se o $\delta t$ é escolhido muito maior que o valor ótimo, o número de iterações pode chegar facilmente a 10000.

Em conclusão, o método de projeção requer a utilização de um $\delta t \simeq 10^{-4}$ para evitar dificuldades numéricas sérias quanto a precisão e custo computacional.

Análises feitas com outras malhas, mostram que o passo de tempo ótimo é, de fato, próximo ao passo de tempo crítico da restrição de estabilidade do esquema explícito $\left(\frac{1}{4} h^{2} R e\right)$, isto é,

$$
\delta t_{\text {ótimo }} \simeq 10 h^{2} R e
$$

Portanto, mesmo com um tratamento implícito do termo viscoso, o $\delta t$ deve ser ajustado dependendo da malha, e de fato reduzido toda vez que a malha for refinada. 
a)

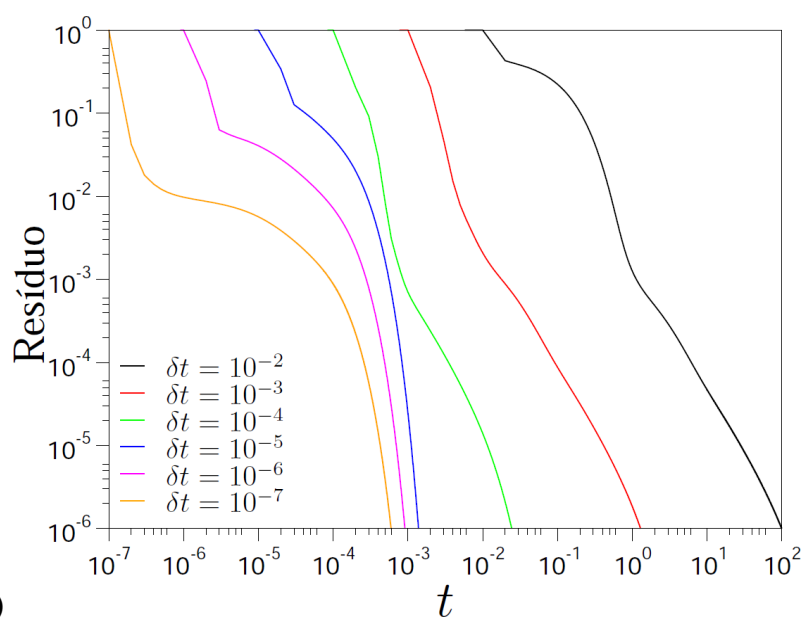

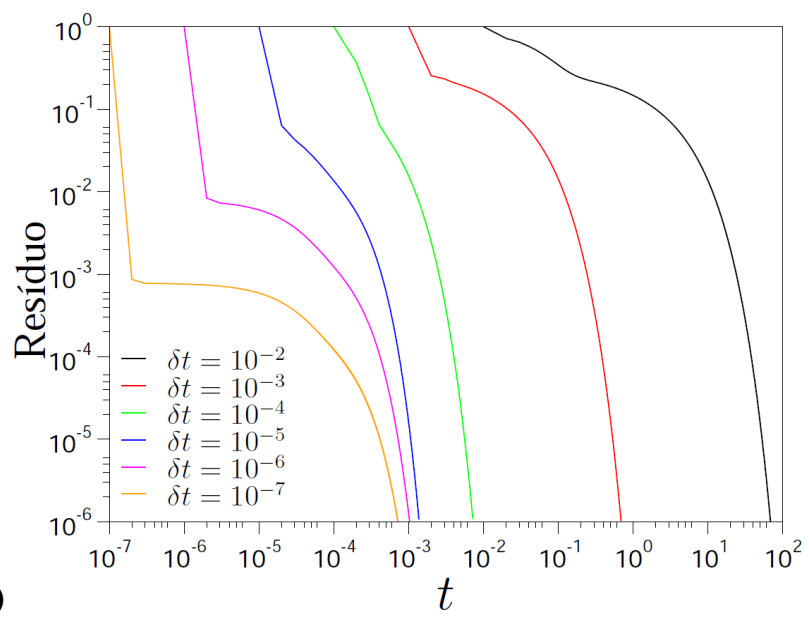

Figura 3.4: Comportamento do resíduo das equações estacionárias em função do tempo para o método de projeção nas formulações a) de elementos finitos e b) de diferenças finitas.

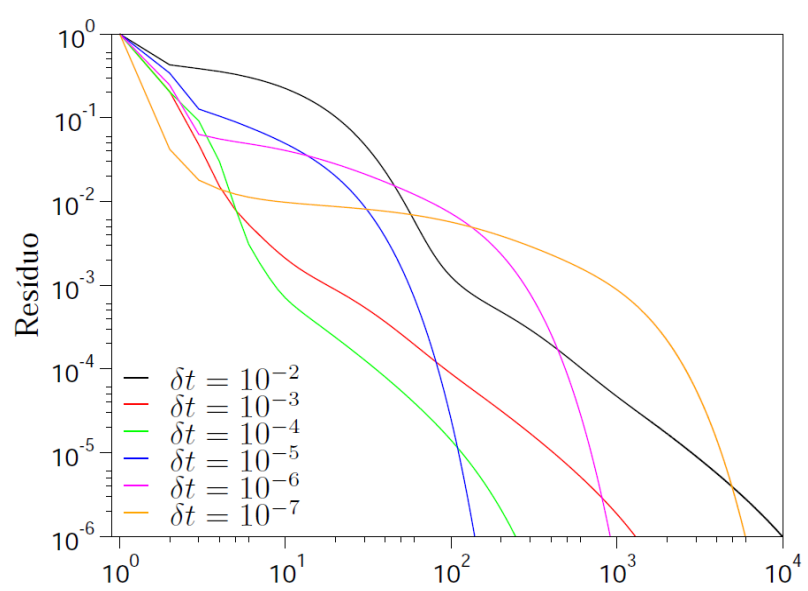

a)

Número de iterações

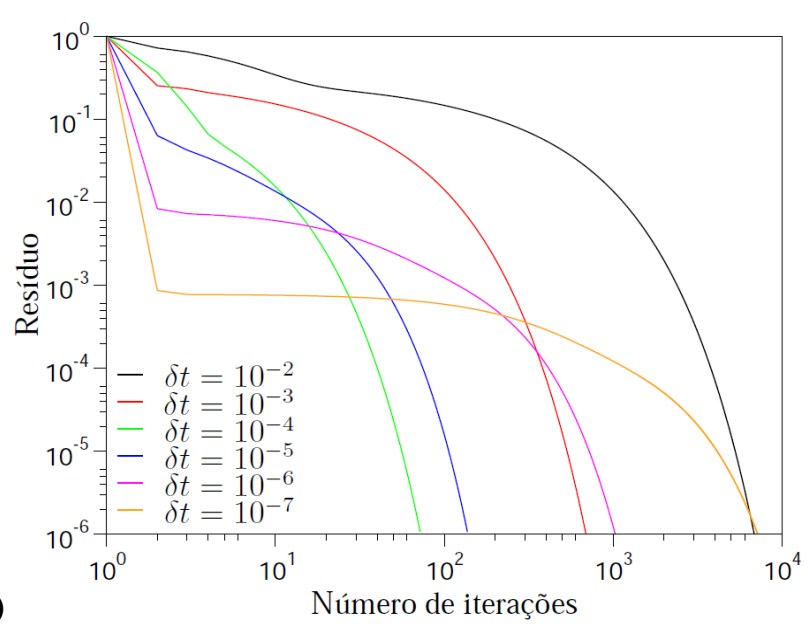

b)

Número de iterações

Figura 3.5: Comportamento do resíduo das equações estacionárias em função do número de iterações para o método de projeção nas formulações a) de elementos finitos e b) de diferenças finitas.

\subsubsection{Discussão do Transiente Espúrio}

A partir das equações (3.10)-(3.13), supondo por simplicidade que os efeitos inerciais e temporais são desprezíveis e que as condições de contorno são homogêneas, o que leva a $\mathbf{r}^{n}=\mathbf{b c}=0$, pode-se eliminar as variáveis intermediárias $\widetilde{\boldsymbol{U}}^{n+1}$ e $\boldsymbol{\Phi}^{n+1}$ para obter

$$
\left(\begin{array}{c}
\boldsymbol{U}^{n+1} \\
\boldsymbol{P}^{n+1}
\end{array}\right)=\left(\begin{array}{cc}
\mathbf{0} & {\left[\mathrm{II}-\mathrm{BG}(\mathrm{DBG})^{-1}\right] \mathrm{DA}^{-1}(\mathrm{AB}-\mathrm{II}) \mathrm{G}} \\
\mathbf{0} & (\mathrm{DBG})^{-1} \mathrm{DA}^{-1}(\mathrm{AB}-\mathrm{II}) \mathrm{G}
\end{array}\right)\left(\begin{array}{c}
\boldsymbol{U}^{n} \\
\boldsymbol{P}^{n}
\end{array}\right)
$$

Portanto, a convergência da solução numérica para a solução estacionária (que neste caso é obviamente zero) é determinada pela norma da matriz

$$
S=(D B G)^{-1} D^{-1}(A B-\mathbb{I}) G=(D B G)^{-1} D\left(B-A^{-1}\right) G
$$


É claro que, se $B=A^{-1}$, o estado estacionário é obtido em apenas uma iteração. No entanto, com a escolha usual $\mathrm{B}=\delta t \mathrm{M}^{-1}$, e sendo um escoamento dominado pelos efeitos viscosos $\left(\mathrm{A} \simeq-\frac{1}{R e} \mathrm{~L}\right)$, a norma da matriz $S$ será não nula. Na discretização de diferenças finitas, sendo $D G=L$, resulta que

$$
\mathrm{S} \simeq \mathrm{L}^{-1} \mathrm{D}\left(\mathrm{II}+\frac{R e}{\delta t} \mathrm{~L}^{-1}\right) \mathrm{G}
$$

Para um domínio de comprimento $L$ e uma malha de tamanho $h$, os autovalores de $\mathrm{L}^{-1}$ estão aproximadamente entre $-L^{2} \mathrm{e}-h^{2}$. Isto faz que se $\delta t>\operatorname{Re} L^{2}$ a norma de $\mathrm{S}$ seja $\|\mathrm{S}\|_{2} \simeq 1 \mathrm{e}$ o método, considerado como procedimento iterativo para determinar o estado estacionário, é muito ineficiente. Isto explica, em particular, as 10000 iterações necessárias quando $\delta t=10^{-2}$.

A conclusão é, portanto, que o método da projeção é ineficiente para o cálculo de escoamentos estacionários para valores baixos de $R e$, sendo particularmente surpreendente que isto aconteça quando a equação de quantidade de movimento é tratada implicitamente e o $\delta t$ é grande.

\subsubsection{Estudo de Resolvedores Lineares para o Método Acoplado}

O comportamento numérico do método de projeção leva a dar preferência ao método acoplado para escoamentos a baixo Re. Entretanto, pode-se notar que a matriz resultante do sistema é muito mal condicionada para escoamentos a baixo Re com grande diferença de escala entre as dimensões (largura vs. comprimento do canal). Utilizando vários métodos para a solução do sistema linear, combinados com diversos pré-condicionadores (PC), serão identificados nessa seção métodos capazes de resolver o sistema linear em tempos computacionais razoáveis.

Para um primeiro teste, seja o canal mostrado na figura 3.1, com $L=7,25,97$ e $H=1$. Os parâmetros utilizados foram $R e=10^{-2}, \delta t=10^{-1}$ e $h=0.1$, onde $h$ é o espaçamento da malha cartesiana utilizada. A partir desta seção, todos os resultados do método acoplado foram obtidos com a formulação de diferenças finitas. O código foi desenvolvido utilizando as ferramentas da biblioteca PETSc (Balay et al., 2008, 2009), que fornece métodos e estruturas de dados que permitem a execução do código em paralelo, e disponibiliza implementações de vários métodos iterativos e PCs.

Nesta primeira etapa foram considerados os PCs LU, Jacobi, ILU, ASM (Método de Schwarz Aditivo) e sem pré-condicionador (none), e os seguintes métodos, combinados com alguns parâmetros, GMRES (Método dos Resíduos Mínimos Generalizado) com $n=50$, onde $n$ é a dimensão do espaço de Krylov, GMRES com $n=1500$, GMRES com $n=50$ e ortogonalização de Gram-Schmidt modificada (MGS), GMRES com $n=1500$ e MGS, e BCGS (Método dos Gradientes Biconjugados Estabilizado). Para o PC ASM foram utilizados 5 blocos, com sub-PC LU em cada bloco e com sobreposição dos blocos (overlap = 1), ou seja, cada bloco da matriz de pré-condicionamento tem informação dos blocos vizinhos. O PC ASM sem sobreposição (overlap = 0) é equivalente ao método de Jacobi por blocos.

Os testes desta seção foram executados em um cluster com computadores Intel Xeon E5345 de 2.33GHz com 16GB de RAM com 8 núcleos de processamento. Como critério de comparação entre 
os métodos, foi considerado o tempo computacional gasto para resolver 10 passos de tempo. A seguir são apresentados, na tabela 3.1, os tempos obtidos para cada um dos métodos, combinados com cada um dos pré-condicionadores. Entre parênteses está o número de iterações do primeiro passo de tempo. Quando o método linear não converge, utilizou-se o símbolo $\infty$.

Tabela 3.1: Tempo de processamento (em segundos) para o método acoplado na simulação do canal (figura 3.1) $\operatorname{com} h=0.1$ e $\delta t=10^{-1}$.

\begin{tabular}{|c|c|c|c|c|}
\hline Métodos & PC & $L=7$ & $L=25$ & $L=97$ \\
\hline- & LU & $0.24(1)$ & $1.49(1)$ & $7.02(1)$ \\
\hline \multirow{3}{*}{ GMRES - 50 } & Jacobi & $\infty$ & $\infty$ & $\infty$ \\
& ILU & $0.30(39)$ & $7.81(616)$ & $\infty$ \\
& ASM & $0.53(15)$ & $2.80(15)$ & $14.07(15)$ \\
& none & $\infty$ & $\infty$ & $\infty$ \\
\hline \multirow{3}{*}{ GMRES - 1500 } & Jacobi & $3.21(253)$ & $\infty$ & $\infty$ \\
& ILU & $0.33(39)$ & $\infty$ & $\infty$ \\
& ASM & $0.56(15)$ & $2.86(15)$ & $14.08(15)$ \\
& none & $\infty$ & $\infty$ & $\infty$ \\
\hline GMRES - 50+ MGS & Jacobi & $\infty$ & $\infty$ & $\infty$ \\
& ILU & $0.31(39)$ & $7.85(699)$ & $\infty$ \\
& ASM & $0.59(15)$ & $2.81(15)$ & $14.28(15)$ \\
& none & $\infty$ & $\infty$ & $\infty$ \\
\hline \multirow{3}{*}{ GMRES - 1500+ MGS } & Jacobi & $3.51(253)$ & $82.93(733)$ & $\infty$ \\
& ILU & $0.33(39)$ & $3.25(91)$ & $85.51(280)$ \\
& ASM & $0.61(15)$ & $2.81(15)$ & $14.28(15)$ \\
& none & $14.12(561)$ & $\infty$ & $\infty$ \\
\hline \multirow{3}{*}{ BCGS } & Jacobi & $0.49(225)$ & $5.05(705)$ & $\infty$ \\
& ILU & $0.28(35)$ & $4.62(172)$ & $\infty$ \\
& ASM & $0.70(9)$ & $3.06(10)$ & $16.32(11)$ \\
& none & $\infty$ & $\infty$ & $\infty$ \\
\hline
\end{tabular}

Nota-se da tabela 3.1 que, com o aumento do comprimento $L$, e consequentemente o aumento do número de equações, o método direto LU e o método GMRES com MGS, convergiram nas três situações testadas. As variações do método GMRES sem MGS com $n=50$ e com $n=1500$, sem pré-condicionadores ou com o PC Jacobi, apresentaram os piores resultados (praticamente todos os casos sem PC não convergiram).

Como um dos objetivos deste trabalho é verificar qual dos métodos (combinados com os PCs) tem melhor comportamento na simulação de fluidos incompressíveis em microescalas, um novo teste foi realizado, aumentando o número de equações envolvidas no sistema. Para isso, as malhas para os canais de comprimento $L=7$ e $L=97$ foram refinadas e testando-se novamente o comportamento dos métodos que obtiveram os melhores resultados, ou seja, GMRES, com $n=1500$ e MGS, e BCGS, e os PCs LU, ILU e ASM (com 5, 10 e 20 blocos, com sub-PC LU em cada bloco). Os resultados são apresentados na tabela 3.2 (detalhes sobre o uso de blocos no ASM podem ser encontrados em Smith et al. (1996)). 
Tabela 3.2: Tempo de processamento (em segundos) para o método acoplado na simulação do canal (figura 3.1) $\operatorname{com} \delta t=10^{-1}$ e vários valores para $h$.

\begin{tabular}{|c|c|c|c|c|c|}
\hline \multirow{2}{*}{ Métodos } & \multirow{2}{*}{ PC } & \multicolumn{2}{|c|}{$L=7$} & \multicolumn{2}{c|}{$L=97$} \\
\cline { 3 - 6 } & & $h=0.01$ & $h=0.005$ & $h=0.05$ & $h=0.02$ \\
\hline- & LU & $28.33(1)$ & $216.04(1)$ & $4.85(1)$ & $58.35(1)$ \\
\hline \multirow{4}{*}{ GMRES } & ILU & $126.40(361)$ & $5385.32(806)$ & $202.15(598)$ & $\infty$ \\
& ASM - 5 blocos & $24.97(34)$ & $153.06(42)$ & $9.62(21)$ & $75.95(25)$ \\
& ASM - 10 blocos & $27.20(45)$ & $195.72(64)$ & $11.54(31)$ & $87.95(35)$ \\
& ASM - 20 blocos & $36.48(75)$ & $263.00(92)$ & $14.75(49)$ & $114.43(54)$ \\
\hline \multirow{4}{*}{ BCGS } & ILU & $\infty$ & $\infty$ & $\infty$ & $\infty$ \\
& ASM - 5 blocos & $27.50(22)$ & $150.34(24)$ & $10.88(14)$ & $80.96(16)$ \\
& ASM - 10 blocos & $32.31(33)$ & $218.96(49)$ & $14.87(26)$ & $103.18(27)$ \\
& ASM - 20 blocos & $50.17(66)$ & $266.63(83)$ & $28.80(68)$ & $177.01(62)$ \\
\hline
\end{tabular}

Da tabela 3.2, pode-se verificar que o método direto LU conseguiu resolver muito bem o problema, com baixo tempo computacional. O método BCGS apresentou problemas de convergência na maioria dos casos ou alto consumo no tempo de processamento nos casos em que obteve resultados. Nota-se ainda da tabela 3.2, que o método GMRES com $n=1500$ e MGS, combinado com o PC ASM, em alguns casos, conseguiu obter resultados de convergência próximos ao LU. Portanto, a escolha deste esquema iterativo com as combinações $n=1500$, MGS e PC ASM, aplicado ao método acoplado produziu uma formulação mais eficiente e robusta na simulação de escoamentos a baixo número de Reynolds com grande diferença de escala entre as dimensões.

\subsubsection{Comportamento do Método Acoplado em Processamento Para- Ielo}

De acordo com os resultados numéricos descritos nas seções anteriores, verifica-se que uma escolha eficiente na simulação de escoamentos em microescala a baixo número de Re é a utilização do método acoplado combinado com o resolvedor GMRES ( $n=1500$, adicionado da ortogonalização de Gram-Schmidt) e o pré-condicionador ASM. Outro ponto de investigação deste trabalho é direcionado ao comportamento do método acoplado na simulação numérica realizada em processamento paralelo.

A simulação numérica tridimensional utilizando processamento paralelo em microfluidos tem sido explorada recentemente em diversas aplicações, como por exemplo em Davidson et al. (2008) na simulação de efeitos eletroviscosos (electrokinetic flow resistance), em Kler et al. (2009) para microfluidos em chips, entre outros. Desta forma, pretende-se nesta seção apresentar os resultados do método acoplado na simulação paralela quando $R e<<1$.

Para isso, foram utilizados os pré-condicionadores ASM com sub-PC ILU (com 8 blocos), ASM com sub-PC LU (com 8, 16, 32 e 64 blocos) e Jacobi por blocos (BJacobi) com sub-PC ILU. Com o objetivo de verificar a eficiência do método GMRES nesta simulação, baseado no canal (ver figura 3.1), construiu-se uma versão tridimensional adicionando altura $Z=1.0$ e mantendo $H=1.0$. Os 
valores de $L$ testados foram escolhidos de forma a obter aproximadamente 1,000,000 de equações em cada um dos casos. Os valores de $h$ variam conforme o canal $(h=0.015$ para $L=1, h=0.03$ para $L=8$ e $h=0.06$ para $L=64$ ) e $R e=10^{-2}$ é o mesmo utilizado na simulação bidimensional. Os resultados são apresentados na tabela 3.3.

Estes testes foram executados em um cluster com computadores Intel Xeon E5345 de $2.33 \mathrm{GHz}$ com 16GB de RAM e com 8 núcleos de processamento. Foram utilizados 8 computadores e 8 processos, ou seja, um processo por processador.

Tabela 3.3: Tempo de processamento do método acoplado com GMRES ( $n=1500$, com MGS) e os PCs ASM e BJacobi na simulação numérica em um canal 3D, com 8 processos em 8 computadores.

\begin{tabular}{|c|c|c|c|c|c|}
\hline PC & Sub-PC & Blocos & $L=1$ & $L=8$ & $L=64$ \\
\hline \multirow{4}{*}{ ASM } & ILU & 8 & $100.6(188)$ & $79.0(184)$ & $296.6(444)$ \\
\cline { 2 - 6 } & & 8 & $224.7(39)$ & $313.9(20)$ & $131.0(17)$ \\
& LU & 16 & $215.3(71)$ & $214.8(42)$ & $144.4(39)$ \\
& & 32 & $202.9(86)$ & $204.6(71)$ & $155.9(71)$ \\
& & 64 & $190.7(98)$ & $185.0(87)$ & $190.0(132)$ \\
\hline BJacobi & ILU & - & $\infty$ & $\infty$ & $\infty$ \\
\hline
\end{tabular}

A partir da tabela 3.3, pode-se ver que, quando a diferença de escala entre as dimensões é pequena ( $L=1$ e $L=8$ ), o PC ASM com sub-PC ILU obteve bons resultados e o PC ASM com sub-PC LU reduziu o tempo de processamento quando o número de blocos aumentou. Já quando a diferença de escala é grande ( $L=64$ ) pode-se notar um comportamento inverso, ou seja, o PC ASM com sub-PC ILU obteve altos tempos de processamento e o PC ASM com sub-PC LU começou a gastar mais tempo quando o número de blocos aumentou. Já o PC BJacobi não convergiu em nenhum dos casos.

Também pode ser notado que para o caso com $L=8$, com PC ASM e sub-PC LU, são necessárias quase o mesmo número iterações que para o caso com $L=64$, porém o tempo de processamento é muito maior. Isto ocorre porque, no primeiro caso, cada bloco do domínio é aproximadamente um cubo, o que faz com que a matriz de pré-condicionamento tenha mais conexões do que a matriz de pré-condicionamento quando $L=64$, que é próximo a um paralelepípedo em cada bloco.

A eficiência do paralelismo na solução do método acoplado foi verificada com os testes de speedup e o tempo de processamento. Para fazer um teste de speed-up, optou-se, com base na tabela 3.3, pelo método GMRES com $n=1500$ e MGS, pré-condicionado por ASM com 16 blocos e com sub-PC LU. O código foi executado utilizando 1, 2, 4, 8 e 16 processos, em 2 processadores de um cluster com computadores Intel Xeon E5430 de 2.66GHz com 64GB de RAM com 8 núcleos de processamento. Na tabela 3.4 e na figura 3.6 são mostrados o tempo, o speed-up e a eficiência, respectivamente. Para este caso, foram considerados os mesmos canais utilizados acima, com aproximadamente 1,000,000 de equações.

O speed-up e a eficiência são definidos como:

$$
\text { speed-up }=\frac{t^{*}}{t_{p}}, \quad \text { eficiência }=\frac{\text { speed-up }}{n p},
$$


onde $t^{*}$ é o tempo computacional gasto no caso sequencial, $t_{p}$ é o tempo computacional utilizando $p$ processos e $n p$ é o número de processos.

Tabela 3.4: Tempo de processamento do método acoplado (GMRES + MGS, $n=1500$, ASM com 16 blocos) na simulação do escoamento tridimensional.

\begin{tabular}{|c|c|c|c|}
\hline Processos & $L=1$ & $L=8$ & $L=64$ \\
\hline 1 & $1947.8(66)$ & $1624.8(54)$ & $990.5(39)$ \\
2 & $900.3(63)$ & $821.2(55)$ & $500.5(39)$ \\
4 & $475.5(55)$ & $428.9(49)$ & $277.0(39)$ \\
8 & $247.8(71)$ & $234.7(42)$ & $162.4(39)$ \\
16 & $181.2(73)$ & $174.5(33)$ & $119.4(31)$ \\
\hline
\end{tabular}

a)

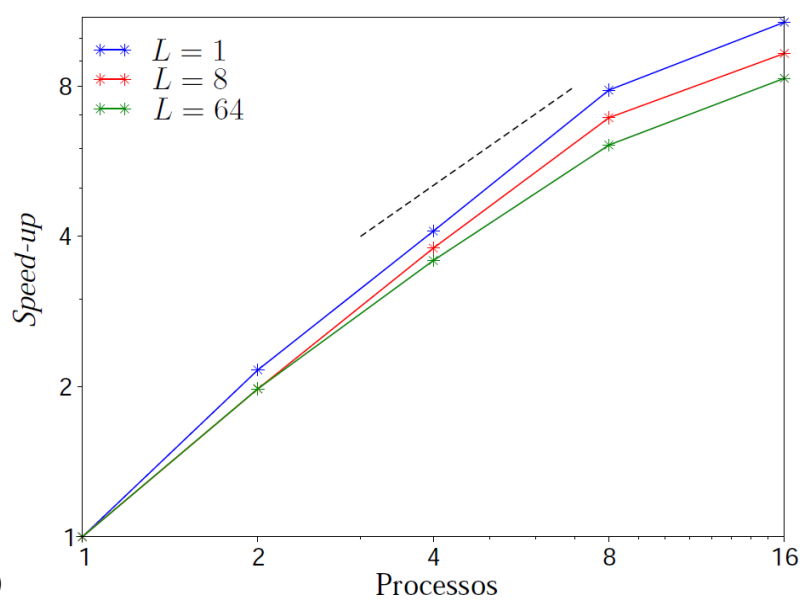

b)

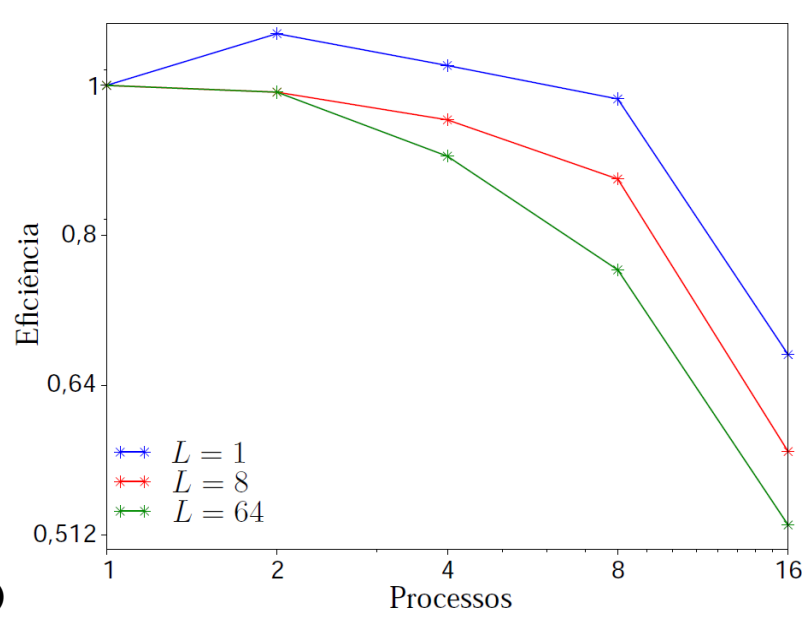

Figura 3.6: a) Speed-up e b) eficiência do método acoplado (GMRES + MGS, $n=1500$, ASM com 16 blocos) na simulação do escoamento tridimensional.

No caso das simulações a baixo números de Reynolds (Re $<<1$ ) com grandes diferenças de escala, de acordo com a figura 3.6.a pode-se observar que para o caso com $L=1$ o speed-up é superlinear utilizando até 8 processos e para os casos com $L=8$ e $L=64$ o speed-up é quaselinear usando até 4 processos. Em todos os casos, conforme aumenta-se o número de processos, o speed-up começa a diminuir, fato que também pode ser observado na figura 3.6.b, onde ocorre uma perda de eficiência quando o número de processos cresce. Isto ocorre porque quando há mais de um processo sendo executado em um processador, o acesso dos núcleos à memória é efetuado de forma sequencial, dependendo do tamanho da largura de banda de cada processador, o que acaba prejudicando o tempo computacional.

\subsection{Conclusões}

Neste capítulo, foi feito um estudo de métodos numéricos para escoamentos incompressíveis em microfluídica a baixo número de Reynolds, analisando o comportamento dos métodos de projeção e acoplado, nas formulações diferenças finitas e elementos finitos. A partir dos resultados obtidos 
na seção 3.4.1, pode-se observar que o método de projeção (em ambas as formulações), aplicado a problemas com grande diferença de escalas entre as dimensões, gera um transiente espúrio, que pode prejudicar a solução. Este fato faz com que o método de projeção tenha uma restrição no passo de tempo correspondente à restrição de esquemas explícitos, mesmo utilizando discretizações implícitas para os termos viscosos e inerciais. Em especial para os problemas de microfluídica, em que os termos viscosos são dominantes, este problema torna o método extremamente caro, pois o passo de tempo passa a depender do espaçamento da malha.

Pode-se então concluir que o método acoplado é mais adequado para a resolução de problemas desta classe. Porém, devido ao mal condicionamento da matriz, o método acoplado pode apresentar dificuldades de convergência, quando a diferença entre as escalas de comprimento é grande. Por isso, foram testadas várias combinações de métodos para solução de sistemas lineares com diferentes pré-condicionadores e mostrou-se que algumas destas combinações não foram capazes de solucionar o sistema linear, especialmente quando a diferença de escala entre as dimensões era grande. Também mostrou-se que é possível resolver este tipo de problema com a utilização do resolvedor GMRES (com $n=1500$ e ortogonalização de Gram-Schmidt modificada) combinado com o pré-condicionador ASM, o qual obteve bons resultados de convergência em tempos computacionais consideráveis. Esta mesma combinação também foi executada em paralelo, possibilitando a otimização do tempo de processamento. Os testes paralelos também mostraram uma patologia no comportamento dos sub-PCs ILU e LU para o PC ASM. Esta patologia está relacionada às razões de escala e pode-se notar que quando esta razão é pequena, o sub-PC ILU converge muito bem, enquanto que o sub-PC LU converge muito bem quando a razão é grande, caso em que o sub-PC ILU não converge.

Com base nos resultados apresentados acima, escolheu-se o método acoplado, na formulação diferenças finitas, para fazer uma aplicação com fronteiras imersas, com um código paralelo, utilizando a biblioteca PETSc (Balay et al., 2008, 2009), para resolver numericamente as equações de Navier-Stokes para escoamentos incompressíveis tridimensionais eficientemente. Esta aplicação será apresentada a seguir, no capítulo 4 . 


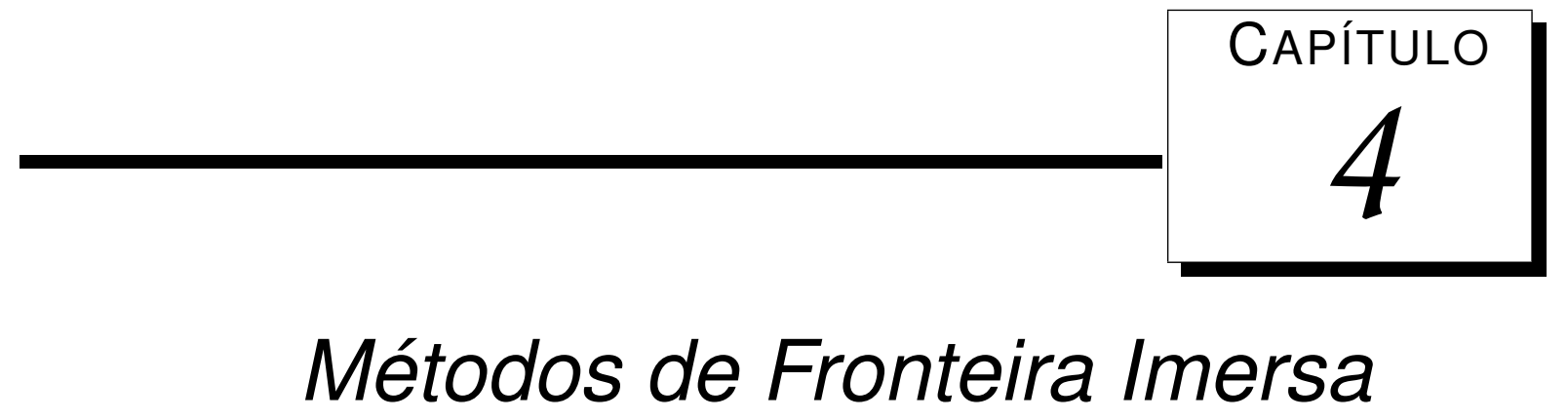

Neste capítulo, é feita uma revisão bibliográfica dos métodos de fronteira imersa. A seguir, são apresentados uma aproximação de primeira ordem e os resultados obtidos com esta aproximação. Depois, é apresentada uma melhoria do método, na tentativa de aumentar a ordem, seguida por análise de convergência e discussão dos resultados.

\subsection{Introdução}

O método das fronteiras imersas surgiu no contexto da interação fluido-estrutura (Peskin, 1972), em que objetos viscoelásticos incompressíveis (ou fronteiras elásticas) estão imersos e interagindo com fluidos incompressíveis viscosos. Neste caso, são utilizadas duas malhas, uma cartesiana fixa, para as variáveis eulerianas, e outra curvilínea móvel, para as variáveis lagrangeanas. A interação entre as variáveis eulerianas, que representam o fluido, e lagrangeanas, que representam a fronteira imersa, pode ser modelada por uma aproximação discreta da função delta de Dirac.

O campo de estudo do método de fronteiras imersas concentra-se principalmente em escoamentos com fronteiras móveis e ao redor de geometrias complexas (Peskin, 1972, 2002; Lai and Peskin, 2000). O desenvolvimento de métodos computacionais robustos como alternativa para as técnicas que utilizam malhas elásticas, ou seja, malhas que se adaptam ao contorno do sólido que serve como obstáculo ao escoamento, é o principal objetivo da comunidade científica que estuda esse método.

Quando um fluido passa por um objeto, ele exerce uma força normal (pressão) à superfície do objeto e, se a superfície do objeto é não-escorregadia, o fluido também exerce uma força tangencial (cisalhamento). Por outro lado, a superfície do objeto também exerce uma força, de sinal oposto, no fluido, fazendo com que a velocidade do fluido na superfície seja zero. Assim, tem-se que o fluido 'enxerga' o objeto através das forças normais e tangenciais ao longo da superfície do objeto.

Pode-se imaginar então, que se um conjunto de forças correto for aplicado ao fluido, este pode se 
comportar como se estivesse passando por um objeto sólido, ou seja, o efeito de certas condições de contorno pode ser modelado pela aplicação de uma força externa, ao invés de se especificar parâmetros para o contorno. Com isso, pode-se simular um escoamento que passa por um objeto utilizando um domínio simples, com uma malha regular, e impondo forças para caracterizar a fronteira do objeto.

Pode-se utilizar uma função da forma

$$
f\left(x_{s}, t\right)=\alpha \int_{0}^{t} \boldsymbol{u}\left(x_{s}, t^{\prime}\right) d t^{\prime}+\beta \boldsymbol{u}\left(x_{s}, t\right),
$$

em que $x_{s}$ são pontos na superfície do objeto, $\boldsymbol{u}$ é a velocidade, $t$ é o tempo e $\alpha$ e $\beta$ são constantes negativas (Goldstein et al., 1993). Esta função representa a informação vinda do campo de velocidades, onde o primeiro termo é responsável pela criação da força que irá diminuir a velocidade do escoamento na superfície rígida (até que ela seja nula) e o segundo termo representa a força criada pelo arrasto de um obstáculo localizado no ponto $x_{s}$. A utilização dessa função nos pontos do contorno pode ser vista como a aplicação de forças que 'aprendem' a simular a condição de contorno desejada.

Uma alternativa ao método de fronteiras imersas clássico é o método de interfaces imersas, que evita o uso da distribuição delta de Dirac para definir os termos forçantes, obtendo maior ordem de precisão (Leveque and Li, 1994; Lee and Leveque, 2003; Xu and Wang, 2006).

Outra opção já explorada é a de impor a condição de contorno por meio de multiplicadores de Lagrange, como no método de domínios fictícios (Girault and Glowinski, 1995; Glowinski et al., 1994, 1999). Neste caso, a dificuldade é transferida para a construção do espaço de multiplicadores.

Lew and Buscaglia (2008) apresentaram um método de imposição direta baseado em uma formulação de Galerkin descontínuo, que evita o tratamento caso-a-caso simplesmente trocando a interpolação nas células interceptadas pelo contorno por uma interpolação descontínua, evitando assim o fenômeno de bloqueio (locking). Embora consiga impor fortemente as condições de contorno e obter precisão ótima, o método necessita de graus de liberdade adicionais.

Recentemente, têm surgido métodos de fronteiras imersas que atingem ordem de precisão superior a um, como os métodos propostos por Codina and Baiges (2009) e Husain and Floryan (2008b), nos quais as condições de contorno são aproximadas de forma a minimizar a diferença entre as condições de contorno exata e aproximada em determinada norma.

Na seção 4.2, é apresentado um método de fronteiras imersas de primeira ordem e os resultados obtidos com este método. A seguir, na seção 4.3, propõe-se um novo método, baseado na ideia por trás dos métodos proposto por Codina and Baiges (2009) e Husain and Floryan (2008b), onde também serão apresentados um estudo de convergência e os resultados obtidos.

\subsection{Aproximação de Primeira Ordem}

Como um primeiro passo na implementação de um código para a solução numérica de escoamentos incompressíveis com fronteira imersa, paralelo e utilizando a biblioteca PETSc, foi utilizada uma 
aproximação de primeira ordem.

Para tal, foi considerado o domínio como mostrado na figura 4.1.

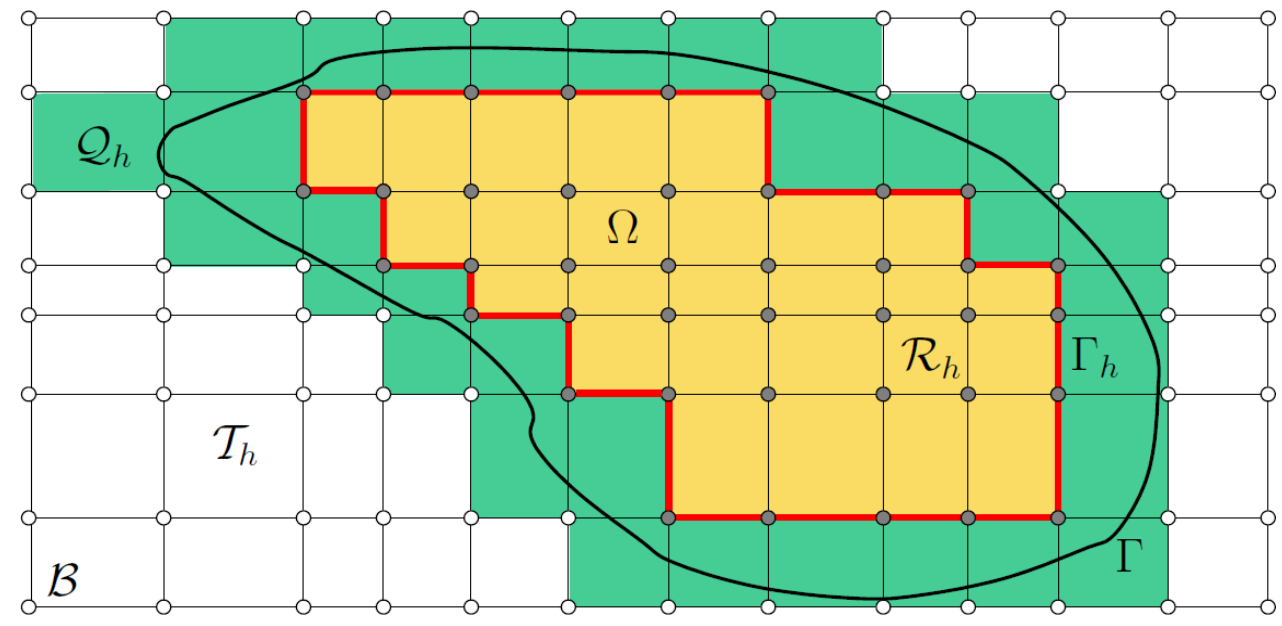

Figura 4.1: Representação do domínio $\mathcal{B}$, com uma malha cartesiana $\mathcal{T}_{h}$. Em amarelo temos as células de $\mathcal{R}_{h}$ e em verde as células de $\mathcal{Q}_{h}$. O contorno $\Gamma_{h}$ é representado em vermelho.

Seja $\mathcal{T}_{h}$ a malha definida em $\mathcal{B}$ e sejam $\mathcal{Q}_{h}$ os elementos de $\mathcal{T}_{h}$ que são cortados pelo contorno $\Gamma$ (elementos em verde na figura 4.1), $\mathcal{R}_{h}$ os elementos de $\mathcal{T}_{h}$ que são completamente interiores a $\Omega$ (elementos em amarelo na figura 4.1) e $\mathcal{S}_{h}=\mathcal{R}_{h} \cup \mathcal{Q}_{h}$ os elementos que têm interseção não nula com $\Omega$.

A aproximação mais simples consiste em resolver as equações num domínio $\Omega_{h}$, impondo as condições de contorno em $\Gamma_{h}=\partial \Omega_{h}$. Neste caso, considerando $\Omega_{h}=\mathcal{R}_{h}$, tem-se uma aproximação tipo escada do contorno, como representado por $\Gamma_{h}$ (em vermelho na figura 4.1). Como a distância entre $\Gamma_{h}$ e $\Gamma$ é de ordem $h$, o erro do método numérico será de ordem $h$.

A definição das equações é feita com base em uma classificação das células, pertencentes ou não a $\Omega_{h}$. Nas células pertencentes a $\Omega_{h}$ são resolvidas as equações (2.20), (2.23) e (2.26), descritas na seção 2.3.1. E nas células não pertencentes a $\Omega_{h}$ e que são cortadas por $\Gamma$ impõe-se o valor da velocidade no contorno. As células que estão completamente fora do domínio, ou seja, que não pertencem a $\Omega_{h}$ nem são cortadas pelo contorno são ignoradas.

Com isso, monta-se o sistema de equações a ser resolvido. Para a solução do sistema não linear foi utilizado o método de Newton e para a solução do sistema linear utilizou-se o método GMRES (Método dos Resíduos Mínimos Generalizado), com pré-condicionador ASM (Método de Schwarz Aditivo), como visto no capítulo 3. Todos os métodos citados são utilizados a partir da biblioteca PETSc. Além disso, também foram utilizadas as estruturas de vetores e matrizes paralelizadas.

Alguns exemplos da aplicação deste método são apresentados na seção a seguir.

\subsubsection{Resultados}

Nesta seção, é apresentado o comportamento do método proposto em alguns casos teste da literatura de solução numérica das equações de Navier-Stokes. O código é baseado na formulação de 
diferenças finitas, descrita na seção 2.3.1, e foi implementado com a biblioteca PETSc, permitindo sua execução em paralelo.

\subsubsection{Cavidade com Tampa Deslizante}

O método foi testado comparando-se com casos da literatura de mecânica dos fluidos. O primeiro teste escolhido foi o caso da cavidade com tampa deslizante, cujos resultados foram comparados com os resultados obtidos por Ghia et al. (1982).

Na figura 4.2, pode-se ver uma representação do domínio, em que $L=1$ e das condições de contorno, onde $\Gamma_{f i t}$ (em amarelo) é uma superfície rígida e $\Gamma_{i n}$ é a condição de deslizamento da tampa, em que $u=1$ e $v=0$.

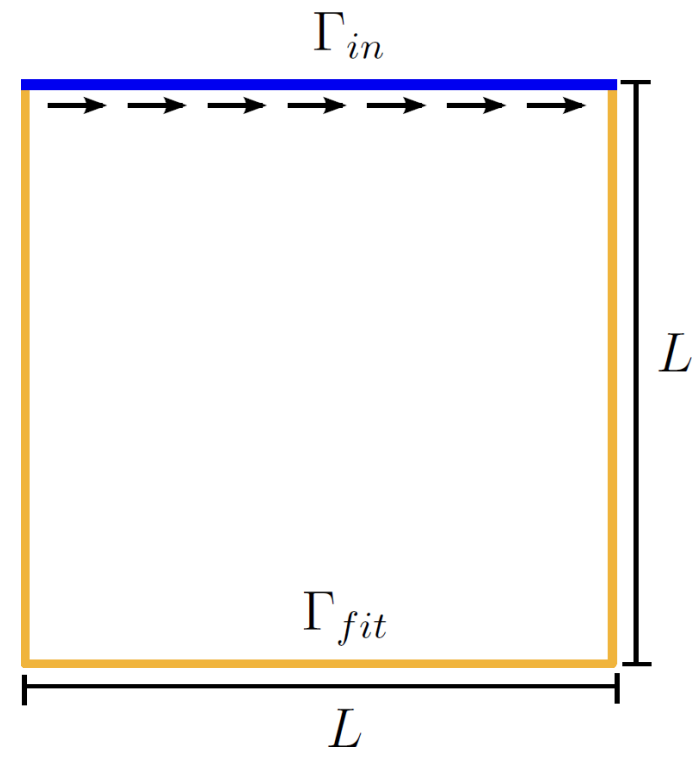

Figura 4.2: Representação esquemática para a cavidade com tampa deslizante, com dimensão $L=1$ e condições de contorno de deslizamento da tampa $\left(\Gamma_{i n}\right)$ e sobre superfície rígida que respeita a malha $\left(\Gamma_{f i t}\right)$.

Este teste foi executado em uma malha de $301 \times 301$ pontos, com $R e=100$, passo de tempo $\delta t=0.01$ e $\mathrm{CFL}=3$. Para a solução do sistema foi utilizado o método GMRES com $n=600 \mathrm{e}$ MGS, com pré-condicionador ASM, com 16 blocos e sub-PC ILU em cada bloco. O teste foi efetuado em um cluster com computadores Intel Xeon E5345 de 2.33GHz, com 16GB de RAM e 8 núcleos de processamento.

Como condição inicial foi considerada a solução, no estado estacionário, obtida com $R e=10^{-2}$, como mostrado na figura 4.3.a, onde são mostradas as linhas de corrente coloridas segundo a magnitude da velocidade. Também são apresentadas as linhas de corrente para o caso estacionário, com $R e=100$, na figura 4.3.b. O tempo de processamento até que o estado estacionário fosse alcançado foi de 34,764 segundos (aproximadamente 10 horas), utilizando 16 núcleos de processamento.

Para a comparação dos resultados obtidos pelo método proposto com os resultados de Ghia et al. (1982), foram considerados os perfis de velocidade nas linhas horizontal e vertical que passam pelo centro da cavidade. Na figura 4.4.a pode-se ver o perfil da velocidade $u$ na linha vertical que passa pelo 

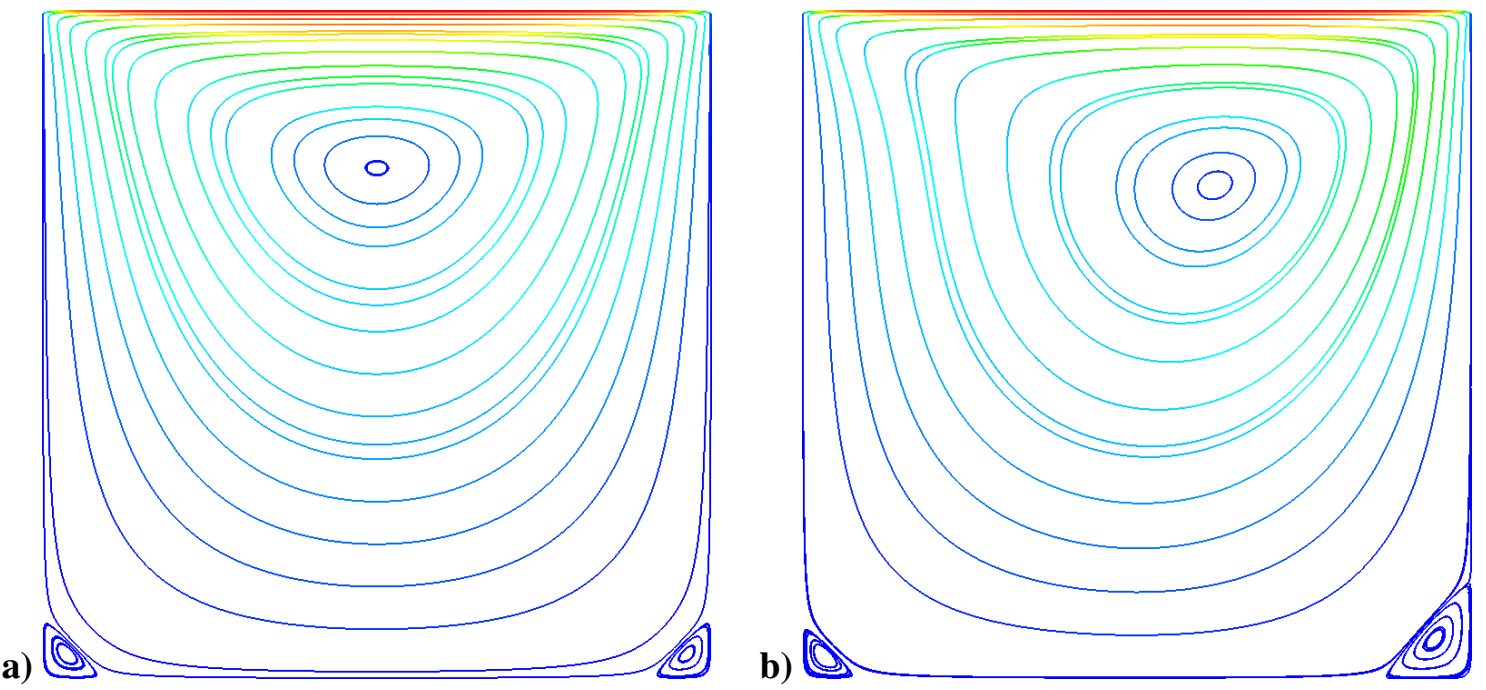

Figura 4.3: Linhas de corrente coloridas segundo a magnitude da velocidade a) condição inicial e b) solução no estado estacionário.

centro do domínio e na figura 4.4.b pode-se ver o perfil da velocidade $v$ ao longo da linha horizontal que passa pelo centro do domínio, comparados com os resultados de Ghia et al. (1982).

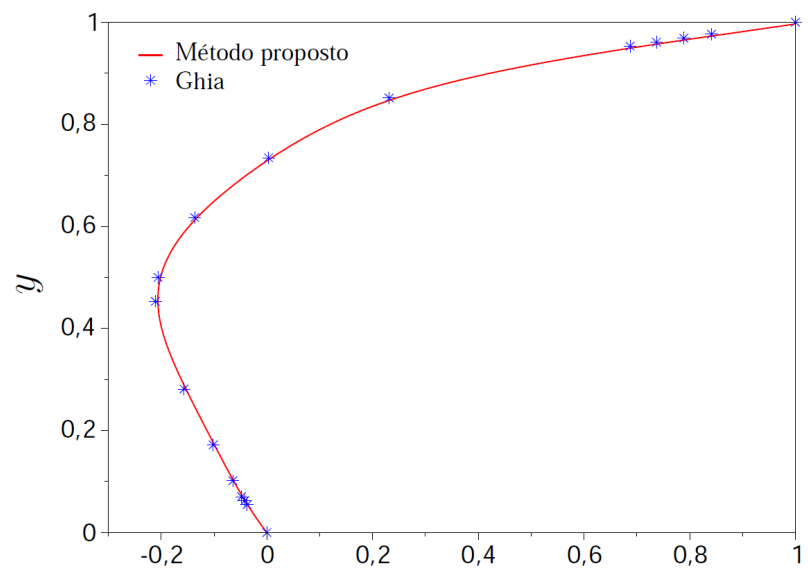

a)

$u$

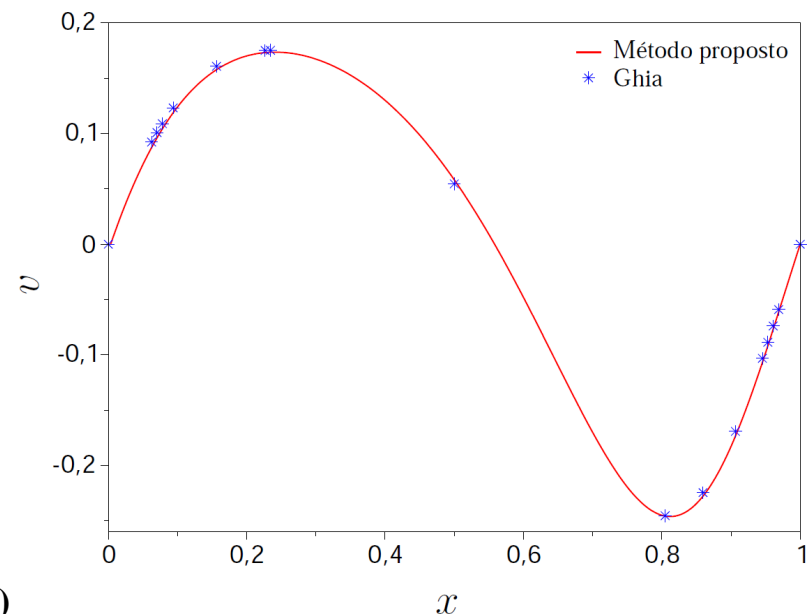

b)

Figura 4.4: a) Perfil da velocidade $u$ ao longo da linha vertical que passa pelo centro do domínio e b) perfil da velocidade $v$ ao longo da linha horizontal que passa pelo centro do domínio, comparadas com os resultados obtidos por Ghia et al. (1982).

Com base nos gráficos apresentados na figura 4.4, pode-se notar que o método proposto obteve resultados muito próximos aos obtidos por Ghia et al. (1982). Assim, conclui-se que o método funciona bem para solucionar numericamente escoamentos de fluidos incompressíveis.

\subsubsection{Escoamento em um degrau}

O segundo caso teste escolhido foi o do escoamento em um degrau, cujos resultados foram comparados com os obtidos por Erturk (2008).

O domínio utilizado está representado na figura 4.5 , onde $h_{i}=1$ é a altura do canal de entrada 
de fluido, $h_{s}=1$ é a altura do degrau, $L_{1}=5$ é o comprimento do canal de entrada, $L_{2}=80$ é o comprimento do canal depois do degrau e $H=2$ é a altura total do canal $\left(H=h_{i}+h_{s}\right)$. As condições de contorno são de entrada de fluido $\left(\Gamma_{i n}\right)$, saída de fluido $\left(\Gamma_{\text {out }}\right)$ e sobre superfície rígida que respeita a malha $\left(\Gamma_{f i t}\right)$.

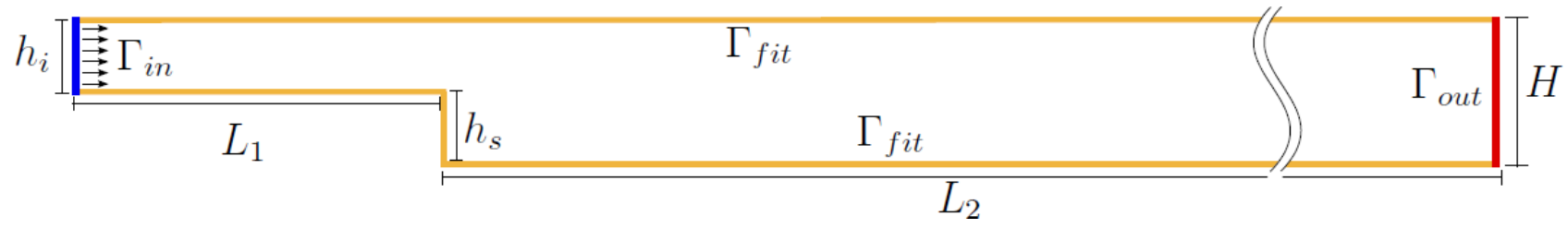

Figura 4.5: Representação esquemática para o escoamento em um degrau, com dimensões $h_{i}=1, h_{s}=1$, $L_{1}=5, L_{2}=80$ e $H=2$ e com condições de contorno de entrada de fluido $\left(\Gamma_{\text {in }}\right)$, saída de fluido $\left(\Gamma_{\text {out }}\right) \mathrm{e}$ sobre superfície rígida que respeita a malha $\left(\Gamma_{f i t}\right)$.

O teste foi executado em uma malha de $4251 \times 101$ pontos, com $R e=100$, passo de tempo $\delta t=0.01$ e $\mathrm{CFL}=0.5$. O método para solução do sistema linear utilizado foi GMRES com $n=600$ e MGS, com pré-condicionador ASM, com 32 blocos e sub-PC LU em cada bloco. O teste foi efetuado em um cluster com computadores Intel Xeon E5345 de $2.33 \mathrm{GHz}$, com 16GB de RAM e 8 núcleos de processamento.

Para a condição inicial, foi considerada a solução, no estado estacionário, obtida com $R e=10^{-2}$, mostrada na figura 4.6.a. Na figura 4.6.b, são apresentadas as linhas de corrente coloridas de acordo com a magnitude da velocidade, para $R e=100$. O tempo computacional gasto para reduzir o resíduo do método de Newton em 5 ordens de grandeza, utilizando 16 núcleos de processamento, foi de 147,355.5 segundos (aproximadamente 41 horas).

a)

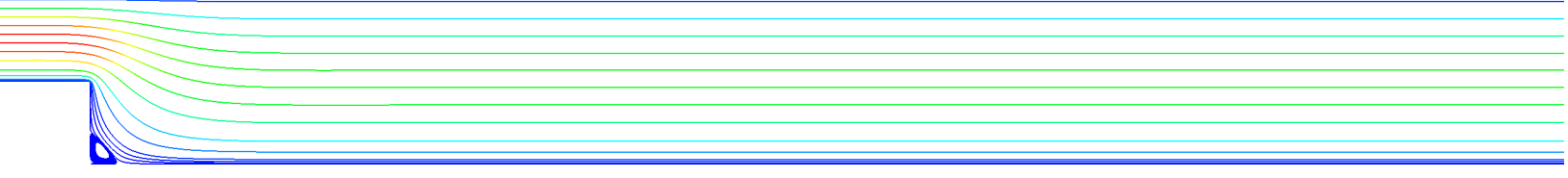

b)

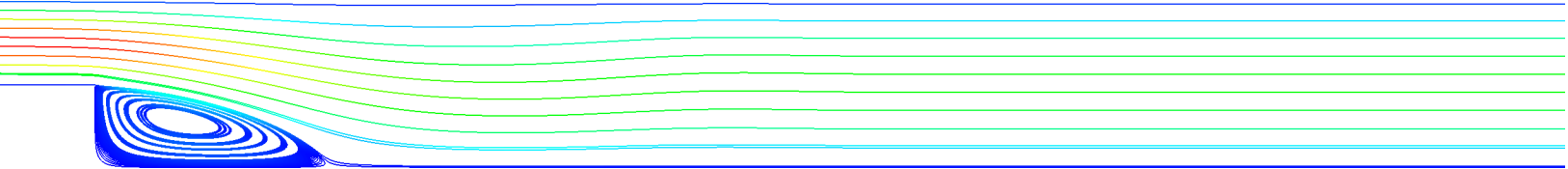

Figura 4.6: Linhas de corrente coloridas segundo a magnitude da velocidade para a) a condição inicial e b) a solução com $R e=100$ do escoamento em um degrau.

Para comparar os resultados obtidos pelo método proposto com os obtidos por Erturk (2008), foi considerado o tamanho do vórtice formado atrás do degrau. Para este caso, com $R e=100$, foi obtido um vórtice de tamanho 2.8, enquanto que o tamanho do vórtice obtido por Erturk (2008) foi 2.9. Portanto, pode-se concluir que os resultados para este caso foram satisfatórios, sendo próximos aos apresentados na literatura. 
A comparação dos resultados obtidos pelo método proposto, comparados aos resultados apresentados na literatura, mostraram que o método proposto conseguiu resolver numericamente escoamentos de fluidos incompressíveis, com um código paralelo, de maneira eficiente. No capítulo 5 serão apresentadas algumas aplicações em escoamentos incompressíveis, utilizando o método proposto.

A seguir, na seção 4.3 será apresentada uma forma de melhorar a aproximação das condições de contorno, baseada no método de mínimos quadrados.

\subsection{Aproximação de Maior Ordem}

Nos últimos anos vem crescendo as pesquisas no intuito de aumentar a ordem de convergência dos métodos de fronteira imersa, já que, na prática, a maioria deles consegue apenas convergência de primeira ordem. Neste contexto, podem ser citados os métodos propostos por Codina and Baiges (2009) e Husain and Floryan (2008b), nos quais as condições de contorno, em especial as de Dirichlet, são impostas de forma a minimizar a distância entre as condições de contorno exata e aproximada no sentido de mínimos quadrados.

Husain e Floryan propuseram o método das condições de fronteiras imersas (immersed boundary conditions) em Husain and Floryan (2008b), para problemas descritos pelo operador laplaciano. Posteriormente, este método foi aplicado a problemas com fronteiras móveis, em Husain and Floryan (2008a), no qual o domínio de solução é fixo e as equações são discretizadas utilizando-se uma combinação das expansões de Fourier e Chebyshev. As condições de contorno são impostas por meio de restrições que anulam determinados modos de Fourier. Essas restrições são satisfeitas no sentido de mínimos quadrados e chegam a obter precisão espectral. Porém este método só é aplicável a geometrias que podem ser representadas por expansões de Fourier.

Já o método de Codina and Baiges (2009) foi proposto no contexto do método dos elementos finitos, no qual é feita uma decomposição no espaço de velocidades nos elementos cortados pelo contorno, representados pelos elementos em azul na figura 4.7 .

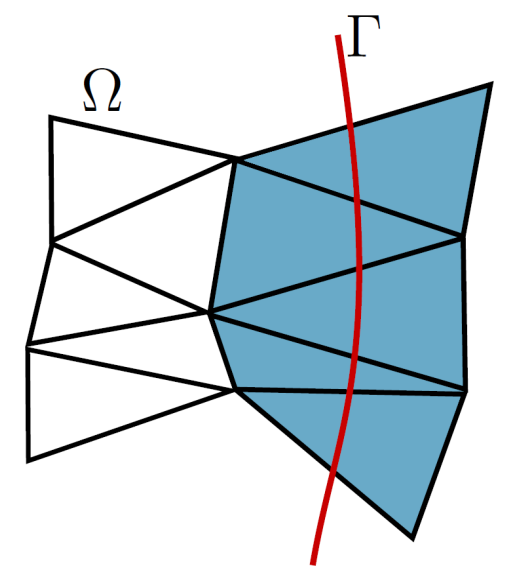

Figura 4.7: Representação da malha próxima ao contorno. Os elementos em azul são os elementos cortados pelo contorno $\Gamma$.

A decomposição faz com que hajam duas equações: uma que descreve o escoamentos nos nós 
totalmente internos ao domínio, ou seja, que pertencem a $\Omega$ e não têm interseção com o contorno, e outra que pode ser vista como uma forma fraca das condições de contorno. A equação que representa a condição de contorno pode ser escrita como

$$
\delta_{\left(0, v_{h, \Gamma}\right)} J\left(u_{h, \Omega}, u_{h, \Gamma}\right)=0,
$$

onde $\delta_{\left(0, v_{h, \Gamma}\right)}$ denota a derivada fraca de um funcional na direção $\left(0, v_{h, \Gamma}\right)$, em que $v_{h, \Gamma}$ é a função teste no espaço de funções que são não nulas no contorno, e $J\left(u_{h, \Omega}, u_{h, \Gamma}\right)$ é um funcional da forma

$$
J\left(u_{h, \Omega}, u_{h, \Gamma}\right)=\left\|u_{h, \Omega}+u_{h, \Gamma}-\bar{u}\right\|_{L^{2}(\Gamma)}^{2},
$$

onde $u_{h, \Omega}$ é a velocidade no espaço de funções nulas no contorno $\left(V_{h, \Omega}\right), u_{h, \Gamma}$ é a velocidade no espaço de funções nulas no contorno $\left(V_{h, \Gamma}\right)$ e $\bar{u}$ é a velocidade exata no contorno $\Gamma$.

Esta equação pode ser vista como uma imposição das condições de contorno nos graus de liberdade dos nós externos dos elementos cortados pelo contorno, representados por quadrados amarelos na figura 4.8, de forma que a distância entre a velocidade calculada em $\Gamma$ e a velocidade exata em $\Gamma$ seja mínima na norma $L^{2}(\Gamma)$.

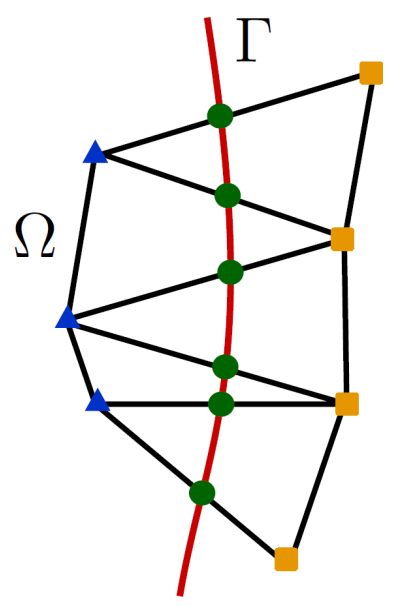

Figura 4.8: Elementos da malha cortados pelo contorno $\Gamma$. Os círculos verdes representam os pontos onde os elementos são interceptados por $\Gamma$, os triângulos azuis são os nós internos, pertencentes a $\Omega$ e quadrados amarelos são os nós externos ao domínio, não pertencentes a $\Omega$.

Neste trabalho, pretende-se estender a ideia básica por trás destes métodos, isto é, aproximar as condições de contorno no sentido de mínimos quadrados, aplicando-a no contexto de diferenças finitas, utilizando malha deslocada (staggered grid) e solução do sistema acoplado.

Para isso, leva-se em consideração o domínio da figura 4.1. Pretende-se minimizar o erro cometido na imposição da velocidade no contorno, ou seja, queremos que a distância entre a velocidade aproximada no contorno $u$ e a velocidade exata no contorno $\bar{u}$ seja mínima.

Para definir a localização do contorno $\Gamma$ foi utilizada uma função implícita $\phi$, tal que $\phi=0 \mathrm{em} \Gamma$ (em vermelho na figura 4.9), $\phi>0$ em $\Omega$ (em amarelo na figura 4.9) e $\phi<0$ fora de $\Omega$ (em azul na 
figura 4.9).

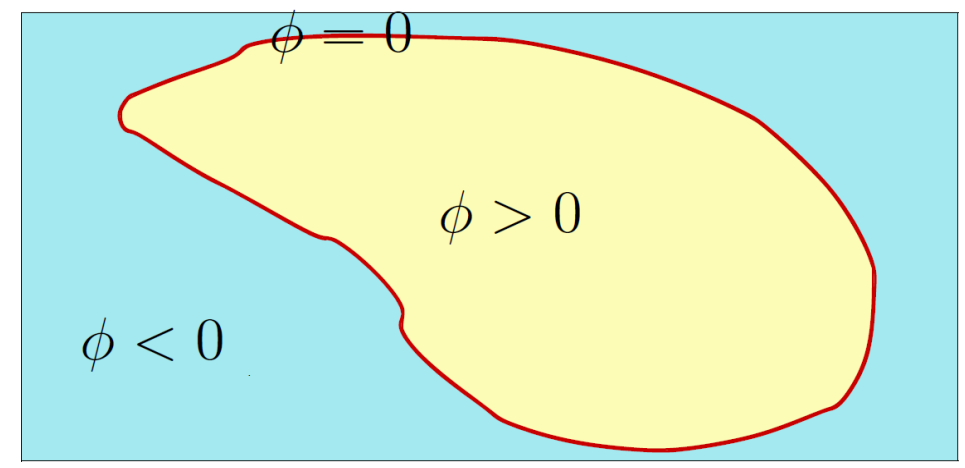

Figura 4.9: Representação do domínio por uma função implícita. A linha vermelha mostra onde $\phi=0$, a área amarela mostra onde $\phi>0$ e a área azul mostra onde $\phi<0$.

Com base no valor desta função implícita, pode-se definir uma interpolação, que permite determinar $u(x)$, onde $x$ é tal que $\phi(x)=0$, nos elementos cortados por $\Gamma$. Para isso, considera-se um elemento do domínio, que é interceptado pelo contorno, como mostrado na figura 4.10. $A, B$ e $C$ são os vértices da célula, nos quais os valores da velocidade e da função implícita são conhecidos, e $x$ e $y$ são os pontos onde $\Gamma$ intercepta as faces da célula, ou seja, onde $\phi=0$.

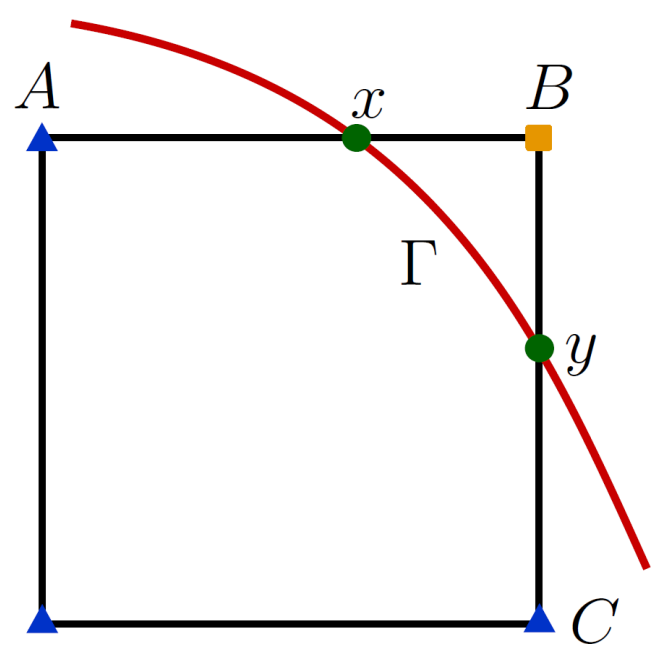

Figura 4.10: Elemento do domínio cortado pelo contorno, em que $A, B$ e $C$ são os vértices do elemento e $x$ e $y$ são os pontos onde o contorno $\Gamma$ corta as arestas do elemento.

Primeiramente, é tratado o caso particular em que apenas uma aresta é cortada pelo contorno. Para isso, considera-se a aresta $A B$, definindo $A$ como um ponto interno, ou seja, $\phi_{A}>0$, e $B$ como um ponto externo, ou seja, $\phi_{B}<0$. Dados os valores da velocidade e da função implícita nos pontos $A$ e $B$, pode-se definir a seguinte interpolação

$$
u=\frac{u_{B} \phi_{A}-u_{A} \phi_{B}}{\phi_{A}-\phi_{B}}
$$


em que $u_{A}$ e $u_{B}$ são as velocidades nos pontos $A$ e $B$, respectivamente, $\phi_{A}$ e $\phi_{B}$ são os valores da função implícita $\phi$ nos pontos $A$ e $B$, respectivamente e $u$ é a velocidade interpolada no ponto $x$, tal que $\phi(x)=0$.

Assim, obtém-se uma equação para a velocidade aproximada no contorno. Agora, é necessário fazer com que a distância entre a velocidade aproximada $u$ e a velocidade exata $\bar{u}$ no contorno seja mínima. Para isso, toma-se como base o método proposto por Codina and Baiges (2009). O funcional (4.2), definido anteriormente, torna-se

$$
J(u)=\|u-\bar{u}\|_{2}^{2}=(u-\bar{u})^{2}=\left(\frac{u_{B} \phi_{A}-u_{A} \phi_{B}}{\phi_{A}-\phi_{B}}-\bar{u}\right)^{2}
$$

e a equação (4.1), também apresentada anteriormente, torna-se

$$
\frac{\partial J(u)}{\partial u_{B}}=0
$$

ou seja,

$$
\frac{\partial J(u)}{\partial u_{B}}=2\left(\frac{u_{B} \phi_{A}-u_{A} \phi_{B}}{\phi_{A}-\phi_{B}}-\bar{u}\right)\left(\frac{\phi_{A}}{\phi_{A}-\phi_{B}}\right)=0 .
$$

Considerando $\phi_{A} \neq 0$ e $\phi_{B} \neq 0$, chega-se a

$$
\frac{u_{B} \phi_{A}}{\phi_{A}-\phi_{B}}-\frac{u_{A} \phi_{B}}{\phi_{A}-\phi_{B}}-\bar{u}=0
$$

Logo, obtém-se uma equação para $u_{B}$

$$
u_{B}=\left(\frac{u_{A} \phi_{B}}{\phi_{A}-\phi_{B}}+\bar{u}\right)\left(\frac{\phi_{A}-\phi_{B}}{\phi_{A}}\right) .
$$

Esta equação representa a imposição da condição de contorno de Dirichlet em $\Gamma$, quando apenas uma aresta é cortada pelo contorno.

Para o caso geral, em que mais de uma aresta é cortada por $\Gamma$, considera-se o funcional como sendo a soma das parcelas equivalentes à contribuição de cada aresta. Para exemplificar, toma-se as arestas $A B$ e $B C$ do elemento mostrado na figura 4.10 .

Supondo que $C$ seja um nó interno, assim como $A$, teremos também uma interpolação para definir u no ponto $y$, onde o contorno corta a aresta $B C$, tal que $\phi(y)=0$, da forma

$$
u=\frac{u_{B} \phi_{C}-u_{C} \phi_{B}}{\phi_{C}-\phi_{B}}
$$

Desta forma, não há uma equação que define unicamente as velocidades no contorno. Porém, 
redefinindo o funcional $J$ como

$$
J(u)=\left(\frac{u_{B} \phi_{A}-u_{A} \phi_{B}}{\phi_{A}-\phi_{B}}-\bar{u}\right)^{2}+\left(\frac{u_{B} \phi_{C}-u_{C} \phi_{B}}{\phi_{C}-\phi_{B}}-\bar{u}\right)^{2}
$$

e calculando seu mínimo, ou seja, determinando $u_{B}$, tal que $\frac{\partial J(u)}{\partial u_{B}}=0$,

$$
\frac{\partial J(u)}{\partial u_{B}}=2\left(\frac{u_{B} \phi_{A}-u_{A} \phi_{B}}{\phi_{A}-\phi_{B}}-\bar{u}\right)\left(\frac{\phi_{A}}{\phi_{A}-\phi_{B}}\right)+2\left(\frac{u_{B} \phi_{C}-u_{C} \phi_{B}}{\phi_{C}-\phi_{B}}-\bar{u}\right)\left(\frac{\phi_{C}}{\phi_{C}-\phi_{B}}\right)=0,
$$

é possível escrever $u_{B}$ da seguinte forma

$$
u_{B}=\left(\frac{u_{A} \phi_{A} \phi_{B}}{\left(\phi_{A}-\phi_{B}\right)^{2}}+\frac{\bar{u} \phi_{A}}{\phi_{A}-\phi_{B}}+\frac{u_{C} \phi_{B} \phi_{C}}{\left(\phi_{C}-\phi_{B}\right)^{2}}+\frac{\bar{u} \phi_{C}}{\phi_{C}-\phi_{B}}\right) \frac{1}{\frac{\phi_{A}^{2}}{\left(\phi_{A}-\phi_{B}\right)^{2}}+\frac{\phi_{C}^{2}}{\left(\phi_{C}-\phi_{B}\right)^{2}}} .
$$

Dessa maneira, tem-se um único valor para $u_{B}$, que consiste na aproximação da velocidade no contorno no sentido de mínimos quadrados. Isto torna o problema bem definido, fazendo com que $u$ esteja o mais próximo possível de $\bar{u}$.

Há assim, uma equação para cada elemento cortado pelo contorno, representando a imposição das condições de contorno. Além disso, há as equações de quantidade de movimento e de incompressibilidade para os elementos interiores ao domínio, como visto no capítulo 2. Essas equações geram um sistema, no qual as equações que representam as condições de contorno de Dirichlet para a velocidade são resolvidas utilizando-se o método dos mínimos quadrados.

Na seção 4.3.1, a seguir, são apresentados os resultados obtidos com a utilização do método proposto acima.

\subsubsection{Testes Numéricos}

Nesta seção são apresentados testes numéricos, nos quais a solução obtida pelo método proposto é comparada com a solução exata de um problema, em uma e duas dimensões, mostrando a convergência do método.

\subsubsection{Equação do Calor - 1D}

O primeiro teste considerado foi um problema envolvendo a solução da equação do calor em uma dimensão.

A equação do calor é dada por

$$
\left\{\begin{array}{l}
-u^{\prime \prime}=1 \text { em } \Omega \\
u=0 \text { em } \Gamma
\end{array}\right.
$$

onde $\Omega=(0, \pi)$ é o domínio em que está definida a equação, o contorno $\Gamma$ passa sobre o ponto $x_{\Gamma}=\pi$ e $\mathcal{B}=(0,4)$ é domínio que contém $\Omega$, como mostrado na figura 4.11 . 


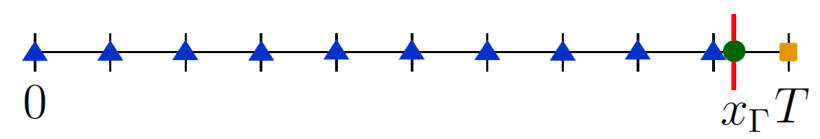

Figura 4.11: Representação do domínio $\mathcal{B}=(0,4)$, onde $x_{\Gamma}=\pi$ e $\Omega=(0, \pi)$.

O programa foi executado utilizando malhas com 10, 20, 40, 80, 160, 320 e 640 pontos, comparando-se a solução obtida com a solução exata do problema, dada por

$$
U=-\frac{1}{2}\left(x^{2}-x_{\Gamma} x\right)=-\frac{1}{2}\left(x^{2}-\pi x\right)
$$

e calculando-se o erro nas normas $L_{2}$ e $L_{\infty}$. O gráfico mostrando o decaimento do erro em função do refinamento da malha, em escala logarítmica, é mostrado na figura 4.12.

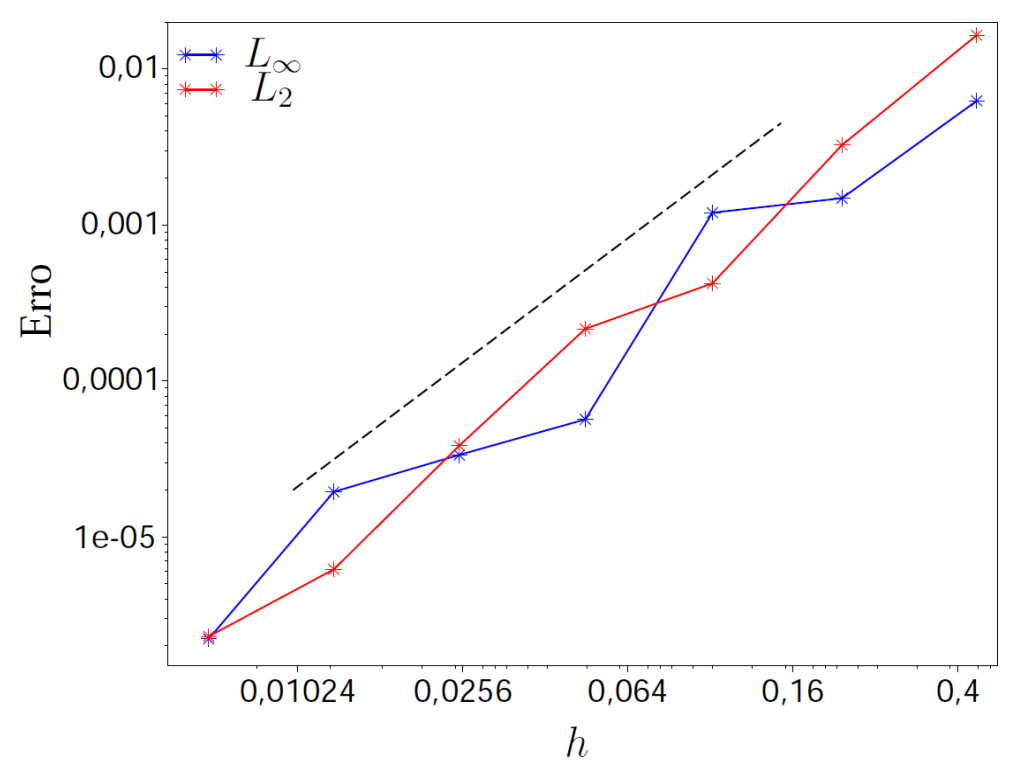

Figura 4.12: Decaimento do erro com o refinamento da malha para a solução da equação do calor, em escala logarítmica.

A partir do gráfico apresentado na figura 4.12, pode-se observar que o erro da solução varia com a posição do contorno em relação à malha. Apesar disso, o método proposto conseguiu obter convergência de ordem $h^{2}$ (linha tracejada).

Na figura 4.13 são apresentados os gráficos das soluções exata $U$ e aproximada $u$, para $h=0.4444$ (malha com 10 pontos) e $h=0.00625$ (malha com 640 pontos). Em ambas pode-se notar, na área ampliada, que a condição de contorno é satisfeita, sendo imposta no ponto correto e com valor exato.

A seguir, na seção 4.3.1.2, apresentaremos os resultados obtidos pelo método proposto em um teste numérico 2D. 
a)

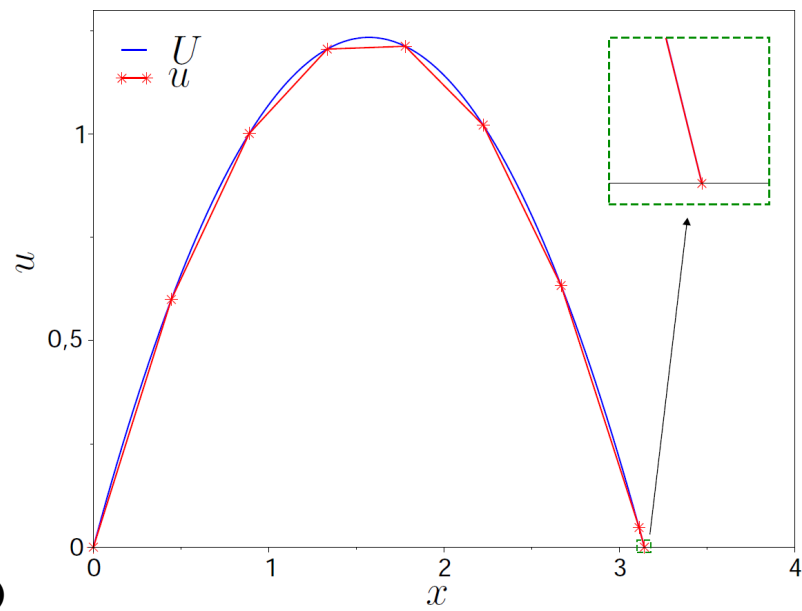

b)

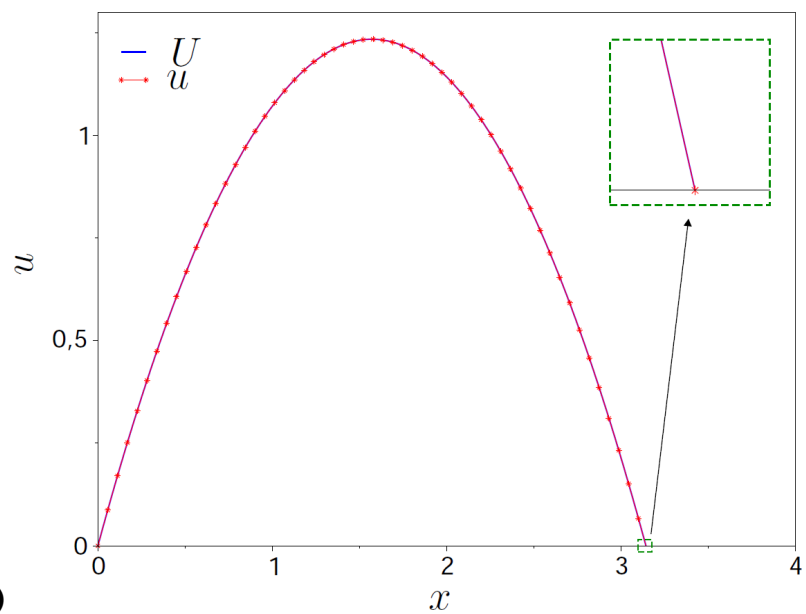

Figura 4.13: Soluções exata $U$ e aproximada $u$ para a) $h=0.4444$ e b) $h=0.00625$. Podemos notar, na ampliação, que a condição de contorno está sendo imposta no ponto correto, com valor exato.

\subsubsection{Equação de Poisson - 2D}

Para o segundo teste numérico, foi considerado um problema envolvendo a equação de Poisson 2D, dada por

$$
\left\{\begin{array}{l}
-\nabla^{2} u=f \quad \text { em } \Omega \\
u=0 \text { em } \Gamma
\end{array}\right.
$$

onde $\Omega$ é o domínio em que está definida a equação e $\Gamma$ é o contorno.

Para este teste foram considerados dois domínios: um círculo de raio $r=\frac{\pi}{2}$ e centro na origem e um quadrado $\left(-\frac{\pi}{2}, \frac{\pi}{2}\right) \times\left(-\frac{\pi}{2}, \frac{\pi}{2}\right)$. Para os dois casos foram consideradas as seguintes malhas: $11 \times 11,21 \times 21,31 \times 31,41 \times 41,61 \times 61,81 \times 81,101 \times 101$ e $121 \times 121$. O programa foi executado, utilizando as diferentes malhas, e a solução obtida foi comparada com a solução exata.

Para o círculo, foi considerado o termo fonte

$$
f(x, y)=\frac{\sin \left(\sqrt{x^{2}+y^{2}}\right)}{\sqrt{x^{2}+y^{2}}}+\cos \left(\sqrt{x^{2}+y^{2}}\right),
$$

cuja solução exata é

$$
U(x, y)=\cos \left(\sqrt{x^{2}+y^{2}}\right)
$$

O gráfico do decaimento do erro em função de $h$, onde $h$ é o espaçamento da malha, é mostrado na figura 4.14.a.

Para o quadrado, foi considerado o termo fonte

$$
f(x, y)=2 \cos (x) \cos (y),
$$


cuja solução exata é

$$
U(x, y)=\cos (x) \cos (y)
$$

O gráfico do decaimento do erro em função de $h$ é mostrado na figura 4.14.b.
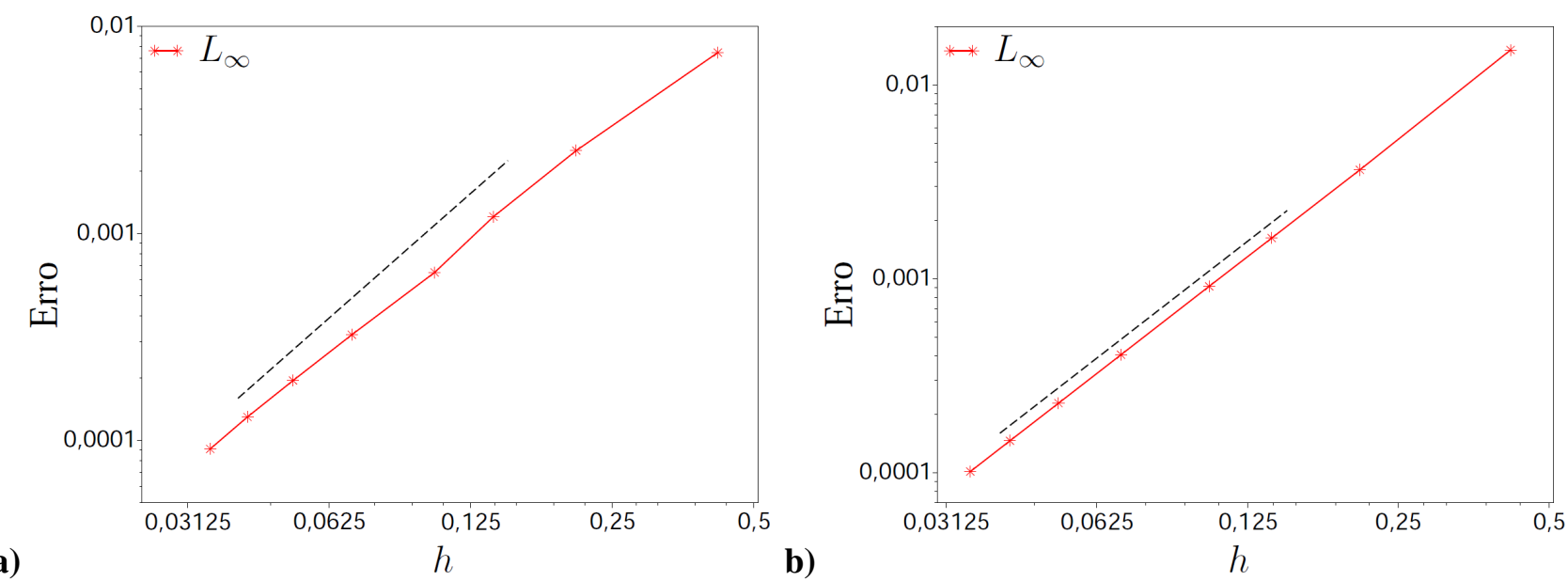

Figura 4.14: Decaimento do erro com a redução do tamanho $h$, em escala $\log \times \log$, para a) o círculo e b) o quadrado.

Da figura 4.14, pode-se observar novamente que o método proposto conseguiu obter convergência de ordem $h^{2}$ (linha tracejada), para os dois domínios considerados.

Estes resultados mostram que foi possível melhorar a ordem da aproximação, podendo até atingir precisão de ordem 2. Este fato serviu de inspiração para estender o método para aplicações envolvendo as equações de Navier-Stokes.

A seguir, na seção 4.3.2, são apresentados alguns exemplos em que foi utilizado o método proposto para a solução numérica de escoamentos incompressíveis.

\subsubsection{Resultados}

Nesta seção, são apresentadas simulações numéricas de escoamentos de fluidos incompressíveis utilizando o método proposto e comparando os resultados obtidos com uma solução analítica e com resultados da literatura de mecânica do fluidos.

\subsubsection{Comparação com Solução Analítica}

Para testar o funcionamento do método na solução das equações de Navier-Stokes, a solução numérica foi comparada com uma solução analítica calculada. Para isso, foi considerado o domínio 
quadrado $\Omega=(-1,1) \times(-1,1)$, com solução analítica dada por

$$
\begin{aligned}
u & =-2 y\left(1-x^{2}\right), \\
v & =2 x\left(1-y^{2}\right), \\
p & =2\left(x^{2}+y^{2}\right)-\left(x^{4}+y^{4}\right)+2 x^{2} y^{2}, \\
f_{x} & =-4 \nu y+4 x^{3} y^{2}, \\
f_{y} & =4 \nu x+4 x^{2} y^{3},
\end{aligned}
$$

onde $u$ e $v$ são as componentes da velocidade nas direções $x$ e $y$, respectivamente, $p$ é a pressão e $f_{x}$ e $f_{y}$ são as forças das equações de quantidade de movimento nas direções $x$ e $y$, respectivamente. Para este caso, foi considerado $R e=1$ e uma malha de $265 \times 265$ pontos.

O sistema linear foi resolvido com o método LU em um computador Intel Xeon E5345 de 2.33GHz, com 16GB de RAM e 8 núcleos de processamento. O tempo de processamento até que se chegasse ao estado estacionário foi de 1864 segundos, em um núcleo de processamento.

As soluções exata e aproximada são mostradas abaixo, nas figuras 4.15, 4.16 e 4.17, onde são mostradas a pressão, as linhas de corrente coloridas segundo a magnitude da velocidade e a magnitude da velocidade, respectivamente.

a)

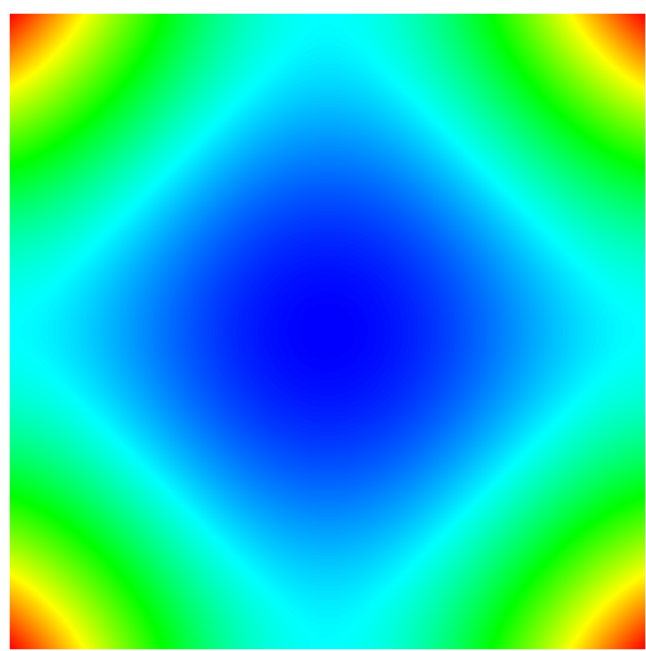

b)

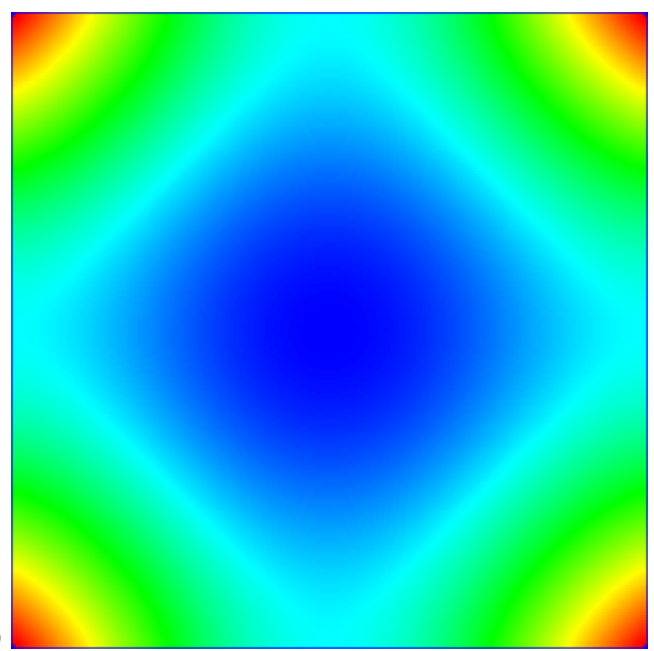

Figura 4.15: Valores das pressões a) exata e b) aproximada para o problema com solução analítica.

Comparando a solução aproximada com a solução exata, obtive-se um erro da ordem de $10^{-8}$ para as componentes da velocidade e da ordem de $10^{-4}$ para a pressão.

Os resultados obtidos mostram que o método proposto consegue resolver numericamente as equações de Navier-Stokes. Porém, também pode-se notar que há um problema quanto à posição do contorno, em relação à malha. Para mostrar este problema, foi feita uma ampliação do canto superior da figura 4.15, mostrado na figura 4.18. Pode-se observar nesta ampliação que há um problema no cálculo da pressão, pois a continuidade não está bem definida nestas células.

Isto ocorre pois há duas velocidades que estão dentro do domínio $\Omega\left(u_{i n}\right.$ e $\left.v_{i n}\right)$, ou seja, que são 
a)

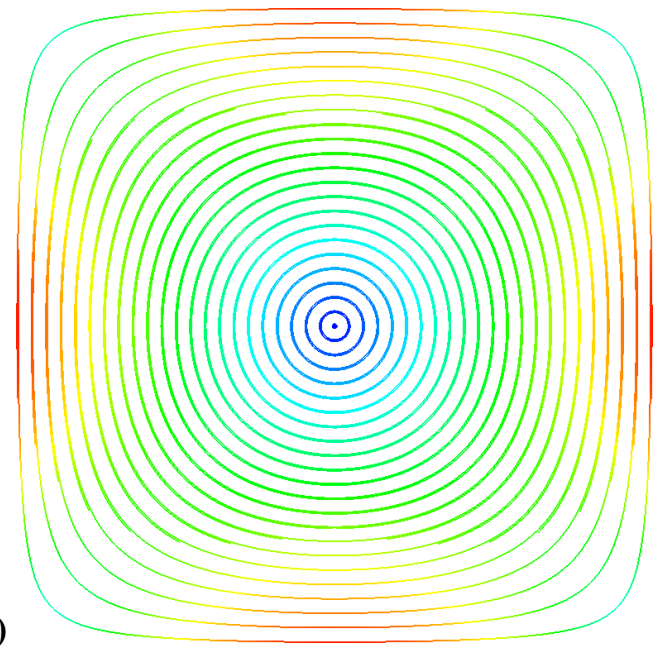

b)

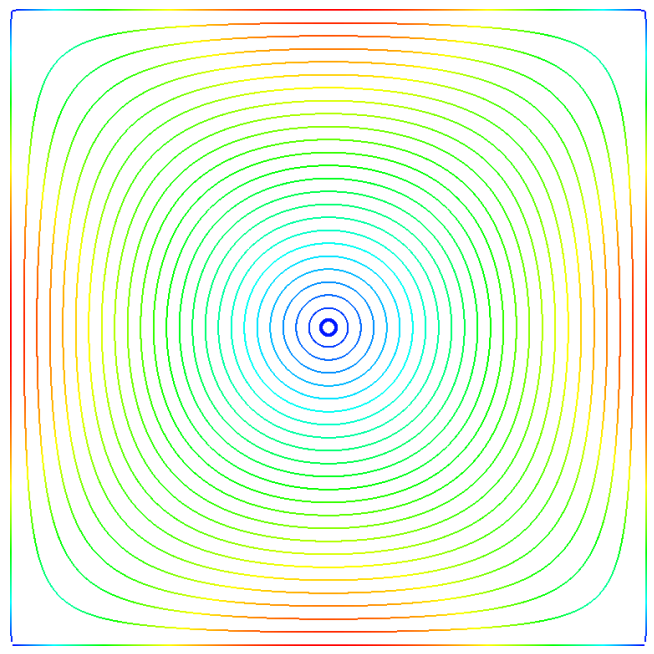

Figura 4.16: Linhas de corrente coloridas segundo a magnitude da velocidade a) exata e b) aproximada para o problema com solução analítica.

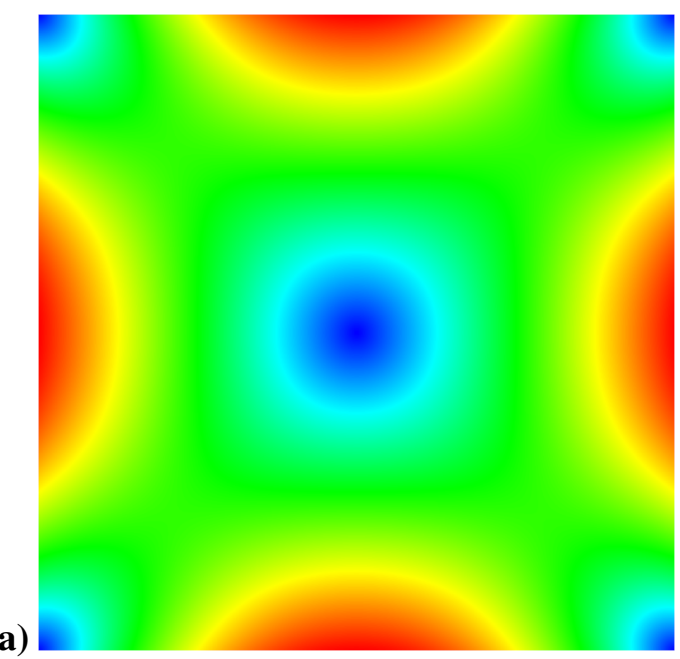

b)

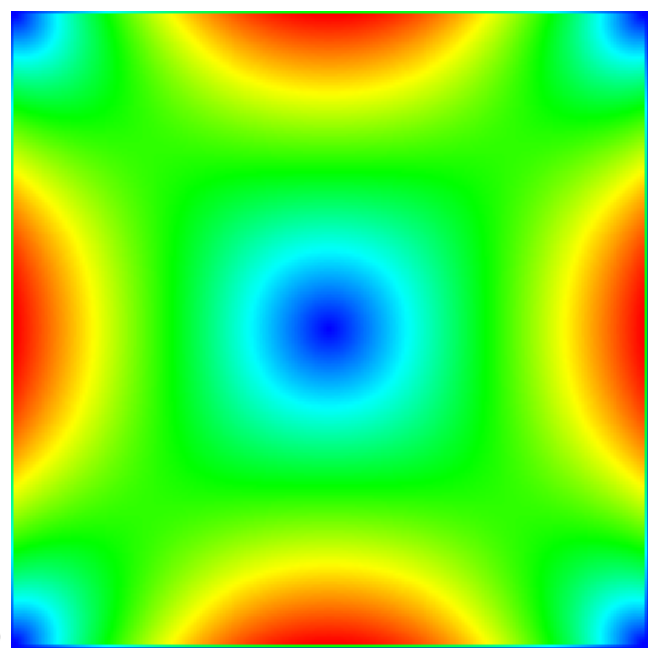

Figura 4.17: Magnitude da velocidade a) exata e b) aproximada para o problema com solução analítica.

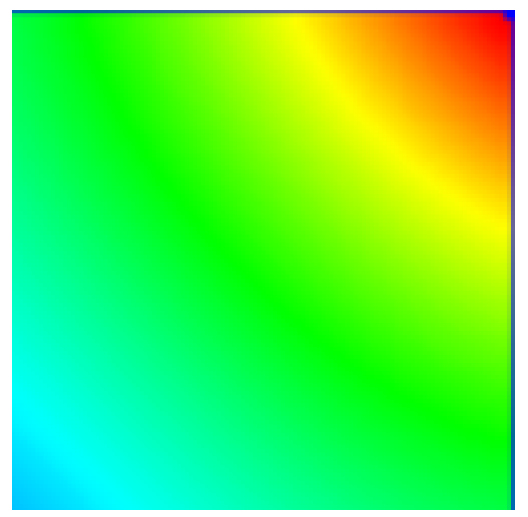

Figura 4.18: Ampliação do canto superior direito da figura 4.15, representando a pressão obtida na solução aproximada para o problema com solução analítica. 
calculadas, e duas velocidades que estão fora do domínio $\Omega\left(u_{\text {out }}\right.$ e $\left.v_{\text {out }}\right)$, ou seja, que são impostas, como pode ser visto na figura 4.19 .

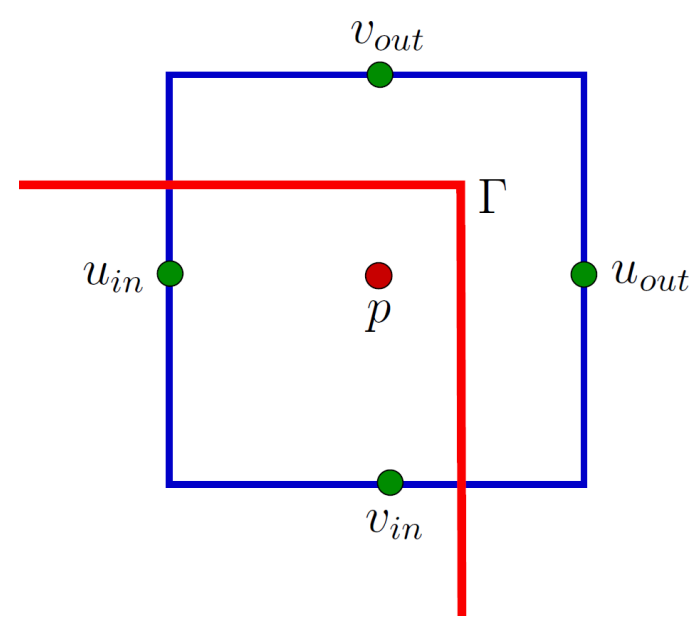

Figura 4.19: Célula do "canto" do domínio, onde $u_{\text {in }}$ e $v_{\text {in }}$ são velocidades dentro do domínio $\Omega$, $u_{\text {out }}$ e $v_{\text {out }}$ são velocidades fora do domínio $\Omega, p$ é a pressão e $\Gamma$ é o contorno.

Também há problema quando a fronteira $\Gamma$ passa sobre um nó de velocidade ou pressão, pois a interpolação torna-se indeterminada.

Uma das propostas de futuros trabalhos, apresentada na seção 6.3, é um estudo mais aprofundado destes problemas, no intuito de encontrar propostas de soluções.

A seguir, na seção 4.3.2.2, é apresentada a comparação do método proposto com um resultado da literatura de mecânica dos fluidos.

\subsubsection{Cavidade com Tampa Deslizante}

Assim como para o método de primeira ordem, os resultados obtidos pelo método melhorado foram comparados com os resultados obtidos por Ghia et al. (1982).

Uma representação do domínio é mostrada na figura 4.20, em que $L=1$, e das condições de contorno, onde $\gamma$ (em amarelo) é uma superfície rígida imersa na malha e $\Gamma_{i n}$ é a condição de deslizamento da tampa, em que $u=1$ e $v=0$, como no caso anterior.

O teste foi efetuado com os mesmos parâmetros do caso de primeira ordem, ou seja, malha de $301 \times 301$ pontos, com $R e=100, \delta t=0.01, \mathrm{CFL}=3$ e solução do sistema utilizando GMRES com $n=600$ e MGS, com pré-condicionador ASM, com 16 blocos e sub-PC ILU em cada bloco. O teste foi executado em um cluster com computadores Intel Xeon E5345 de 2.33GHz, com 16GB de RAM e 8 núcleos de processamento.

Assim como no caso anterior, considerou-se como condição inicial a solução, no estado estacionário, obtida com $R e=10^{-2}$. A condição inicial, com $R e=10^{-2}$, e a solução no estado estacionário, com $R e=100$, são apresentadas na figura 4.21. O tempo de processamento até que o resíduo do método de Newton reduzisse 10 ordens de grandeza, utilizando 16 núcleos de processamento, foi de 61234.2 segundos. 


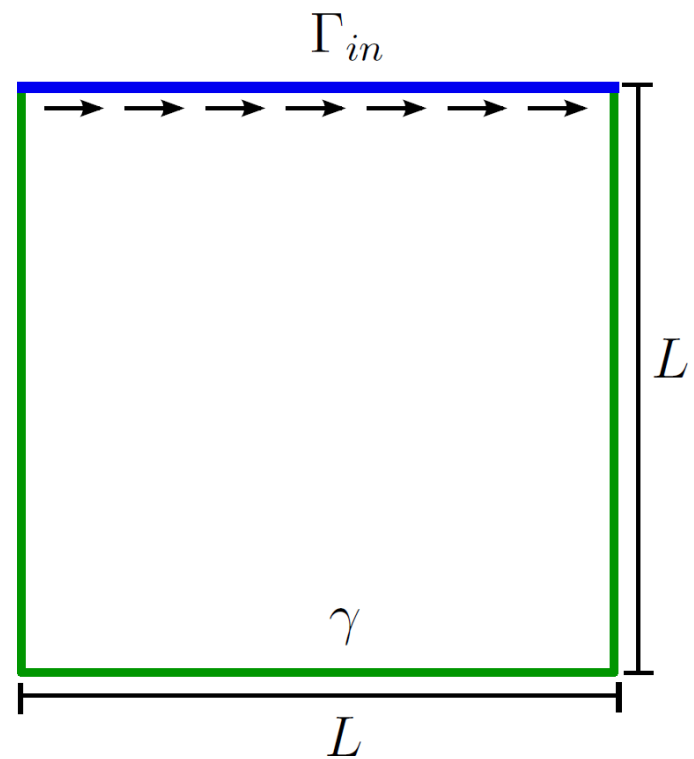

Figura 4.20: Representação esquemática para a cavidade com tampa deslizante, com dimensão $L=1 \mathrm{e}$ condições de contorno de deslizamento da tampa $\left(\Gamma_{i n}\right)$ e sobre superfície rígida imersa na malha $(\gamma)$.

a)

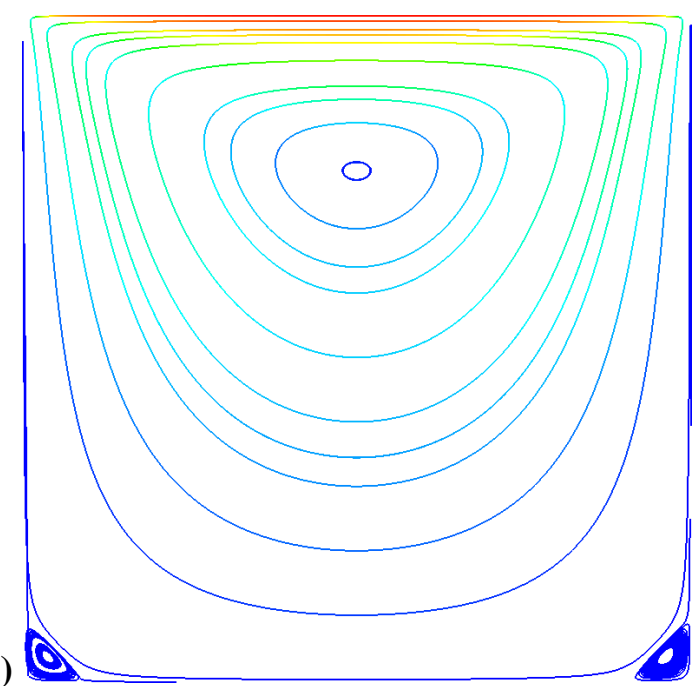

b)

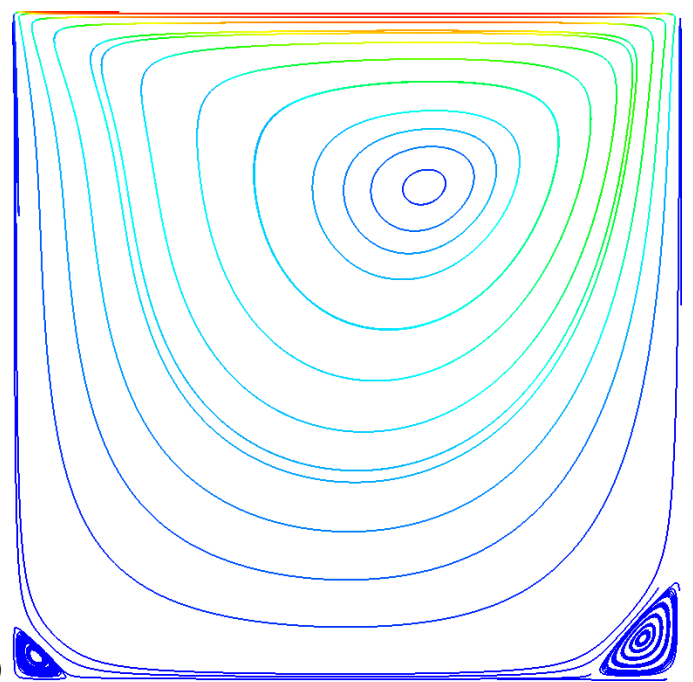

Figura 4.21: Linhas de corrente coloridas segundo a magnitude da velocidade para a cavidade com tampa deslizante para $R e=100$ a) condição inicial e b) solução no estado estacionário.

Para a comparação dos resultados também foram considerados os perfis de velocidade nas linhas horizontal e vertical que passam pelo centro da cavidade. Na figura 4.22, pode-se ver o perfil da velocidade $u$ ao longo da linha vertical que passa pelo centro do domínio (4.22.a) e o perfil da velocidade $v$ ao longo da linha horizontal que passa pelo centro do domínio (4.22.b), comparadas com os resultados obtidos por Ghia et al. (1982).

Novamente, pode-se observar que a solução obtida pelo método proposto está muito próxima da solução obtida por Ghia et al. (1982). Conclui-se assim, que o método melhorado proposto também consegue resolver numericamente as equações que descrevem escoamentos de fluidos incom- 


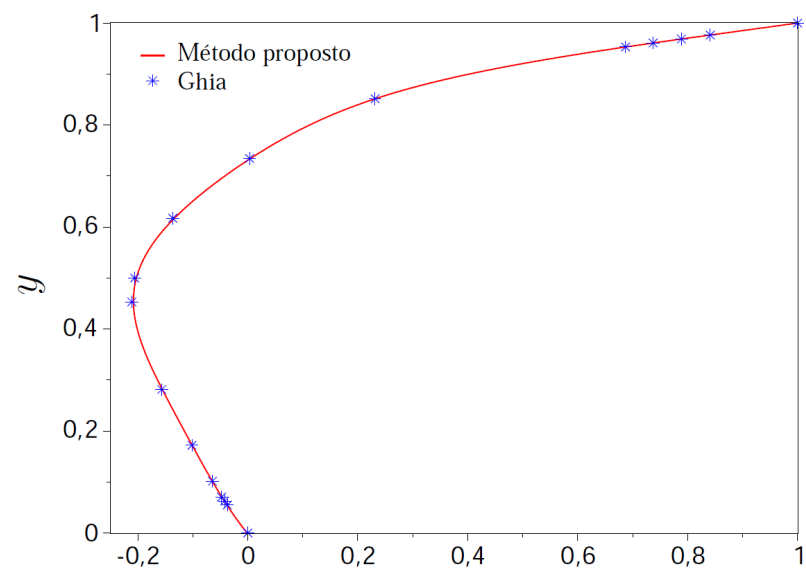

a)

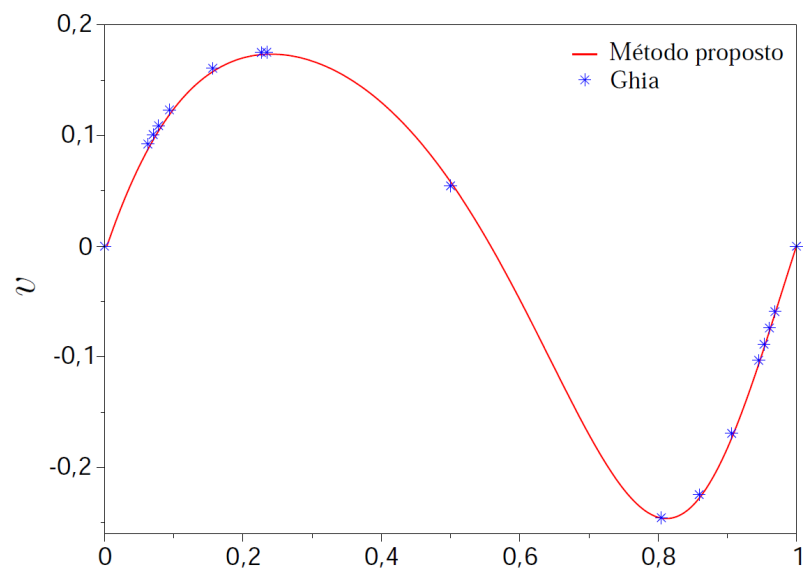

b)

Figura 4.22: a) Perfil da velocidade $u$ ao longo da linha vertical que passa pelo centro do domínio e b) perfil da velocidade $v$ ao longo da linha horizontal que passa pelo centro do domínio, comparadas com os resultados obtidos por Ghia et al. (1982).

pressíveis.

\subsubsection{Conclusões}

Na seção 4.3.1 foi mostrado que é possível implementar um código para resolver numericamente as equações que descrevem escoamentos de fluidos incompressíveis com fronteira imersa, utilizando a biblioteca PETSc, de forma a obter bons resultados em paralelo e com baixo tempo de processamento.

Pode-se notar, também, através dos resultados da seção 4.3.2, que a extensão do método de Codina and Baiges (2009) para a discretização por diferenças finitas conseguiu atingir segunda ordem de precisão na aproximação das condições de contorno.

Portanto, foi possível implementar um código paralelo para a solução numérica de escoamentos de fluidos viscosos incompressíveis com fronteira imersa que produza bons resultados com pouco tempo de processamento.

No próximo capítulo serão apresentadas aplicações em mecânica dos fluidos utilizando o método de primeira ordem. 


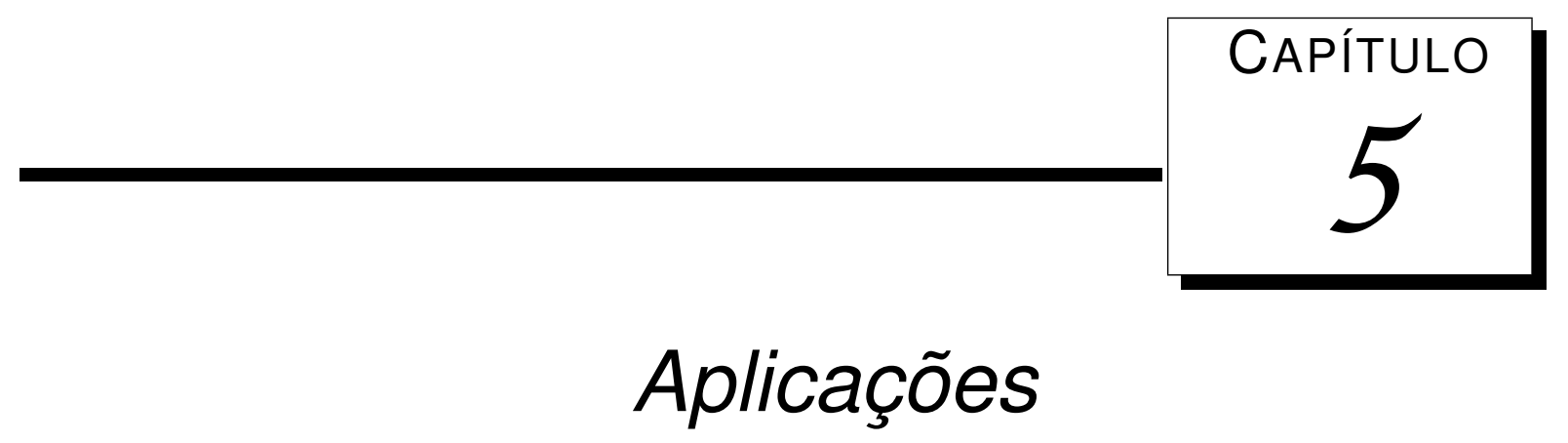

Neste capítulo apresentaremos os resultados obtidos com um código para a solução numérica de escoamentos incompressíveis, que utiliza a formulação de diferenças finitas descrita na seção 2.3 .1 e o método de fronteiras imersas de primeira ordem, no qual o contorno aproximado coincide com a malha, descrito na seção 4.2. Este código foi implementado utilizando-se a biblioteca PETSc, descrita na seção 3.2 .

\subsection{Aplicações 2D}

$\mathrm{Na}$ aplicação do código em duas dimensões foram executados dois casos: o escoamento ao redor de um cilindro circular e o escoamento em um canal contendo um obstáculo em forma de "c". Esses dois casos são apresentados a seguir nas seções 5.1.1 e 5.1.2, respectivamente.

\subsubsection{Escoamento ao Redor de Cilindro Circular}

O primeiro caso 2D é o escoamento ao redor de um cilindro circular, cujo domínio é mostrado na figura 5.1, onde $L=8$ e $H=1$, e raio do cilindro é $r=0.1$. As condições de contorno são de entrada de fluido $\left(\Gamma_{i n}\right)$, saída de fluido $\left(\Gamma_{\text {out }}\right)$ e sobre superfície rígida que respeita a malha $\left(\Gamma_{f i t}\right)$.

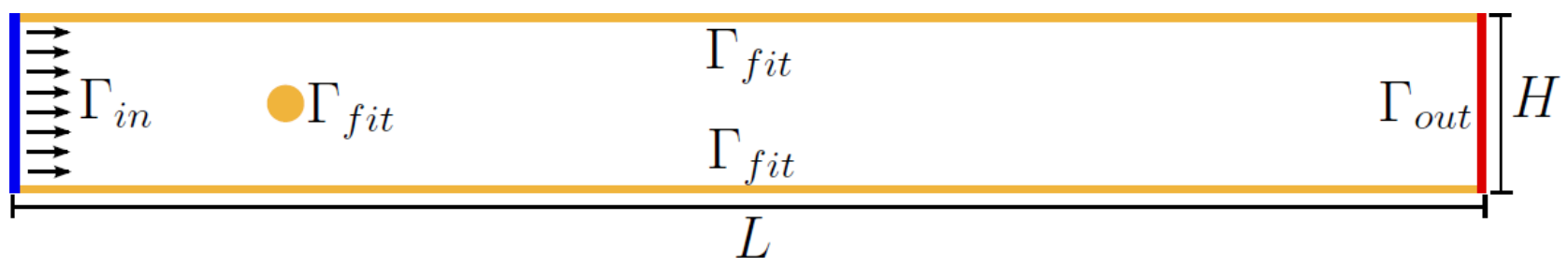

Figura 5.1: Representação esquemática para o escoamento ao redor de um cilindro circular, com dimensões $L=8, H=1$ e raio do cilindro $r=0.1$ e com condições de contorno de entrada de fluido $\left(\Gamma_{i n}\right)$, saída de fluido $\left(\Gamma_{\text {out }}\right)$ e sobre superfície rígida que respeita a malha $\left(\Gamma_{f i t}\right)$. 
Para este teste foi utilizada uma malha de $3203 \times 403$ pontos, o que nos dá 1,287,204 células e aproximadamente 4,000,000 de incógnitas. Para a solução do sistema linear foi utilizado o método GMRES com $n=600$ e MGS, pré-condicionado pelo método ASM, com 32 blocos e sub-PC LU. Foram considerados vários números de Reynolds, que definem os casos apresentados a seguir. Todos os casos foram executados em um cluster com computadores Intel Xeon E5345 de $2.33 \mathrm{GHz}$, com $16 \mathrm{~GB}$ de RAM e 8 núcleos de processamento.

\subsubsection{Caso 1: $R e=10^{-2}$}

Para mostrar o funcionamento do método para baixo número de Reynolds, executamos o código com $R e=10^{-2}, \delta t=0.1$ e CFL $=40$. Os resultados são mostrados na figura 5.2, onde podemos ver a pressão (5.2.a), a magnitude da velocidade (5.2.b) e as linhas de corrente coloridas segundo a magnitude da velocidade (5.2.c). Até atingir o estado estacionário, o código levou 2,229 segundos (aproximadamente 37 minutos), utilizando 16 núcleos de processamento.

a)

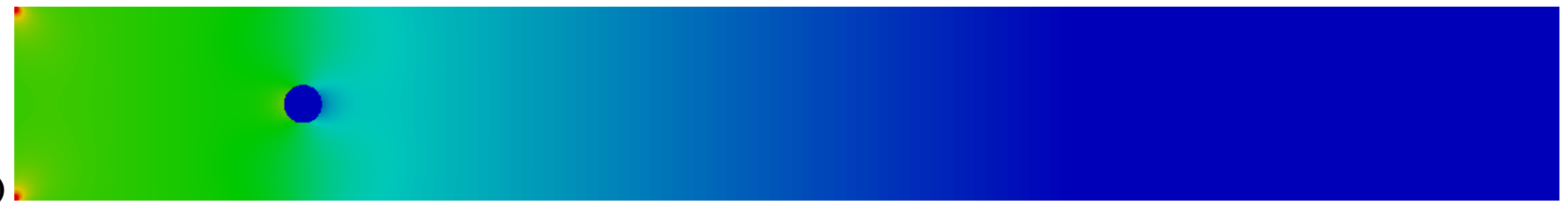

b)

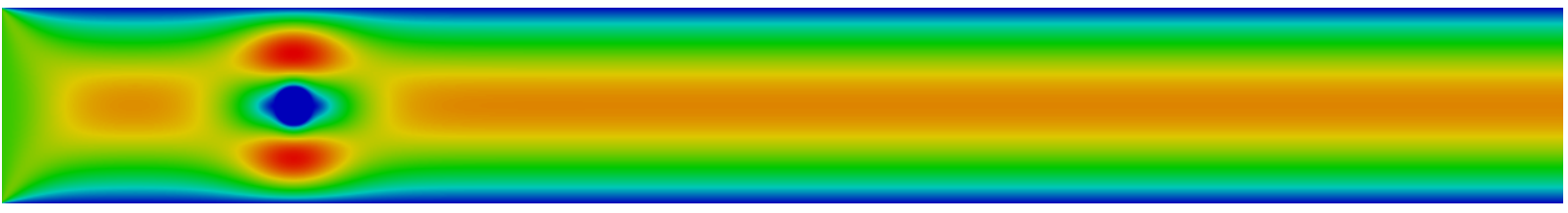

c)

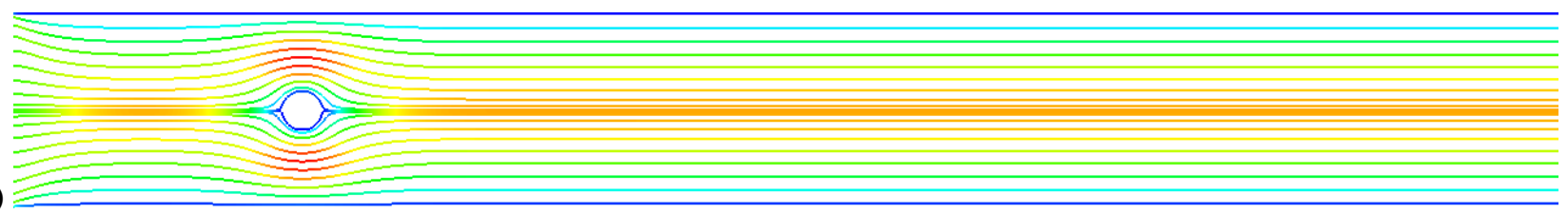

Figura 5.2: Resultados para o estado estacionário do escoamento ao redor de um cilindro circular, com $R e=10^{-2}$. a) Pressão; b) Magnitude da velocidade; c) Linhas de corrente coloridas segundo a magnitude da velocidade.

Podemos notar que o método proposto foi capaz de resolver bem um problema com baixo número de Reynolds e com pouco tempo de processamento.

A seguir, vamos mostrar o funcionamento do método para o caso com $R e=100$.

\subsubsection{Caso 2: $R e=100$}

Este caso foi executado com $R e=100, \delta t=0.01$ e CFL $=4$. Como condição inicial foi considerada a solução obtida no estado estacionário do exemplo anterior, com $R e=10^{-2}$. A seguir, na figura 5.3, podemos ver a pressão (5.3.a), a magnitude da velocidade (5.3.b) e as linhas de corrente, coloridas de acordo com a magnitude da velocidade (5.3.c). O tempo de processamento necessário para reduzir o resíduo em 4 ordens de grandeza, com 16 núcleos de processamento, foi de 388,829 segundos (aproximadamente 4.5 dias). 
a)

\section{.}

b)

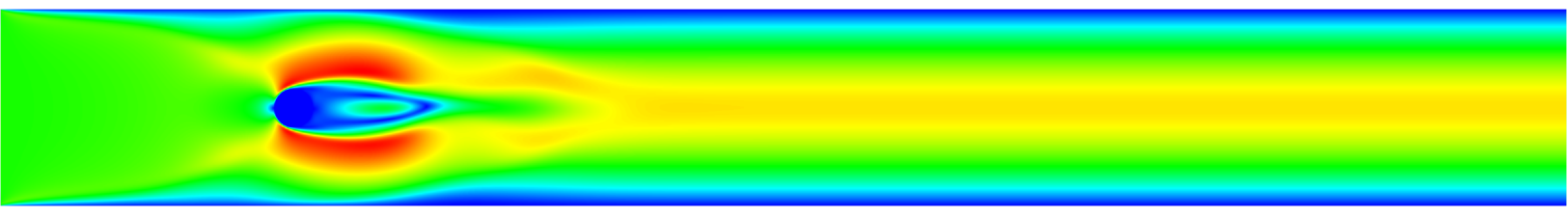

c)

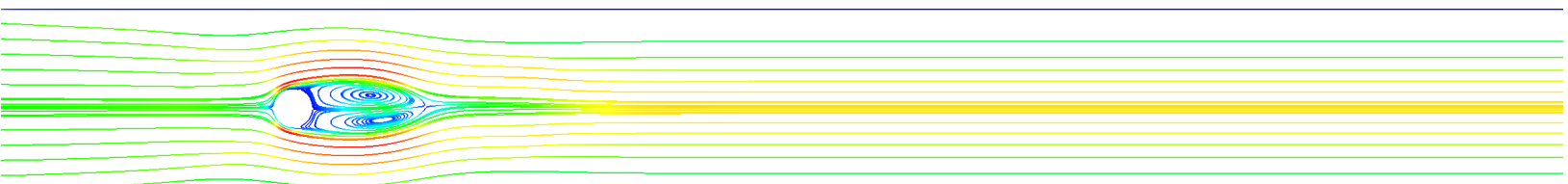

Figura 5.3: Resultados para o escoamento ao redor de um cilindro circular, com $R e=100$. a) Pressão; b) Magnitude da velocidade; c) Linhas de corrente coloridas segundo a magnitude da velocidade.

Podemos ver que o método conseguiu obter bons resultados para este problema, capturando os vórtices formados atrás do cilindro. Por estes resultados apresentados, notamos que o método paralelo foi eficiente.

\subsubsection{Escoamento em um Canal com Obstáculo em Forma de "c"}

A segunda aplicação do código em duas dimensões foi feita em um canal que contém um obstáculo em forma de "c", como mostrado na figura 5.4, onde $L=6$ e $H=1$. As condições de contorno são de entrada de fluido $\left(\Gamma_{i n}\right)$, saída de fluido $\left(\Gamma_{\text {out }}\right)$ e sobre superfície rígida que respeita a malha $\left(\Gamma_{f i t}\right)$. O tamanho característico do obstáculo é $l=0.2$.

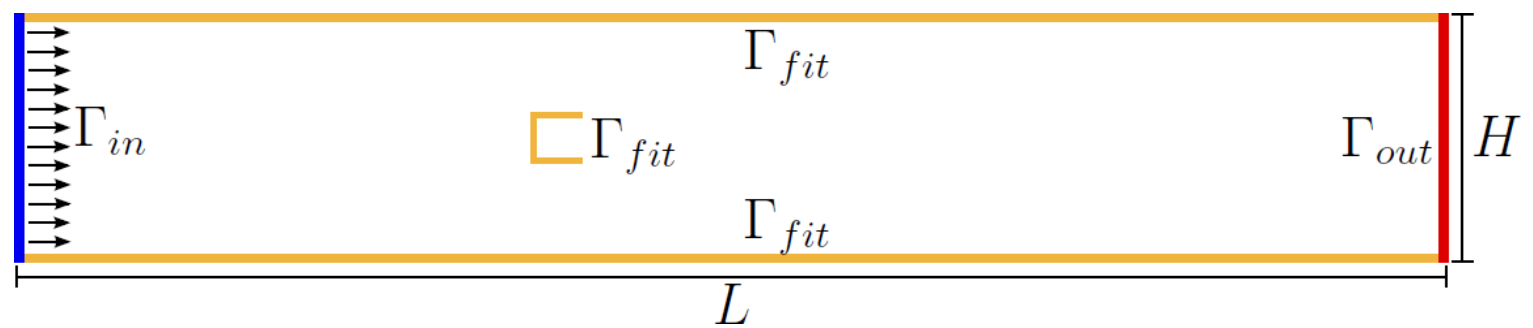

Figura 5.4: Representação esquemática para o escoamento em um canal com obstáculo em forma de "c", com dimensões $L=6, H=1$ e tamanho característico do obstáculo $l=0.2$ e com condições de contorno de entrada de fluido $\left(\Gamma_{i n}\right)$, saída de fluido $\left(\Gamma_{o u t}\right)$ e sobre superfície rígida que respeita a malha $\left(\Gamma_{f i t}\right)$.

Para esta aplicação, foi utilizada uma malha de $501 \times 101$ pontos e foram feitos dois casos, variando-se o número de Reynolds. O sistema linear foi resolvido com o método GMRES com $n=600$ e MGS, pré-condicionado por ASM com 16 blocos e sub-PC LU em cada bloco. Todos os casos foram executados em um cluster com computadores Intel Xeon E5345 de 2.33GHz com 16GB de RAM e com 8 núcleos de processamento. 


\subsubsection{Caso 1: $R e=0.002$}

Executamos um problema de microfluídica a baixo número de Reynolds para mostrar o funcionamento do código. Neste caso, utilizamos um passo de tempo $\delta t=0.1$ e CFL $=8.33$. Foram executados 10 passos de tempo, até atingir o estado estacionário. O tempo computacional gasto foi de 47.98 segundos. Na figura 5.5 são mostradas a pressão (5.5.a), a magnitude da velocidade (5.5.b) e as linhas de corrente, coloridas segundo a magnitude da velocidade (5.5.c).

a)

\section{ᄃ}

b)

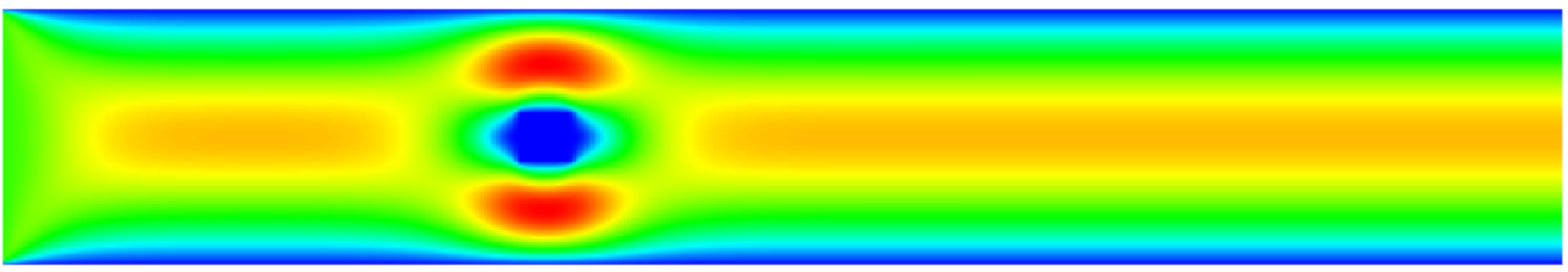

c)

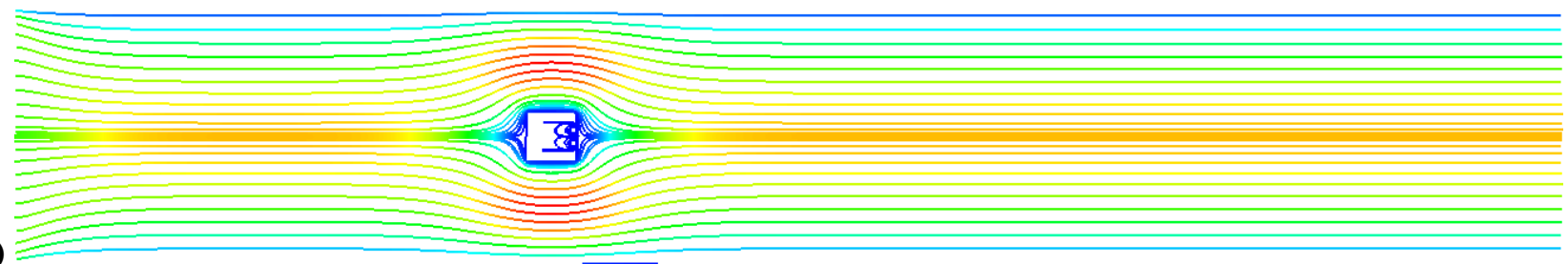

Figura 5.5: Resultados para o canal com obstáculo em forma de "c", com $R e=10^{-2} \mathrm{e} t=10$. a) Pressão; b) Magnitude da velocidade; c) Linhas de corrente coloridas segundo a magnitude da velocidade.

A solução obtida para este caso foi utilizada como condição inicial para o caso apresentado a seguir.

\subsubsection{Caso 2: $R e=20$}

Para o caso $R e=20$ foi utilizado um passo de tempo $\delta t=0.01$ e $\mathrm{CFL}=0.833$. Foram executados 1,000 passos de tempo, até que o resíduo das equações reduzisse 10 ordens de grandeza. O tempo computacional gasto foi de 4,013.43 segundos (pouco mais de 1 hora). Na figura 5.6 são apresentadas a pressão (5.6.a), a magnitude da velocidade (5.6.b) e as linhas de corrente coloridas de acordo com a magnitude da velocidade (5.6.c), obtidas no último passo de tempo.

Com base nos resultados apresentados, podemos notar que o método implementado também obteve bons resultados, em paralelo e com baixo tempo de processamento, para este problema.

Os resultados desta seção mostram que o método funciona muito bem para problemas bidimensionais. Na seção 5.2, a seguir, vamos mostrar o comportamento do código em problemas tridimensionais. 


\section{ᄃ}

a)

b)

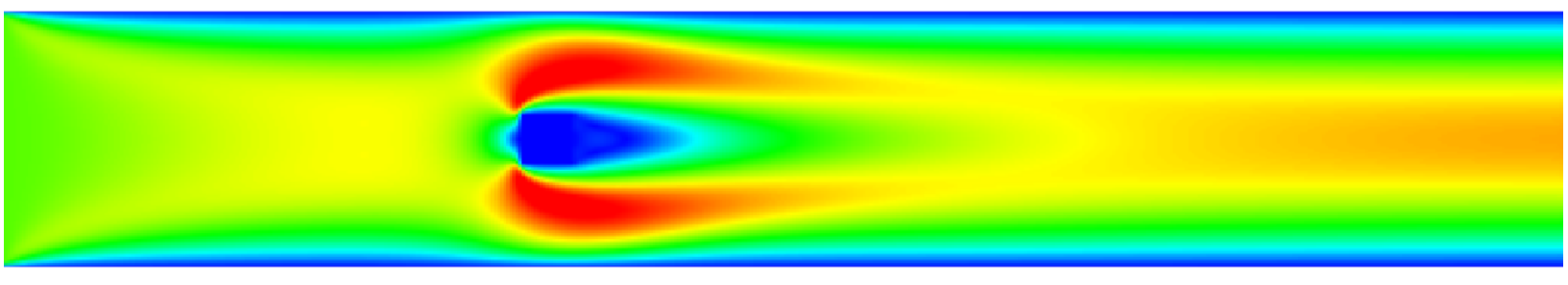

c)

\section{(a)}

Figura 5.6: Resultados para o canal com obstáculo em forma de "c", com $R e=20$ e $t=1000$. a) Pressão; b) Magnitude da velocidade; c) Linhas de corrente coloridas segundo a magnitude da velocidade.

\subsection{Aplicações 3D}

\subsubsection{Simulação em Microcanais}

Em muitos problemas de microfluidos as geometrias envolvidas são, em geral, construídas com domínios retangulares. Por exemplo, em Rodd et al. (2005) os autores analisaram o escoamento de um fluido não-newtoniano em um microcanal 3D do tipo contração-expansão enquanto que Gulati et al. (2008) estudaram o comportamento de fluidos viscoelásticos na modelagem do DNA em uma 2:1 microcontração 3D. Outros resultados interessantes utilizando geometrias retangulares tridimensionais para microcanais podem ser encontrados em Wang et al. (2003), Davidson et al. (2008), Bhattacharya et al. (2009), entre outros.

Neste teste numérico, vamos aplicar a formulação mais eficaz obtida na seção 3.4.4 em uma simulação tridimensional de microcanais com $R e<<1$. Nossa simulação será definida em um microcanal conforme descrito na figura 5.7. As condições de contorno, como definidas na seção 2.2, são de superfície rígida (amarelo $\left(\Gamma_{f i t}\right)$ ), entrada $\left(\operatorname{azul}\left(\Gamma_{i n}\right)\right)$ e saída (vermelho $\left.\left(\Gamma_{\text {out }}\right)\right)$. Este problema foi resolvido em uma malha com 3,609,788 células e aproximadamente 14,400,000 incógnitas.

Para este caso, utilizamos os seguintes parâmetros: método GMRES com $n=600$ e MGS, pré-condicionado por ASM com 16 blocos, com sub-PC ILU em cada bloco. Para esta simulação, utilizamos $R e=10^{-4}$, passo de tempo $\delta t=0.1$ e $\mathrm{CFL}=3$. Reduzimos a dimensão do espaço de Krylov e escolhemos sub-PC ILU para o PC ASM, pois as diferenças de escalas não eram muito grandes e, de acordo com a tabela 3.3, esse sub-PC possui menor tempo de processamento. Outro 


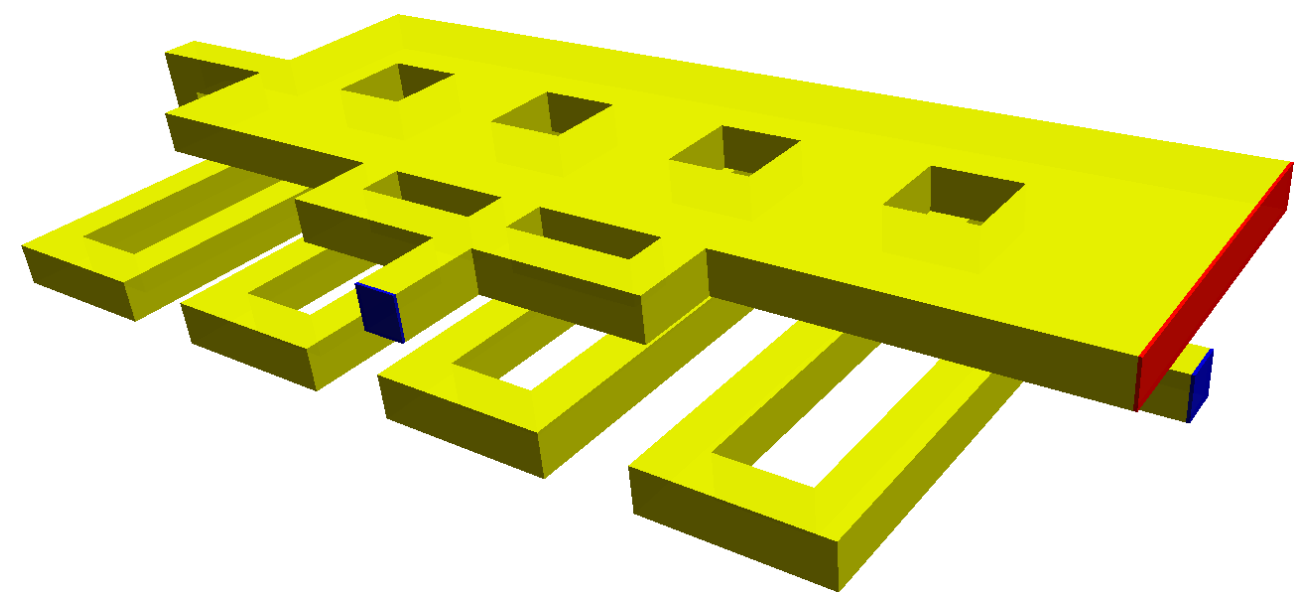

Figura 5.7: Representação do microcanal utilizado para a simulação 3D, com comprimento $L=14$, largura $H=6$ e altura $Z=1.5$ e com condições de contorno de entrada de fluido (azul $\left(\Gamma_{i n}\right)$ ), saída de fluido (vermelho $\left.\left(\Gamma_{\text {out }}\right)\right)$ e sobre superfície rígida.que respeita a malha (amarelo $\left.\left(\Gamma_{f i t}\right)\right)$.

fato que nos levou a escolher o sub-PC ILU foi termos restrição da quantidade de memória necessária para resolver o problema. Este teste foi efetuado utilizando um cluster com computadores Intel Xeon E5430 de 2.66GHz com 64GB de RAM com 8 núcleos de processamento.

Na figura 5.8 podemos ver fitas de corrente coloridas segundo a magnitude da velocidade. Para reduzir o resíduo do método de Newton em 10 ordens de grandeza foram necessários 2 passos de tempo, gastando 41,742.1 segundos (aproximadamente 11.5 horas), utilizando 16 núcleos de processamento. O primeiro passo de tempo desta simulação demorou 595 iterações para reduzir o resíduo do método GMRES em 4 ordens de grandeza.

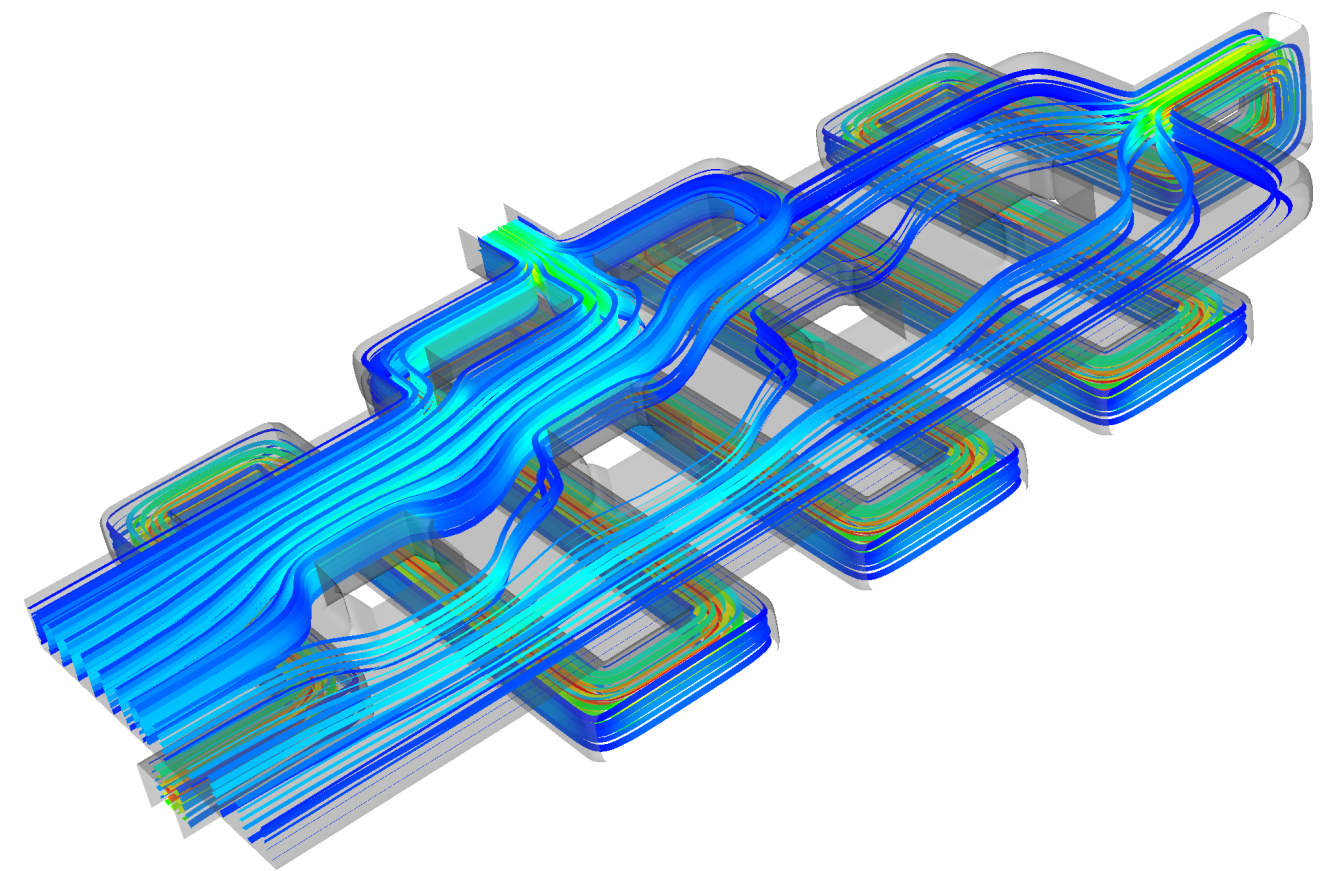

Figura 5.8: Fitas de corrente coloridas segundo a magnitude da velocidade para o microcanal 3D. 
Os resultados apresentados acima mostram que, para a solução numérica de escoamentos incompressíveis em microcanais a baixo Re, o método GMRES com $n \geq 600$ e ortogonalização de Gram-Schmidt modificada, pré-condicionado por ASM com 16 blocos e com sub-PC ILU, consegue resolver muito bem o problema, em paralelo, com baixo tempo de processamento, utilizando ferramentas da biblioteca PETSc (Balay et al., 2008, 2009).

\subsubsection{Canal com Esferas}

O último exemplo numérico 3D a ser apresentado é um canal com esferas na seção central, como mostrado na figura 5.9. O canal possui comprimento $L=3$, largura $H=1$ e altura $Z=1$. As condições de contorno são de entrada de fluido $\left(\Gamma_{i n}\right.$, em azul na figura 5.9), de saída de fluido ( $\Gamma_{\text {out }}$, em verde na figura 5.9) e sobre superfície rígida que respeita a malha ( $\Gamma_{f i t}$, em amarelo na figura 5.9). As esferas (em vermelho na figura 5.9) também representam condição de contorno sobre superfície rígida.

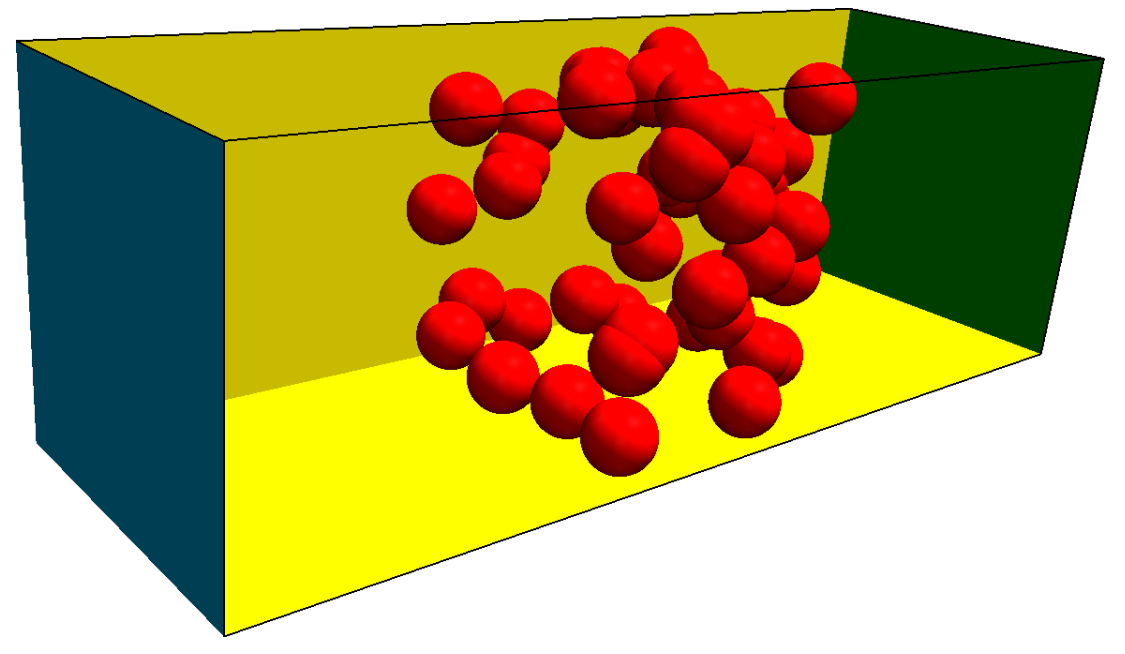

Figura 5.9: Representação do canal com esferas na seção central, com comprimento do canal $L=3$, largura $H=1$ e altura $Z=1$ e com condições de contorno de entrada de fluido (azul $\left(\Gamma_{i n}\right)$ ), de saída de fluido (verde $\left.\left(\Gamma_{\text {out }}\right)\right)$ e sobre superfície rígida que respeita a malha (canal em amarelo e esferas em vermelho $\left.\left(\Gamma_{f i t}\right)\right)$.

Para esta simulação foram utilizadas 1,820,700 células e aproximadamente 7.3 milhões de incógnitas. O código foi executado em um cluster com computadores Intel Xeon E5430 de 2.66GHz com 64GB de RAM e com 8 núcleos de processamento. Foram considerados dois números de Reynolds, que definem os casos apresentados a seguir.

\subsubsection{Caso 1: $R e=10^{-2}$}

Primeiramente, apresentamos um resultado com baixo número de Reynolds, como nas aplicações apresentadas anteriormente.

Para este caso, com $R e=10^{-2}$, utilizamos o método GMRES com $n=600$ e MGS para a solução do sistema linear, pré-condicionado pelo método ASM, com 32 blocos e com sub-PC ILU em cada bloco. 
Consideramos $\delta t=0.1$ e CFL $=8.33$. Executamos 10 passos de tempo, até atingir o estado estacionário. O tempo computacional necessário para executar os 10 passos de tempo foi de 29,592.7 segundos (aproximadamente 8 horas), utilizando 16 núcleos de processamento.

Na figura 5.10 são apresentadas as linhas de corrente, coloridas segundo a magnitude da velocidade.

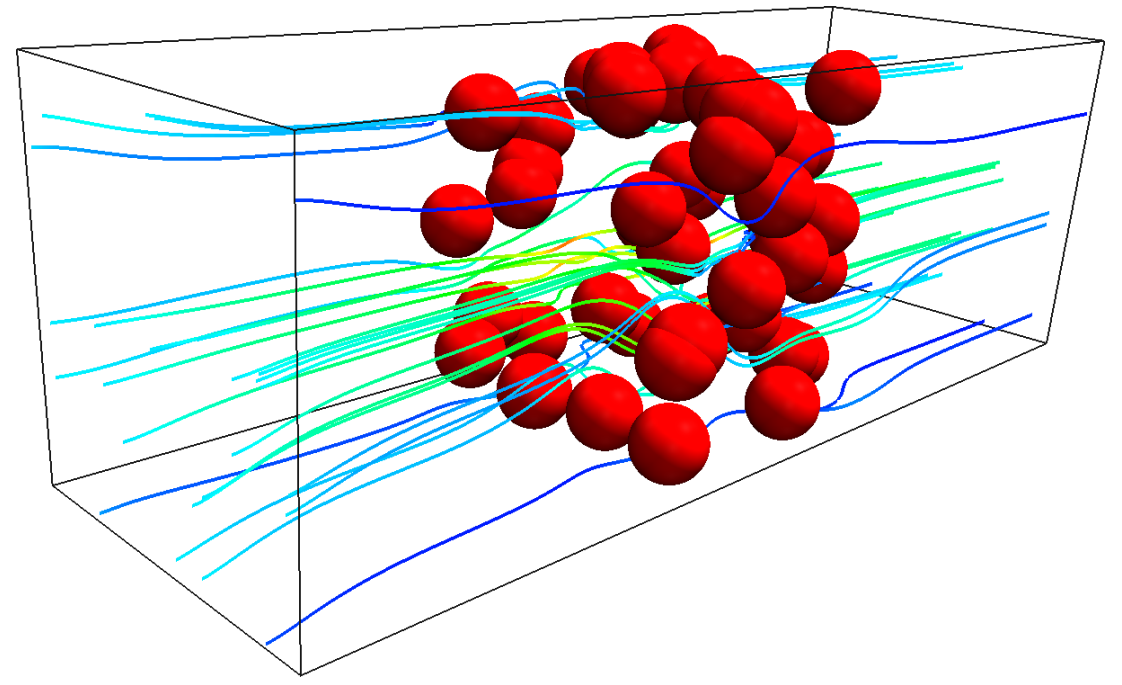

Figura 5.10: Linhas de corrente para $R e=10^{-2}$, coloridas segundo a magnitude da velocidade para o canal com esferas.

Novamente, os resultados mostram que a combinação do método GMRES (com $n=600$ e MGS) combinado com o PC ASM (com 32 blocos e sub-PC ILU em cada bloco) funciona muito bem para casos com baixo número de Reynolds, resolvendo o problema em paralelo e com baixo tempo computacional.

\subsubsection{Caso 2: $R e=100$}

O segundo e último caso mostra o funcionamento do código para problemas com número de Reynolds maior. Neste caso também foi utilizado o método GMRES com $n=600$ e ortogonalização de Gram-Schmidt modificada, pré-condicionado por ASM, com 32 blocos e sub-PC ILU em cada bloco.

Consideramos a solução no estado estacionário do caso anterior, com $R e=10^{-2}$, como a condição inicial para este problema e tomamos $\delta t=0.01$ e $\mathrm{CFL}=0.833$. O tempo de processamento para reduzir o resíduo do método de Newton em 5 ordens de grandeza foi de 356,571 segundos (aproximadamente 4 dias), utilizando 16 núcleos de processamento. Apresentamos as linhas de corrente coloridas de acordo com a magnitude da velocidade na figura 5.11.

Podemos notar que os resolvedores utilizados também foram capazes de resolver o problema eficientemente, com $R e=100$.

Dessa forma, podemos concluir que o método proposto também obteve boas soluções, na resolução numérica de escoamentos incompressíveis, utilizando vários processadores e necessitando de 


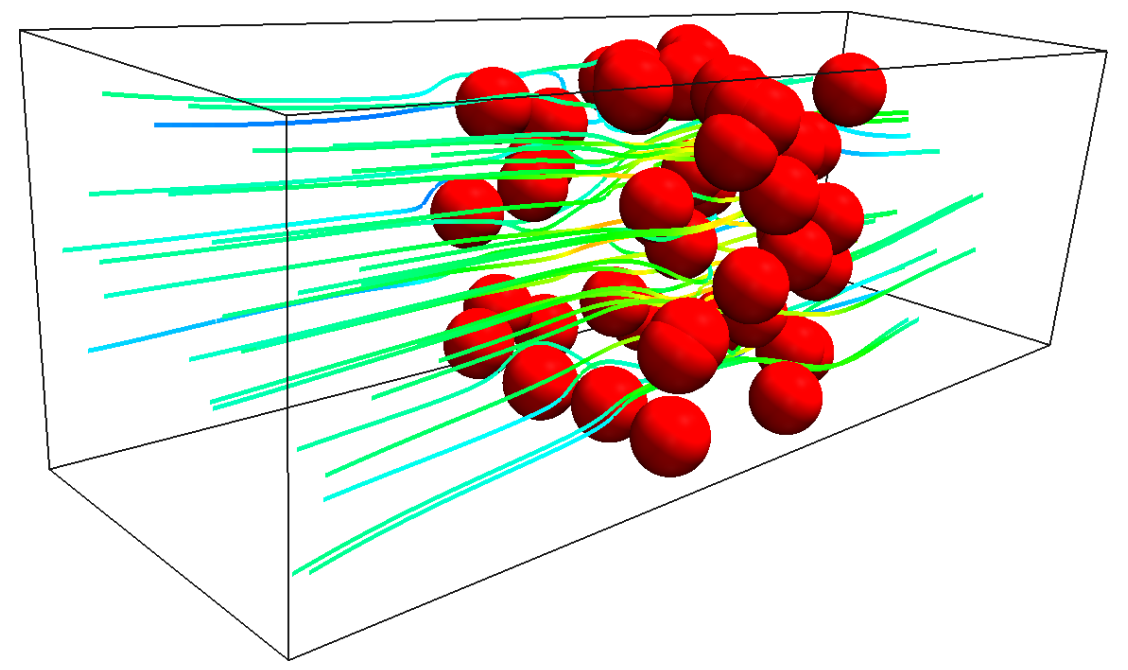

Figura 5.11: Linhas de corrente para $R e=100$, coloridas segundo a magnitude da velocidade para o canal com esferas.

pouco tempo computacional.

\subsubsection{Conclusões}

Neste capítulo foram apresentadas várias simulações, com grande número de incógnitas, e os resultados destas simulações mostraram que conseguimos implementar um código paralelo, utilizando a biblioteca PETSc (Balay et al., 2008, 2009), para resolver numericamente as equações de Navier-Stokes para escoamentos incompressíveis em microcanais tridimensionais eficientemente. 


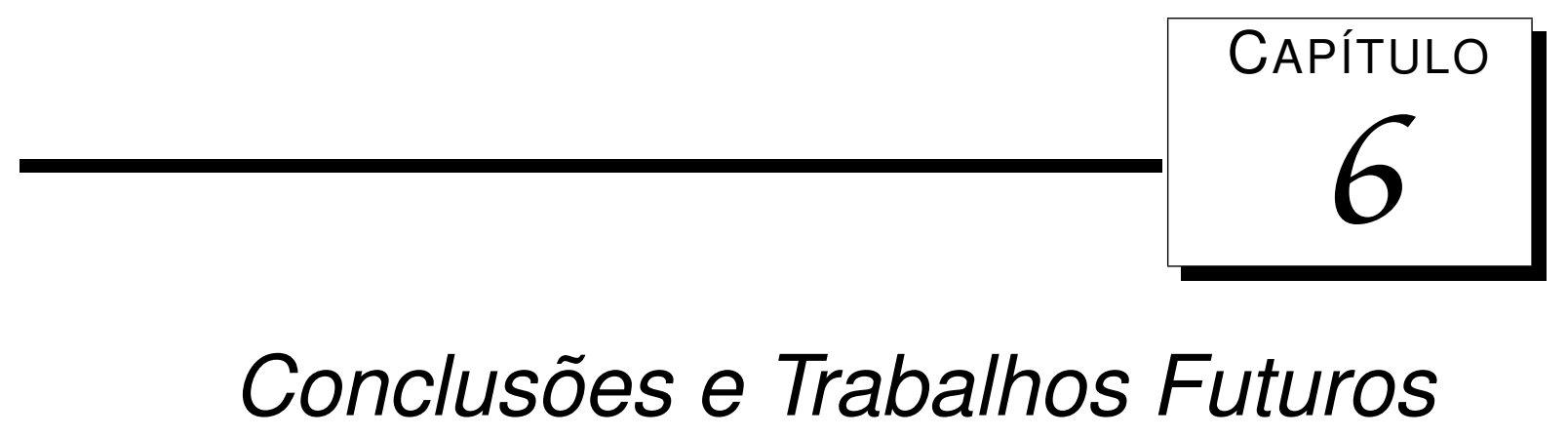

Neste capítulo vamos sintetizar os resultados obtidos nos capítulos anteriores, apresentar algumas considerações finais e as contribuições ao estado da arte dos métodos de fronteira imersa. Também vamos apresentar uma proposta de trabalhos futuros.

\subsection{Síntese do Trabalho}

No capítulo 2 foram apresentadas as equações de Navier-Stokes para escoamentos incompressíveis e as técnicas básicas de discretização destas equações por diferenças finitas utilizando malha deslocada. Foram também apresentadas as condições de contorno e a discretização destas condições.

Já no capítulo 3 foi feita uma comparação dos métodos acoplado e segregado na solução numérica de escoamentos incompressíveis em microescala. Com o objetivo de familiarizar o leitor com a biblioteca PETSc, foi apresentada uma descrição de sua estrutura e funcionalidade. Com base na flexibilidade desta ferramenta, foi feito um estudo do comportamento dos resolvedores de sistemas lineares para problemas em microescala, em que estes sistemas são mal condicionados. Além disso, foi feita uma análise do funcionamento destes métodos em paralelo.

O capítulo 4 começa com uma revisão bibliográfica dos métodos de fronteira imersa, seguido pela apresentação de um método de fronteira imersa de primeira ordem paralelo, baseado na biblioteca PETSc, e de alguns resultados obtidos com este método. Na segunda parte foi apresentada uma extensão do método de Codina and Baiges (2009) para diferenças finitas, um estudo de convergência do método e os resultados obtidos em sua aplicação em escoamentos incompressíveis.

Finalmente, no capítulo 5, foram apresentadas aplicações do método de fronteira imersa de primeira ordem em diversos casos envolvendo escoamentos de fluidos incompressíveis. 


\subsection{Considerações Finais sobre os Resultados}

Os resultados e conclusões dos problemas de escoamentos de fluidos apresentados neste trabalho foram discutidos nos capítulos 3, 4 e 5. Entretanto, uma breve consideração final será apresentada.

A utilização da biblioteca PETSc permitiu a análise do comportamento de métodos para solução de sistemas lineares, combinados com diferentes pré-condicionadores, de maneira fácil e prática, proporcionando a determinação dos melhores resolvedores. Também foi possível mostrar a melhoria de performance obtida na utilização destes resolvedores em paralelo.

A implementação do método de fronteiras imersas utilizando PETSc se mostrou eficiente, além de permitir sua execução em paralelo, reduzindo assim, o tempo de processamento necessário.

A extensão do método de Codina and Baiges (2009) para a formulação de diferenças finitas, em malha deslocada, possibilitou a obtenção de segunda ordem de precisão para os exemplos apresentados. Também pode-se notar a melhoria obtida na aproximação das condições de contorno quando comparado ao método de primeira ordem.

Portanto, neste trabalho, foi mostrado que é possível implementar métodos de fronteiras imersas para a solução numérica de escoamentos incompressíveis de fluidos viscosos, utilizando a ferramenta PETSc, em paralelo e com baixo tempo computacional.

\subsection{Trabalhos Futuros}

Os aspectos mais relevantes dos temas que serão abordados em trabalhos futuros são:

- Estudar os efeitos causados em função da posição da condição de contorno em relação à malha (por exemplo, quando o contorno passa sobre uma incógnita de velocidade ou pressão) para a extensão do método de Codina and Baiges (2009);

- Extensão deste método para o caso tridimensional. 


\section{Referências Bibliográficas}

Akbar, M. K. \& Ghiaasiaan, S. M., 2006. Simulation of Taylor flow in capillaries based on the volume-of-fluid technique. Industrial \& Engineering Chemistry Research, vol. 45, n. 15, pp. 5396-5403.

Arnold, D., Brezzi, F., \& Fortin, M., 1984. A stable finite element for the Stokes equations. Calcolo, vol. 21 , pp. 337-344.

Atzberger, P., Kramer, P., \& Peskin, C., 2007. A stochastic immersed boundary method for fluid-structure dynamics at microscopic length scales. Journal of Computational Physics, vol. 224, pp. 1255-1292.

Balay, S., Buschelman, K., Eijkhout, V., Gropp, W. D., Kaushik, D., Knepley, M. G., McInnes, L. C., Smith, B. F., \& Zhang, H., 2008. PETSc - Portable, Extensible Toolkit for Scientific Computation - users manual. Technical Report ANL-95/11 - Revision 3.0.0, Argonne National Laboratory.

Balay, S., Buschelman, K., Gropp, W. D., Kaushik, D., Knepley, M. G., McInnes, L. C., Smith, B. F., \& Zhang, H., acesso em 09/2009. PETSc - Portable, Extensible Toolkit for Scientific Computation - web page. http://www.mcs.anl.gov/petsc.

Beebe, D. J., Mensing, G. A., \& Walker, G. M., 2002. Physics and applications of microfluidics in biology. Annual Review of Biomedical Engineering, vol. 4, n. 1, pp. 261-286.

Beratlis, N., Balaras, E., Parvinian, B., \& Kiger, K., 2005. A numerical and experimental investigation of transitional pulsatile flow in a stenosed channel. Journal of Biomechanical Engineering, vol. 127, pp. 1147-1157.

Bhattacharya, P., Samanta, A., \& Chakraborty, S., 2009. Numerical study of conjugate heat transfer in rectangular microchannel heat sink with $\mathrm{Al}_{2} \mathrm{O}_{3} / \mathrm{H}_{2} \mathrm{O}$ nanofluid. Heat Mass Transfer, vol. 45, pp. 1323-1333. 
Castelo, A., Tomé, M., Cesar, M., Cuminato, J., \& McKee, S., 2000. Freeflow: An intregated simulation system for three-dimensional free surface flows. Computing and Visualization in Science, vol. 2, pp. 199-210.

Cebral, J. \& Löhner, R., 2005. Efficient simulation of blood flow past complex endovascular devices using an adaptive embedding technique. IEEE Transactions on Medical Imaging, vol. 24, pp. 468-476.

Chorin, A., 1968. Numerical solution of the Navier-Stokes equations. Mathematics of Computation, vol. 22, pp. 745-762.

Codina, R. \& Baiges, J., 2009. Approximate imposition of boundary conditions in immersed boundary methods. International Journal for Numerical Methods in Engineering, vol. 80, pp. 1379-1405.

Davidson, M., Bharti, R., Liovic, P., \& Harvie, D., 2008. Electroviscous effects in low Reynolds number flow through a microfluidic contraction with rectangular cross-section. In Proceedings of World Academy of Science, Engineering and Technology, pp. 256-261.

Denaro, F., 2003. On the applications of the Helmoltz-Hodge decomposition in projection methods for incompressible flows with general boundary conditions. International Journal for Numerical Method in Fluid, vol. 43, pp. 43-69.

Dukowicz, J. \& Dvinsky, A. S., 1992. Approximate factorization as a high order splitting for the implicit incompressible flow equations. Journal of Computational Physics, vol. 102, pp. 336-347.

Eggleton, C. \& Popel, A., 1998. Large deformation of red blood cell ghosts in a simple shear flow. Physics of Fluids, vol. 10, pp. 1834-1845.

Erturk, E., 2008. Numerical solutions of 2-D steady incompressible flow over a backward-facing step, part I: High Reynolds number solutions. Computer and Fluids, vol. 37, pp. 633-655.

Ge, L. \& Sotiropoulos, F., 2007. A numerical method for solving the 3D unsteady incompressible Navier-Stokes equations in curvilinear domains with complex immersed boundaries. Journal of Computational Physics, vol. 225, pp. 1782-1809.

Ghia, U., Ghia, K. N., \& Shin, C. T., 1982. High-Re solutions for incompressible flow using the Navier-Stokes equations and a multigrid method. Journal of Computational Physics, vol. 48, pp. 387-411.

Girault, V. \& Glowinski, R., 1995. Error analysis of a fictitious domain method applied to a Dirichlet problem. Japan Journal of Industrial and Applied Mathematics, vol. 12, pp. 487-514. 
Glowinski, R., Pan, T.-W., Hesla, T., \& Joseph, D., 1999. A distributed Lagrange multiplier/fictitious domain method for particulate flows. International Journal of Multiphase Flow, vol. 25, pp. 755-794.

Glowinski, R., Pan, T.-W., \& Periaux, J., 1994. A fictitious domain method for Dirichlet problems and applications. Computer Methods in Applied Mechanics and Engineering, vol. 111, pp. 283-303.

Goldstein, D., Handler, R., \& Sirovich, L., 1993. Modeling a no-slip flow boundary with an external force field. Journal of Computational Physics, vol. 105, n. 2, pp. 354-366.

Guermond, J., Minev, P., \& Shen, J., 2006. An overview of projection methods for incompressible flows. Computer Methods in Applied Mechanics and Engineering, vol. 195, pp. 6011-6045.

Guermond, J. \& Shen, J., 2003. On error estimates of rotational pressure-correction projection methods. Mathematics of Computations, vol. 73, pp. 1719-1737.

Gulati, S., Muller, S., \& Liepmann, D., 2008. Direct measurements of viscoelastic flows of DNA in a 2:1 abrupt planar micro-contraction. Journal of Non-Newtonian Fluid Mechanics, vol. 155, pp. $51-66$.

Harlow, F. \& Welch, J., 1965. Numerical calculation of time-dependent viscous incompressible flow of fluid with free surface. Physics of Fluids, vol. 8, pp. 2182-2189.

Hodge, W., 1952. The Theory and Applications of Harmonic Integrals. Cambridge University Press, Cambridge.

Husain, S. \& Floryan, J., 2008a. Implicit spectrally-accurate method for moving boundary problems using immersed boundary conditions concept. Journal of Computational Physics, vol. 227, pp. 4459-4477.

Husain, S. Z. \& Floryan, J. M., 2008b. Immersed boundary conditions method for unsteady flow problems described by the Laplace operator. International Journal for Numerical Methods in Fluids, vol. 56, pp. 1765-1786.

Ito, K. \& Li, Z., 2003. Solving a nonlinear problem in magneto-rheological fluids using the immersed interface method. Journal of Scientific Computing, vol. 19, n. 1-3, pp. 253-292.

Kim, Y. \& Peskin, C., 2007. Penalty immersed boundary method for an elastic boundary with mass. Physics of Fluids, vol. 19, pp. 053103.

Kler, P., López, E., Dalcín, L., Guarnieri, F., \& Storti, M., 2009. High performance simulations of electrokinetic flow and transport in microfluidic chips. Computer Methods in Applied Mechanics and Engineering, vol. 198, pp. 2360-2367. 
Kreutzer, M. T., 2003. Hydrodynamics of Taylor flow in capillaries and monolith channels. PhD thesis, Delft University of Technology, Delft, Holland.

Lai, M.-C. \& Peskin, C., 2000. An immersed boundary method with formal second-order accuracy and reduced numerical viscosity. Journal of Computational Physics, vol. 160, pp. 705-719.

Lee, L. \& Leveque, R., 2003. An immersed interface method for incompressible Navier-Stokes equations. SIAM Journal on Scientific Computing, vol. 25, pp. 832-856.

Lee, M., Oh, D., \& Kim, Y., 2001. Canonical fractional-step methods and consistent boundary conditions for the incompressible Navier-Stokes equations. Journal of Computational Physics, vol. 168, pp. 73-100.

Leveque, R. \& Li, Z., 1994. The immersed interface method for elliptic equations with discontinuous coefficients and singular sources. SIAM Journal on Numerical Analysis, vol. 31, pp. 1019-1044.

Lew, A. \& Buscaglia, G., 2008. A discontinuous-Galerkin-based immersed boundary method. International Journal for Numerical Methods in Engineering, vol. 76, pp. 427-454.

Liu, W., Kim, D., \& Tang, S., 2005. Mathematical foundations of the immersed finite element method. Computational Mechanics, vol. 39, pp. 211-222.

Mittal, R. \& Iaccarino, G., 2005. Immersed boundary methods. Annual Review of Fluid Mechanics, vol. 37, pp. 239-261.

Mut, F., 2008. Extensions to the computational hemodynamics modeling of cerebral aneurysms. $\mathrm{PhD}$ thesis, George Mason University.

Perot, J., 1993. An analysis of the fractional step method. Journal of Computational Physics, vol. 108, pp. 51-58.

Peskin, C., 1972. Flow patterns around heart valves: A numerical method. Journal of Computational Physics, vol. 10, pp. 252-271.

Peskin, C., 1977. Numerical analysis of blood flow in the heart. Journal of Computational Physics, vol. 25, pp. 220-252.

Peskin, C., 2002. The immersed boundary method. Acta Numerica, vol. 11, pp. 479-517.

Quarteroni, A., Saleri, F., \& Veneziani, A., 2000. Factorization methods for the numerical approximation of Navier-Stokes equations. Computer Methods in Applied Mechanics and Engineering, vol. 188, pp. 505-526. 
Rejniak, K., 2007. An immersed boundary framework for modelling the growth of individual cells: An application to the early tumour development. Journal of Theoretical Biology, vol. 247, pp. 186-204.

Rodd, L. E., Scott, T. P., Boger, D. V., Cooper-White, J. J., \& McKinley, G. H., 2005. The inertio-elastic planar entry flow of low-viscosity elastic fluids in micro-fabricated geometries. Journal of Non-Newtonian Fluid Mechanics, vol. 129, pp. 1-22.

Shen, J., 1996. On error estimates of the projection methods for the Navier-Stokes equations: second-order schemes. Mathematics of Computations, vol. 65, pp. 1039-1065.

Smith, B., Bjorstad, P., \& Gropp, W., 1996. Domain Decomposition, Parallel Multilevel Methods for Elliptic Partial Differential Equations. Cambridge University Press.

Squires, T. M. \& Quake, S. R., 2005. Microfluidics: Fluid physics at the nanoliter scale. Reviews of Modern Physics, vol. 77, n. 3.

Steinman, D., Milner, J., Norley, C., Lownie, S., \& Holdworth, D., 2003. Image-based computational simulation of flow dynamics in a giant intracranial aneurysm. American Journal of Neuroradiology, vol. 24 , pp. 559-566.

Stone, H., Stroock, A., \& Ajdari, A., 2004. Engineering flows in small devices: Microfluidics toward a lab-on-a-chip. Annual Review of Fluid Mechanics, vol. 36, n. 1, pp. 381-411.

Temam, R., 1969. Sur l'approximation de la solution des equations de Navier-Stokes par la methode de pas fractionnaires (II). Archieves of Rational Mechanics and Analysis, vol. 33, pp. 377-385.

Tilch, R., Tabbal, A., Zhu, M., Decker, F., \& LÃ $\uparrow$ hner, R., 2008. Combination of body-fitted and embedded grids for external vehicle aerodynamics. Engineering Computations, vol. 25, pp. $28-41$.

Wang, H., Iovenitti, P., Harvey, E., \& Masood, S., 2003. Numerical investigation of mixing in microchannels with patterned grooves. Journal of Micromechanics and Microengineering, vol. 13, pp. 801-808.

Whitesides, G. M., 2006. The origins and the future of microfluidics. Nature, vol. 442, n. 7101, pp. $368-373$.

Wörner, M., Ghidersa, B., \& Onea, A., 2007. A model for the residence time distribution of bubble-train flow in a square mini-channel based on direct numerical simulation results. International Journal of Heat and Fluid Flow, vol. 28, n. 1, pp. 83 - 94. The International Conference on Heat Transfer and Fluid Flow in Microscale (HTFFM-05).

Xu, S. \& Wang, Z. J., 2006. An immersed interface method for simulating the interaction of a fluid with moving boundaries. Journal of Computational Physics, vol. 216, pp. 454-493. 
Yang, J. \& Balaras, E., 2006. An embedded-boundary formulation for large-eddy simulation of turbulent flows interacting with moving boundaries. Journal of Computational Physics, vol. 215, pp. 12-40.

Ye, T., Mittal, R., Udaykumar, H., \& Shyy, W., 1999. An accurate cartesian grid method for viscous incompressible flows with complex immersed boundaries. Journal of Computational Physics, vol. 156, pp. 209-240.

Zhang, K., 2005. A discrete splitting finite element method for numerical simulations of incompressible Navier-Stokes equations. International Journal for Numerical Methods in Fluids, vol. 64, pp. 285-303.

Zhang, L., Gerstenberger, A., Wang, X., \& Liu, W., 2004. Immersed finite element method. Computer Methods in Applied Mechanics and Engineering, vol. 193, n. 21-22, pp. 2051-2067. 